\title{
Teoria dos Fractais
}

\author{
Humberto Rossetti Baptista
}

Dissertação apresentada ao Instituto de Matemática e Estatística da Universidade de São Paulo

Para obtenção do grau de Mestre em Ciência da Computação

Orientador:

Cyro Patarra

São Paulo Junho de 1998 


\title{
Resumo
}

O campo de fractais sofre pela falta de estruturação e definição. Apresentamos aqui uma teoria de unificação para o estudo e aplicação de fractais. Esta é batente direta possível possibilitando seu uso nos mais variados campos de aplicação. Após o embasamento teórico segue uma discussão sobre técnicas computacionais de cálculo e visualização.

\begin{abstract}
The fractal study field suffers the lack of structuring and definition. Here we present a unification theory for the study and application of fractals. This is rather direct allowing the use in several different application areas. After the theory presentation follows a discussion on evaluation and visualization computational techniques.
\end{abstract}




\section{Conteúdo}

1 Órbitas 10

1.1 Geral . . . . . . . . . . . . . . . . . . . 12

1.2 Em espaços métricos . . . . . . . . . . . . 22

2 Mapas 29

2.1 Geral. . . . . . . . . . . . . . . . . . . . . . . . . . . . . .

2.2 Em espaços métricos . . . . . . . . . . . . . 33

3 Fractais 45

3.1 Tipologia revisitada . . . . . . . . . . . . . 45

3.1 .1 Algébricos ou Simbólicos . . . . . . . . . . . . . 46

3.1 .2 Fractais Afins . . . . . . . . . . . . . 50

3.1.3 Fractais Não-Lineares . . . . . . . . . . . . . 50

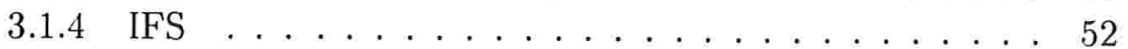

3.1.5 Fractais Probabilísticos . . . . . . . . . . 55

3.2 Dimensões, Potências e Medidas . . . . . . . . . . . . 57

3.2 .1 Medidas . . . . . . . . . . . . . . 57

3.2 .2 Dimensões . . . . . . . . . . . . . . . . . . 57

3.2 .3 Antigas Definições . . . . . . . . . . . . . . . 67

3.3 Definição . . . . . . . . . . . . . . . . . 71

3.4 Novas direções . . . . . . . . . . . . . . . . . . 73

4 Técnicas de Cálculo e Visualização 74

4.1 Cálculo e precisão . . . . . . . . . . . . . . 76

4.1.1 Noção da quantidade de informação . . . . . . . . . . . 76

4.1 .2 Representação numérica . . . . . . . . . . . . . 78

4.1.3 Problemas de trabalho com precisão finita . . . . . . . 81

4.1 .4 'Segurança' nos cálculos . . . . . . . . . . . . . . . 81

4.1.5 Caoticidade e expoentes de Lyapunov . . . . . . . . 83 
4.2 Visualização e cálculo de órbitas . . . . . . . . . . 86

4.2 .1 Questão numérica . . . . . . . . . . . . 86

4.2 .2 Visualização. . . . . . . . . . . . . . . . . . . 88

4.2 .3 Eficiência espaço-temporal . . . . . . . . . . . . . . . . 89

4.2 .4 Cálculo de propriedades . . . . . . . . . . . . . 89

4.3 Visualização e cálculo de mapas . . . . . . . . . . . . . 92

4.3.1 Questão numérica . . . . . . . . . . . . . 93

4.3 .2 Visualização. . . . . . . . . . . . . . . . 93

4.3.3 Eficiência espaço-temporal . . . . . . . . . . . . . 95

4.3.4 Cálculo de propriedades . . . . . . . . . . . . 95

4.3.5 Cálculo e Visualização de IFS . . . . . . . . . . . . . 104

4.3.6 Estratégias de varredura . . . . . . . . . . . . . 105

4.4 Cálculo de dimensões e outros indicadores . . . . . . . . . . 113

4.4.1 Dimensões: Algoritmos e eficiência . . . . . . . . . . 113

4.4 .2 Outros Indicadores . . . . . . . . . . . . . . 116

4.5 Conclusão . . . . . . . . . . . . . . . . . . 117

$\begin{array}{ll}\text { Bibliografia } & 119\end{array}$ 


\section{Introdução}

A pesquisa de fractais tem se mostrado útil em diversas situações e surgido em uma série de campos aparentemente não relacionados entre si. Resultados aparecem como modelagem de sistemas, técnicas de codificação, síntese de imagens, avaliação e estudo de objetos naturais e como uma visão renovada da geometria.

O paradigma de estudo dos fractais se apoia e relaciona profundamente com o uso de computadores pela sua natureza intrinsecamente iterativa e pela repetição maciça de procedimentos simples. Técnicas de cálculo e visualização, problemas de estabilidade e convergência e formas de manipulação de sistemas complexos de maneira simples são algumas das aplicações mais importantes na ciência da computação.

Qualquer um dos temas acima, ou mesmo uma questão específica de algum deles seria tema suficiente para uma boa pesquisa no campo. Porém, na experiência do autor um fato mais importante se sobressaiu: a confusão reinante em um mesmo campo de aplicação. As dificuldades de linguagem, trabalhos desnecessários e redescobertas são a principal matéria dos artigos publicados e o avanço do campo se reduz desnecessariamente.

Mais ainda, pela diversidade de aplicações e campos envolvidos é muito difícil desenvolver métodos computacionais abrangentes, acessíveis e úteis ao mesmo tempo. O resultado é que as técnicas e teorias sobre fractais acabam diluídas e perdidas em meio as técnicas e ferramentas próprias de cada campo.

A falta de definição também leva a uma super-especialização do campo com a conseqüente perda de generalidade. A única coisa que une, então, as diversas áreas de aplicação é a "visão intuitiva", na verdade a falta de idéias formais pertinentes aos vários campos impede a unificação. Cada campo então desenvolve "sua" teoria de fractais, esquecendo ou ignorando o avanço dos demais e ligando esta a elementos intrínsecos do campo. Isto gera uma grande dificuldade para uma primeira aproximação da teoria, impede a passagem do particular para o universal e atrapalha sobremaneira o 
aproveitamento do conhecimento em outras áreas de pesquisa e desenvolvimento

Depois de alguns anos de pesquisa no campo de fractais nota-se uma ausência surpreendente: não existe uma teoria de fractais unificada! Isso é sentido em livros ou seminários de apresentação dos fractais, aonde uma pergunta permanece sem resposta bem definida: "O que é fractal?".

A leitura dos trabalhos de Benoît Mandelbrot, onde o termo foi cunhado, - que foram usados como base em quase todos os campos de aplicação de fractais - revela uma primeira definição que acabou sendo considerada inadequada pelo próprio autor: a baseada na "dimensão fractal",[MAN83, pag. 15]:

"Whenever we work in the Eucliedean span $R^{E}$, both $D_{T}$ [dimensão topológica] and $D$ [dimensão de Hausdorff-Besicovitch] are at least 0 and to most $E$. But the resemblance ends here. The dimention $D_{T}$ is always an integer, but $D$ need not to be an integer. And the two dimentions need not concide; they only satisfy the Szpilrajn inequality $D \geq D_{T}$. For All Euclid, $D=D_{T}$. But nearly all sets in this Essay satisfy $D>D_{T}$. There was no term to denote such sets, which led me to coin the term fractal, and to define it as it folows:

A fractal is by definition a set for which the Hausdorff-Besicovitch dimention strictly exceeds the topological dimention." 1

O próprio autor reconhece no mesmo trabalho (pg. 16-17) que o "Estudo matemático da forma deve ir além da topologia" e propõe um estudo duplo, tendo a topologia e os fractais como bases. Ele também define o termo dimensão fractal para evitar confusão entre a dimensão de HausdorffBesicovitch com a dimensão dos espaços de Hausdorff.

Infelizmente esta definição exclui inúmeros objetos que seriam naturalmente chamados de fractais, uma maior discussão deste problema está na seção 3.2 .

\footnotetext{
1 "Sempre que trabalhamos no espaço euclidiano $R^{E}$, ambas $D_{T}$ [dimensão topológica] e $D$ [dimensão de Hausdorff- Besicovitch] são no mínimo zero e no máximo $E$. Mas a similaridade termina aí. A dimensão $D_{T}$ é sempre um número inteiro, enquanto $\mathrm{D}$ não precisa ser um inteiro. E ambas não precisam coincidir tampouco; elas somente tem que satisfazer a desigualdade de Szpilrajn: $D \geq D_{T}$. Para todas formas euclidianas $D=D_{T}$. Mas quase todos conjuntos neste Ensaio satisfazem $D>D_{T}$. Não havia nome para tais conjuntos, o que me levou a cunhar o nome fractal, e a defini-lo como segue:

Um fractal é por definição um conjunto cuja dimensão de Hausdorff-Besicovitch excede estritamente sua dimensão topológica."
} 
Esta carência de definição tem seus benefícios como aponta Mandelbrot dizendo que é necessário cuidado com as definições para não cercear um campo jovem e em expansão. Depois de 15 anos estudando este campo deveríamos, porém, ser capazes de dar uma definição adequada, mas a afirmação acima passou da categoria 'coerente e adequada' para 'desculpa'. E deve ser evitada, pois causa uma grande confusão e impede o avanço saudável de um campo, tanto na parte teórica quanto na prática. O aviso de Mandelbrot inspirou e foi levado em consideração por todo este trabalho.

Outro autor muito influente, e o primeiro cientista a apresentar uma aplicação economicamente rentável dos fractais, é Michael Fielding Bansley e em [BAR88] dá uma outra "definição" para fractais, pesadamente apoiada na topologia:

"We refer to $(H(X), h)$ [espaço métrico de subconjuntos de $X$ com a métrica de Hausdorff $h$ induzida] as 'the space of fractals'. It is too soon to be formal about the exact meaning of 'a fractal'. At the present stage of development of science and mathemathics, the idea of a fractal is most useful as a broad concept. Fractals are not defined by a short legalistic statement, but by the many pictures and contexts which refer to them. For us [...] any subset of $(H(X), h)$ is a fractal. However as with the concept of 'space' more meaning is suggested than is formalized." 2

Esta definição também tem alguns problemas: é muito geral e recai na afirmação de Mandelbrot e deixa a polêmica da discussão sobre a definição para o futuro. Assim como a definição de Mandelbrot esta é discutida na seção 3.3 .

Este trabalho procura apresentar uma teoria unificada de fractais, com uma formalização dos conceitos básicos, culminando na definição de fractal. Além disto temos a revisão dos "clássicos" do campo segundo a teoria apresentada e uma apresentação das técnicas computacionais mais importantes.

Muito cuidado foi tomado na escolha da definição de fractal para manter a abrangência do campo de aplicações e ao mesmo tempo fornecer elementos

\footnotetext{
2 "Nos referimos a $(H(X), h)$ [espaço métrico de subconjuntos de $X$ com a métrica de Hausdorff $h$ induzida] como "o espaço dos fractais". É muito cedo para sermos formais sobre o significado exato de "um fractal". No estagio atual de desenvolvimento da ciência e da matemática, a idéia de fractal é mais útil como um conceito amplo. Os fractais não são definidos por uma curta definição "legal", mas pelas inúmeras imagens e contextos que se referem a eles. Para nós [...] qualquer subconjunto de $(H(X), h)$ é um fractal. Porém assim como com o conceito de 'espaço' mais é sugerido do que realmente formalizado."
} 
palpáveis para estruturação de uma teoria útil e não trivial.

A definição de fractal apresentada é a síntese do fator comum a todos elementos do campo: a iteração. Ela serve como alternativa prática e ao mesmo tempo flexível para acomodar os diversos desenvolvimentos do campo e unificá-lo com uma teoria abrangente.

O objetivo é apresentar uma base bem definida e mais sólida para a pesquisa e aplicação. Neste trabalho existem diversos exemplos que ilustram as idéias apresentadas e fazem a ponte das noções usuais com as dadas aqui. Não se pretende esgotar o assunto ou mesmo apontar todos os ramos de pesquisa relacionados, mas sim dar uma idéia geral de como o campo está e possibilitar a interpretação de sua evolução em termos de uma teoria consistente.

Esta dissertação se divide em quatro capítulos, cada um acrescenta ao anterior novos conceitos delineando assim a teoria a as principais técnicas utilizadas.

Os capítulos 1 e 2 tratam de órbitas e mapas, que são os blocos básicos da definição dos fractais. A preocupação de definir uma teoria abrangente obriga o uso do mínimo possível para as definições e resultados. Portanto estas seções são divididas em duas partes: uma que não pressupõe a existência de nenhuma estrutura especial nos conjuntos estudados e outra que necessita de conjuntos equipados com uma métrica (espaços métricos).

O capítulo 3 apresenta a definição de fractais e delineia uma classificação dos principais grupos de fractais em relação ao que foi apresentado unificando os conceitos vindos de diversos campos.

No final - ao capítulo 4 - são discutidas técnicas e resultados computacionais importantes para o cálculo e visualização dos fractais, bem como, sua aplicação em problemas práticos. 


\title{
Simbologia
}

\author{
$A, B, D, E$ \\ Conjuntos (ou espaços) \\ $a, b, c, e$ \\ Elementos de conjuntos (ou pontos de espaços) \\ $f, g, h$ \\ Funções \\ $n, m, k, p, q$ \\ Números inteiros e/ou índices \\ $x, y, z$ \\ $a, b, c, d, e$ \\ $f: A \mapsto B$ \\ $f \circ g$ \\ Elementos de órbitas ou de $n$-uplas \\ Valores reais ou complexos \\ Função que leva elementos do conjunto $A$ no $B$ \\ Composição de $f$ com $g$, ou seja: \\ $\Rightarrow$ \\ $(f \circ g)(x)=f(g(x))$ \\ Implica \\ $\Leftrightarrow$ \\ Equivalente, ou se e somente se \\ Final de uma demonstração \\ Contido (total ou parcialmente) \\ Contido propriamente (parcialmente) \\ Não está contido \\ Pertence \\ Não pertence \\ A variável $a$ se aproxima do (tende ao) valor $\alpha$ \\ Portanto \\ Tal que \\ Conjunto vazio \\ União \\ Interseção \\ Existe \\ Qualquer \\ $P(A) \quad$ Conjunto das partes do conjunto $A$, ou \\ seja, $B \in P(A) \Leftrightarrow B \subseteq A$
}




$\begin{array}{ll}{[a, b]} & \text { Intervalo: conjunto de todos valores entre } \\ & \text { entre } a \text { e } b \text { inclusive } \\ {[a, b[} & \text { O mesmo que }[a, b] \text { sem o elemento } b \\ ] a, b] & {[a, b] \text { sem o } a} \\ ] a, b[ & {[a, b] \text { sem os extremos }(a \text { e } b)} \\ \{a . . b\} & \text { Inteiros de } a \text { até } b \text { inclusive: }\{i \in \mathbb{Z} / a \leq i \leq b\} \\ \left(x_{1}, x_{2}, \ldots, x_{n}\right) & \text { Enupla (ou } n \text {-upla) ordenada } \\ \left\{x_{1}, x_{2}, \ldots, x_{n}\right\} & \text { Conjunto de elementos } \\ \mathbb{N} & \text { Conjunto dos números naturais } \\ \hat{\mathbb{N}} & \text { Conjunto dos naturais estendido: } \mathbb{N} \cup\{\infty\} \\ \mathbb{Z} & \text { Conjunto dos inteiros } \\ \mathbb{Q} & \text { Conjunto dos racionais } \\ \mathbb{R} & \text { Conjunto dos reais } \\ \mathbb{C} & \text { Conjunto dos complexos } \\ \hat{\mathbb{C}} & \text { Esfera de Riemann ou } \mathbb{C} \cup\{\infty\} \\ \text { sse } & \text { Se e somente se }\end{array}$

Cada termo novo introduzido no texto está sublinhado no local de sua definição (e primeira ocorrência). Teoremas e resultados são apresentados em proposições (Prop.:). Definições, proposições, algoritmos são numerados de acordo com o capítulo em que aparecem. 


\section{Capítulo 1}

\section{Órbitas}

No estudo de fractais nota-se uma característica básica: auto-semelhança e uma forma de criação comum: o uso de transformações iteradas, que aqui são modeladas por funções iteradas. No decorrer deste trabalho o papel das funções iteradas irá ficando mais claro e os termos e conceitos apresentados neste capítulo serão fundamentais para o estabelecimento de uma teoria dos fractais.

Normalmente trabalha-se com funções arbitrárias entre espaços diferentes como $f: E \rightarrow F$ onde $E$ e $F$ são conjuntos quaisquer, mas aqui estamos interessados em processos (descritos e modelados por funções) que podem ser aplicados repetidamente. Logo trabalharemos com funções de um conjunto nele mesmo $(f: E \rightarrow E)$ a menos que seja explicitamente denotado o contrário. Além disso assumiremos que o conjunto onde estas funções operam é representado por $\mathrm{E}$ (a menos de menção em contrário).

Definição 1.1 Função inversa: Dada uma função $f$, se existe outra função $f^{-1}$ tal que $\left(f^{-1} \circ f\right)(a)=a$ para $\forall a \in E$, esta é dita uma função inversa de $f$.

Neste trabalho não precisamos da unicidade da inversa, ou seja podem existir várias inversas de uma mesma função $f$. Quando estamos falando de uma função e sua inversa costuma-se usar o nome função direta para a função original.

Definição 1.2 Função iterada de ordem n: dadas uma função $f$ e um natural $n \in \mathbb{N}$ a função iterada $f^{n}$ é definida por:

$$
f^{n}(x)= \begin{cases}\left(f \circ f^{(n-1)}\right)(x) & \text { se } n>0 \\ x & \text { se } n=0\end{cases}
$$


alternativamente podemos dizer que:

$$
f^{n}(x)=\underbrace{f \circ f \circ \cdots f}_{n \text { vezes }}(x) \text { e que } f^{0}(x)=x
$$

Se o número de iterações $(n)$ de $f$ for explícito ou decorrente do contexto denotamos por $f^{i t}$. Quando existe, indicamos por $f^{*}$ o limite: $f^{*}(x)=$ $\lim _{n \rightarrow \infty} f^{n}(x)$.

Exemplo 1.1 Problema de Collatz (ou $3 n+1$ ):

Seja $f$ a função dada por ${ }^{1}$ :

$$
f(n)= \begin{cases}n / 2 & \text { se } n \text { é par } \\ 3 n+1 & \text { se } n \text { é ímpar }\end{cases}
$$

Itera-se $f$ a partir de qualquer número natural. O problema consiste em saber se todos os naturais irão eventualmente (pela iteração de $f$ ) atingir os valores 1 e 2 :

\begin{tabular}{c|ccccccccc}
$n$ & 10 & 5 & 8 & 4 & 2 & 1 & 2 & 1 & $\cdots$ \\
\hline$f(n)$ & 5 & 8 & 4 & 2 & 1 & 2 & 1 & 2 & $\cdots$
\end{tabular}

Este problema, analizar o comportamento de $f^{k}(n)$ para todos naturais $n \in \mathbb{N}$, ainda está em aberto.

Quando existe uma inversa de $f$ (denotada por $f^{-1}$ ) costumamos estender a definição de função iterada para ordem negativa $-n \operatorname{com} n \in \mathbb{N}$ por:

$$
f^{-n}(x)=\left(f^{-1} \circ f^{-n+1}\right)(x)
$$

esta definição deve ser usada com cautela pois a falta de unicidade da $f^{-1}$ pode causar confusão. Uma alternativa é usar a notação $f^{-n}$ indexada (ou identificada de outra forma) para indicar com qual função inversa de $f$ estamos iterando.

Definição 1.3 Ponto fixo de uma função $f$ : é um elemento a de E tal que $f(a)=a$.

Definição 1.4 Imagem do conjunto $A$ por $f: f(A)=\{f(a) / a \in A\}$ e esta definição se estende naturalmente para $f^{n}(A)$.

\footnotetext{
${ }^{1}$ Esta função pode ser "acelerada" tomando-se $(3 n+1) / 2$ no lugar de $3 n+1$
} 
Definição 1.5 Pré-imagem do conjunto $A$ por $f: f^{-1}(A)=\{a / f(a) \in A\}$ e esta definição também se estende naturalmente para $f^{-n}(A)$.

Definição 1.6 Conjunto fixo de $f$ : é um subconjunto $A$ de E para o qual temos: $f(A)=A$.

\subsection{Geral}

Iterando uma função surge uma seqüência de valores: a órbita. As propriedades destas é que possibilitam o entendimento global do comportamento das funções iteradas.

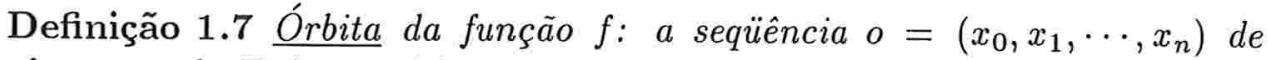
elementos de E é uma órbita de $f$ quando $x_{i}=f\left(x_{i-1}\right)$ com $^{2} 1 \leq i \leq n$. $O$ elemento $x_{0}$ é chamado de semente ou valor inicial da órbita. Onde $n$ é o tamanho da órbita ou ordem da órbita e é denotado por Tam(o). Quando $n<\infty$ a órbita é finita, caso contrário infinita.

Nota-se que a imagem da função Tam é $\hat{\mathbb{N}}$, ou seja, $\mathbb{N} \cup\{\infty\}$. E ainda utilizando a notação $f^{n}$ podemos dizer que $x_{i}=f^{i}\left(x_{0}\right)$ para todos $i \in \mathbb{N}$. Observamos que $o=\left(x_{0}, x_{1}, \cdots\right)$ é uma órbita e a partir de sua semente - $x_{0}$ - é possível determinar todos valores de $o$. Por esta característica determinística das órbitas podemos denotar $o=\left(x_{0}, x_{1}, \cdots\right)$, por $o\left(x_{0}\right)$ ou simplesmente $o(x)$ quando a semente for um valor qualquer de $E$. Em contextos onde o valor inicial não importar ou já tiver sido especificado pode-se usar simplesmente $o$.

Como toda órbita finita pode ser estendida para formar uma infinita, simplesmente iterando-se $f$, podemos restringir nosso estudo teórico às orbitas infinitas e quando for necessário a implementação de algoritmos computacionais usaremos somente órbitas finitas (afinal queremos programas terminando em tempo finito) para estudar as órbitas de uma função em geral.

O estudo das órbitas é interessante quando não se consegue uma forma fechada (também chamada de expressão analítica) para $f^{n}$ ou se a forma

\footnotetext{
${ }^{2}$ Sempre que alguma variável em $\mathbb{N}$ for ilimitada usaremos a notação var $=\infty$ considerando que a mesma assuma valores em $\hat{\mathbb{N}}$, ou seja, em $\mathbb{N} \cup\{\infty\}$. Esta convenção também é muito útil para não sobrecarregar expressões que envolvem limitações desta variável.
} 
fechada não for viável computacionalmente. Por exemplo ${ }^{3}$, a função $f(x)=$ $x^{2}+c$ tem uma forma fechada que é tão complicada (senão mais) do que a iteração direta da função.

Definição 1.8 Conjunto das órbitas de $f$ : é o conjunto dado por $\operatorname{Orb}(f)=$ $\{o(x) / x \in E\}$, nota-se que este conjunto tem a mesma cardinalidade de $E$.

Definição 1.9 Equação iterada: é uma relação de recorrência dada por $x_{n}=f\left(x_{n-1}\right)$, também conhecida como equação de diferenças.

Algumas vezes trabalha-se com equações iteradas que dependem de $n-$ $k$ valores anteriores: $x_{n}=f\left(x_{n-1}, x_{n-2}, \cdots, x_{k}\right)$. Isto, a princípio, não encaixa na definição de função iterada, mas se fizermos a seguinte adaptação:

$$
\left(\begin{array}{c}
x_{n} \\
x_{n-1} \\
\vdots \\
x_{k+2} \\
x_{k+1}
\end{array}\right)=\left(\begin{array}{c}
f\left(x_{n-1}, x_{n-2}, \cdots, x_{k}\right) \\
x_{n-1} \\
\vdots \\
x_{k+2} \\
x_{k+1}
\end{array}\right)=F\left(\begin{array}{c}
x_{n-1} \\
x_{n-2} \\
\vdots \\
x_{k+1} \\
x_{k}
\end{array}\right)
$$

teremos construído $F$, uma função iterada que leva elementos de $E^{n-k}$ em elementos de $E^{n-k}$.

Definição 1.10 Órbita direta e órbita inversa: em certos contextos chamamos as órbitas (como definido anteriormente) de órbitas diretas, já que estas se apoiam no uso da $f$ diretamente. Porém para certos casos vale a pena calcular as órbitas inversas, baseadas na iteração da função inversa. Estas dependem da existência de uma inversa de $f$ e existem técnicas computacionais adequadas para lidar com a falta de unicidade no cálculo da inversa.

Exemplo 1.2 Jogo do caos na reta $\mathbb{R}$

Seja $f: \mathbb{R} \rightarrow \mathbb{R}$ a função ${ }^{4}$ :

$$
f(x)= \begin{cases}3 x & \text { Se } x<=0,5 \\ 3-3 x & \text { caso contrário }\end{cases}
$$

\footnotetext{
${ }^{3}$ Equações diferenciais são um campo extremamente fértil de exemplos de sistemas sem solução fechada, mas não serão tratados aqui porque não são funções iteradas discretas. Porém vários exemplos e funções apresentados vêm de discretizações de sistemas de equações diferenciais ou por seções de Poincaré das mesmas.

${ }^{4}$ Conhecida como transformação da tenda: $f_{a}(x)=a x$ se $x \leq 0,5$ ou $f_{a}(x)=a(1-x)$ caso contrário. Aqui estamos considerando $f_{3}$.
} 
Esta função faz com que $x$ fique três vezes mais longe da origem se estiver próximo de $0(<=0,5)$ ou fique três vezes mais longe de 1 se estiver mais próximo dele $(>0,5)$.

O jogo consiste em: cada jogador escolhe um ponto, aquele cujo ponto demorar mais para escapar do intervalo $[0 ; 1]$ (ou qualquer outro intervalo finito) é o vencedor ${ }^{5}$.

O movimento de um ponto, é por exemplo $x_{0}=0,2$ :

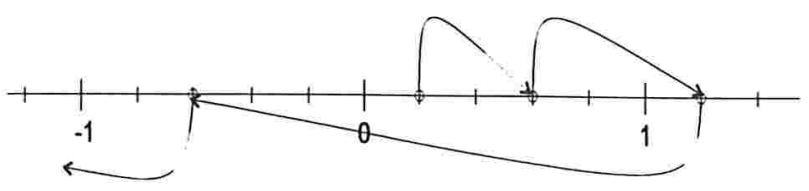

Gráfico da órbita de 0,2

neste caso $o=\left(x_{0}=0,2 ; 0,6 ; 1,2 ;-0,6 ;-1,8 ; \ldots\right)$.

Já no caso de $x_{0}=0,3$ :

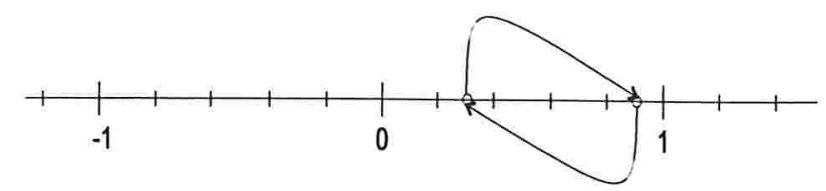

Gráfico da órbita de 0,3

neste caso $o=\left(x_{0}=0,3 ; 0,9 ; 0,3 ; 0,9 ; 0,3 ; \ldots\right)$.

Se tomamos $x_{0}=0$ ou 1 ou 0,75 então $f\left(x_{0}\right)=x_{0}$, estes são pontos fixos de $f$.

Seja $B=\{0,1 ; 0,2\}$ o conjunto imagem de $B$ é $f(B)=\{0,3 ; 0,9\}$. Ou ainda se tomamos $A=\{0,3 ; 0,9\}$ teremos o conjunto imagem de $A$ exatamente igual a ele: $f(A)=A$ ou seja $A$ é um conjunto-fixo de $f$.

Uma forma interessante de observar as órbitas (e outras características interessantes) de uma função de $\mathbb{R}$ em $\mathbb{R}$ é o diagrama de iteração: Desenha-se a função e a reta $y=x$, a iteração parte de um ponto $x_{0}$ no eixo $x$, sobe até encontrar o gráfico de $f($ em $f(x))$, em seguida segue lateralmente até encontrar a reta $y=x$ (daí $x_{1}=f\left(x_{0}\right)$ ), então segue verticalmente até encontrar $f$ (em $f\left(x_{1}\right)$ ou $f\left(f\left(x_{0}\right)\right)$ ) e assim por diante:

\footnotetext{
${ }^{5}$ Para tornar o jogo mais interessante pode-se proibir a escolha de qualquer ponto que já tenha sido empregado.
} 


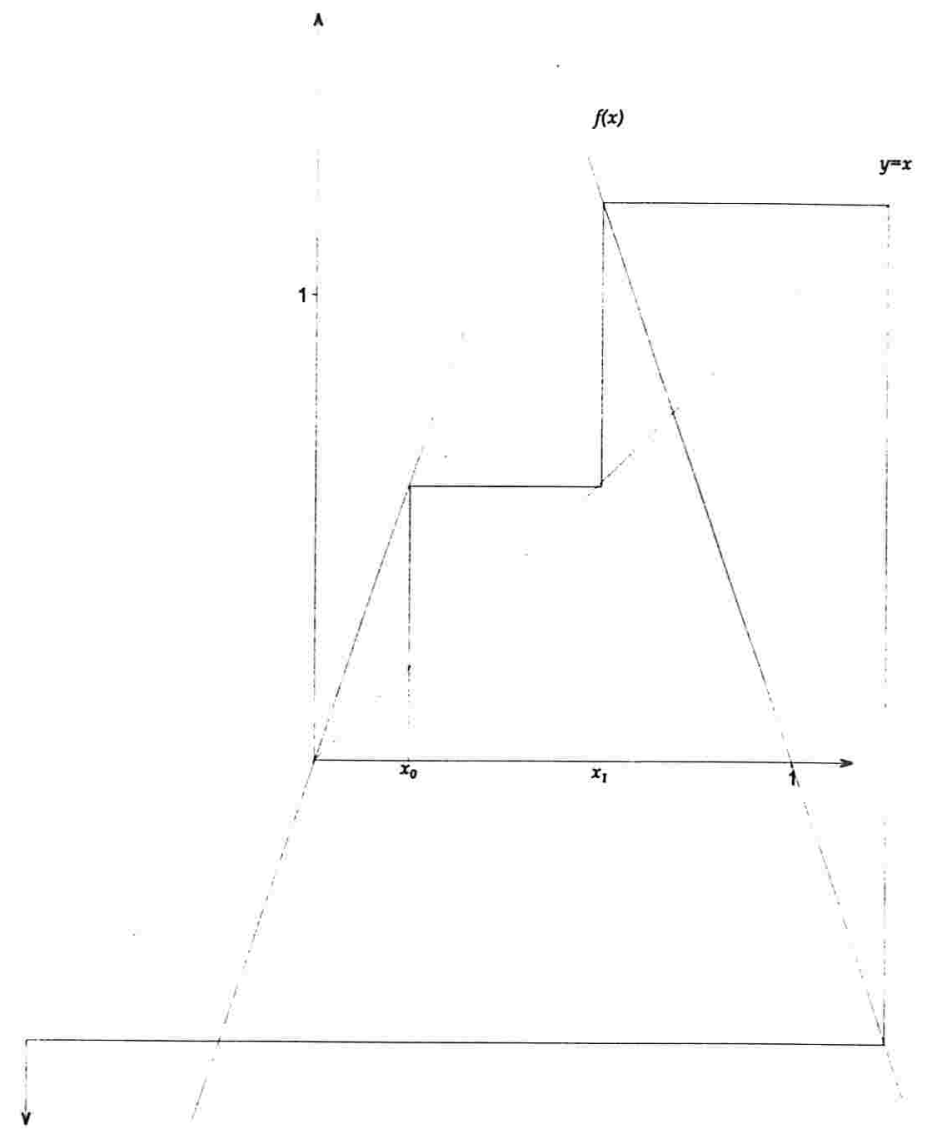

Diagrama de iteração da órbita de 0,2

Neste tipo de diagrama identifica-se rapidamente pontos fixos, seqüências divergentes etc.

Para estudar muitos fenômenos modelados por equações iteradas procura-se uma forma fechada de $f^{n}$ para descrever o comportamento de todos os elementos de $\operatorname{Orb}(f)$.

Definição 1.11 Extensão de uma órbita finita o: é uma $o^{\prime}=\left(x_{0}^{\prime}, x_{1}^{\prime}, x_{2}^{\prime}, \cdots\right)$ tal que $x_{i}=x_{i}^{\prime}$ para $0 \leq i \leq \operatorname{Tam}\left(o^{\prime}\right)$ e $\operatorname{Tam}\left(o^{\prime}\right)=\infty$, ou seja, é uma órbita com os mesmos valores de o só que com tamanho infinito. Sempre é possível calcular uma extensão de uma órbita pela iteração repetida de $f$.

Definição 1.12 Sobreposição de órbitas: $o\left(x_{0}\right)$ está sobreposta a órbita $o^{\prime}\left(x_{0}^{\prime}\right)$ sse $x_{k+i}=x_{i}^{\prime}$ para $0 \leq i \leq \operatorname{Tam}\left(o^{\prime}\right)$ e $k \in\{0 . . \operatorname{Tam}(o)\}$, note-se 
que apesar de ter elementos em comum com o (a partir da posição $k$ ), $o^{\prime}$ pode ter mais elementos do que o:

$$
\begin{aligned}
& o=\left(x_{0}, x_{1}, \cdots, \quad x_{k}, \quad x_{k+1}, \quad x_{k+2}, \cdots\right) \\
& o^{\prime}=\left(\begin{array}{cccc}
\downarrow & \uparrow & \downarrow & \\
x_{0}^{\prime}, & x_{1}^{\prime}, & x_{2}^{\prime}, & \cdots
\end{array}\right)
\end{aligned}
$$

Definição 1.13 Subórbita: ó é uma subórbita de o quando está sobreposta a o, mas não tem elementos a mais do que o, ou seja:

$$
\begin{aligned}
& o=\left(x_{0}, x_{1}, \cdots, \quad x_{k}, \quad x_{k+1}, \quad x_{k+2}, \cdots, \quad x_{k+n}, \cdots\right) \\
& o^{\prime}=\left(\begin{array}{ccccc}
\uparrow & \uparrow & \uparrow & & \uparrow \\
x_{0}^{\prime}, & x_{1}^{\prime}, & x_{2}^{\prime}, & \cdots, & x_{n}^{\prime}
\end{array}\right)
\end{aligned}
$$

No caso de duas órbitas infinitas os conceitos de sobreposição e subórbitas coincidem.

Proposição 1.1 sejam: $o, o^{\prime} \in \operatorname{Orb}(f)$

$o^{\prime}$ é uma subórbita de o sse $x_{0}^{\prime}=x_{k}$ para algum $k \in\{0 . . \operatorname{Tam}(o)\}$ demo.: se ó é subórbita de o então existe $k \in\{0 . . T a m(o)\}$ tal que $x_{k}=x_{0}^{\prime}$ (na definição quando $i=0$ )

se existe $k \in\{0 . . \operatorname{Tam}(o)\}$ tal que $x^{\prime} 0=x_{k}$ temos $x_{i}^{\prime}=f^{i}\left(x_{0}^{\prime}\right)=f^{i}\left(x_{k}\right)=$ $x_{k+1}$, ou seja, ó é subórbita de o $\square$

Definição 1.14 Órbita periódica: $o \in \operatorname{Orb}(f)$ é uma órbita periódica se $\exists k, n \in\{0 . . \operatorname{Tam}(\bar{o})\}, k<n$ tais que

$$
o=\left(x_{0}, x_{1}, \cdots, x_{k}, x_{k+1}, x_{k+2}, \cdots, x_{n}=x_{k}, x_{n+1}=x_{k+1}, \cdots\right),
$$

ou seja a partir da $k$-ésima posição os valores da órbita se repetem de $n-k$ em $n-k$ posições. Além disso:

- $o_{\text {pre }}=\left(x_{0}, x_{1}, \cdots, x_{k-1}\right)$ é chamada de parte pré-periódica,

- $\overline{o_{p e r}}=\left(x_{k}, x_{k+1}, \cdots, x_{n}=x_{k}, x_{n+1}=x_{k+1}, \cdots\right)$ é a parte periódica $e$

- $o_{\text {per }}=\left(x_{k}, x_{k+1}, \cdots, x_{n-1}\right)$ é um período de tamanho $n-k$ (também chamado periodicidade $n-k$ ).

Se $n=\infty$ diz-se que a órbita o é aperiódica.

Se uma órbita $o(x)$ tem período de tamanho 1 então ela contém um ponto fixo de $f$. 
Exemplo 1.3 O jogo do caos e órbitas períodicas

Ainda com a $f$ do exemplo 1.2 podemos observar que na órbita de $x_{0}=0,3$ temos uma órbita periódica sem parte pré- periódica e com período de tamanho 2:

$$
o=(0,3 ; 0,9 ; 0,3 ; 0,9 ; 0,3 ; 0,9 ; 0,3 ; 0,9 ; 0,3 ; 0,9 ; \ldots)
$$

$\mathrm{O}$ ainda no caso de $x_{0}=0,1$ temos uma órbita um pouco diferente:

$$
o=(0,1 ; 0,3 ; 0,9 ; 0,3 ; 0,9 ; 0,3 ; 0,9 ; 0,3 ; 0,9 ; \ldots)
$$

esta também é periódica $o_{\text {per }}=(0,3 ; 0,9)$ e tem uma parte pré-periódica: $o_{\text {pre }}=(0,1)$ de tamanho 1 .

Em alguns contextos surge uma definição de "ciclicidade" semelhante a de periodicidade. Porém, alguns autores vêm sugerindo o uso do termo ciclicidade quando uma órbita tiver um comportamento cíclico, mas não necessariamente periódico, ou seja, quando "der voltas" voltando a passar por uma região de $E$ repetidas vezes, mas sem ter um período definido (este comportamento também é descrito como 'oscilatório'). Esta distinção é válida e tem bastante utilidade, sendo adotada neste trabalho.

Proposição 1.2 Se uma órbita o $(x)$ é periódica e o conjunto A contém os valores de seu período: $A=\left\{x_{i} / x_{i}\right.$ pertence a $\left.o_{\text {per }}\right\}$ então

$A$ é um conjunto-fixo de $f$, ou seja, $f(A)=A$

Demo.:

$f\left(x_{i}\right)=x_{i+1} \in$ A para todos $i \in\{k . . n-2\}$ e ainda $f\left(x_{n-1}\right)=x_{k} \in A$, logo $f(A)=A$ :

$$
\underbrace{x_{k} \stackrel{f}{\rightarrow} x_{k+1} \stackrel{f}{\rightarrow} \cdots \stackrel{f}{\rightarrow} x_{n-1} \stackrel{f}{\rightarrow} x_{n}}_{\in A}
$$

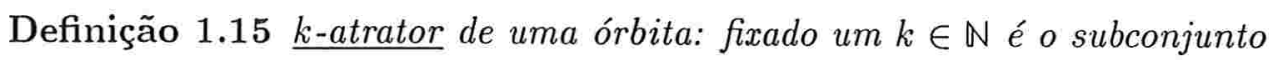
$B \subseteq E$, tal que $x_{n} \in B$ para todos $n \geq k$, se $B$ é infinito dizemos que ele é um $\underline{k \text {-atrator estranho. }}$.

Não se pode ter $k$-atratores estranhos em um espaço finito, pois mesmo que $B=E, B$ ainda seria finito. Os $k$-atratores estranhos têm suscitado muito interesse pois apresentam um comportamento cíclico, mas não periódico, além de terem propriedades dimensionais interessantes (vide seção $4)$. 
Proposição 1.3 Seja B um k-atrator de uma órbita o para algum $k>0$, então:

- se $B=\{a\}$ então a é um ponto fixo de $f$. Basta notarmos que se $x_{n} \in B$, temos que $f\left(x_{n}\right)=x_{n}$.

- se $B$ é finito então a órbita é periódica. Se todos $x_{n}$ com $n>k$ são pertencentes a $B$ então temos $x_{m}=x_{n}$ para $m>n>k$ (caso contrário $B$ seria infinito) daí temos que a órbita é periódica, pois se repete de pelo menos $m-n$ em $m-n$ posições.

- se E é finito todas as órbitas de $f$ são periódicas: como $E$ é finito qualquer $B$ em E é finito também. Daí temos o caso acima para todas órbitas de $E$

Caso $E$ seja finito as orbitas em $E$ podem ter um período de no máximo $|E|$ elementos (cardinalidade de $E$ ). Uma função com uma órbita assim tem todas as suas órbitas recaindo no mesmo período. Em um espaço finito podemos ter no máximo $|E|^{|E|}$ funções diferentes.

Definição 1.16 atrator de uma órbita o: é o menor elemento do conjunto $\left\{B^{\prime}\right.$ é um $k$-atrator de o $\left.k \in \mathbb{N}\right\}$, ou seja, o atrator está contido em todos os $k$-atratores com $k \in \mathbb{N}$.

Definição 1.17 atrator estranho de uma órbita: é o menor elemento do conjunto $\left\{B^{\prime}\right.$ é um k-atrator estranho/ $\left.k \in \mathbb{N}\right\}$ observamos que nem sempre este elemento existe.

Exemplo $1.4 \mathrm{O}$ atrator estranho do jogo do caos.

A função $f$ do exemplo 1.2 tem um atrator óbvio: $\infty$, mas existem outros atratores: $0 ; 1 ; 0,75$, e quanto a atratores estranhos? Existe um só: o conjunto de Cantor Triádico, construído da seguinte forma: 


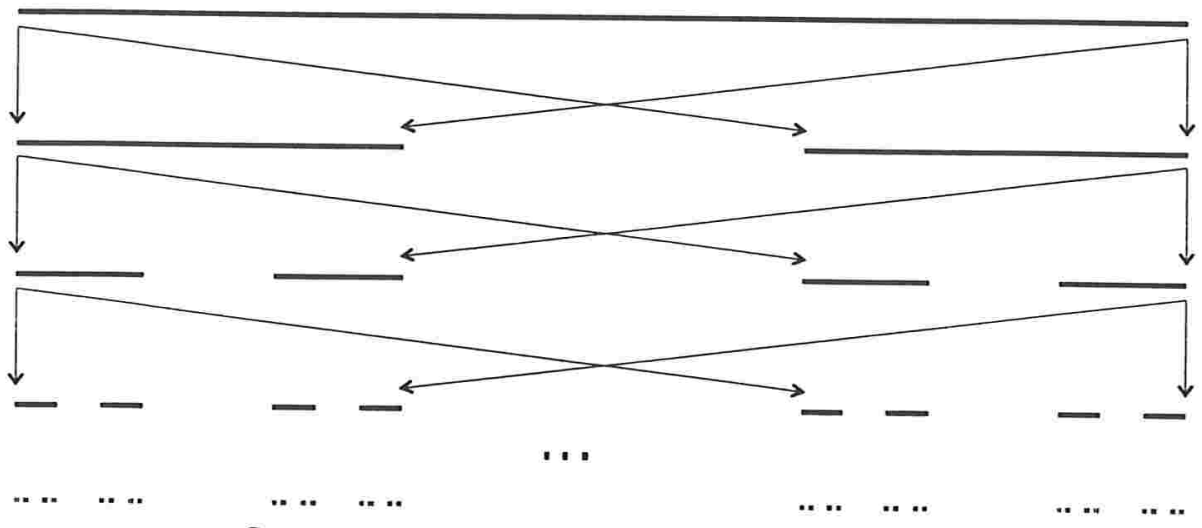

Construção do conjunto de Cantor Triádico.

Acima temos um segmento de reta de tamanho 1 sendo encolhido a $1 / 3$ de seu tamanho, mantido na origem, e uma cópia dele, também reduzida, colocada a $2 / 3$ de distância da origem. A seguir o processo é repetido no conjunto de segmentos resultante. Esta iteração levada ao infinito nos dá o conjunto de Cantor Triádico.

Qualquer elemento deste conjunto é levado a outro elemento dele por $f$ (é um conjunto-fixo de $f$ ) e é infinito.

Definição 1.18 Bacia de atração de um atrator $B$ : é o conjunto $A \subset E$ tal que todas as órbitas que tem como sementes os elementos de A têm como atrator $B$.

\section{Exemplo 1.5 Método de Newton}

Seja $f: \mathbb{C} \rightarrow$ a função que aproxima $\sqrt[3]{1}$ pelo método de Newton $^{6}$ dada por:

$$
f(z)=\frac{2 z^{3}+1}{2 z^{2}}
$$

A questão interessante é, dado $z_{0}$, para qual valor de $\sqrt[3]{1}$ o método converge. Se desenharmos no plano complexo todos os pontos que se aproximam de 1 pela iteração de $f$ obteremos sua bacia de atração:

${ }^{6}$ Para uma função derivável $f$, é dado pela iteração de:

$$
n_{f}(x)=x-\frac{f(x)}{f^{\prime}(x)}
$$

que aproxima uma raiz de $f$. 


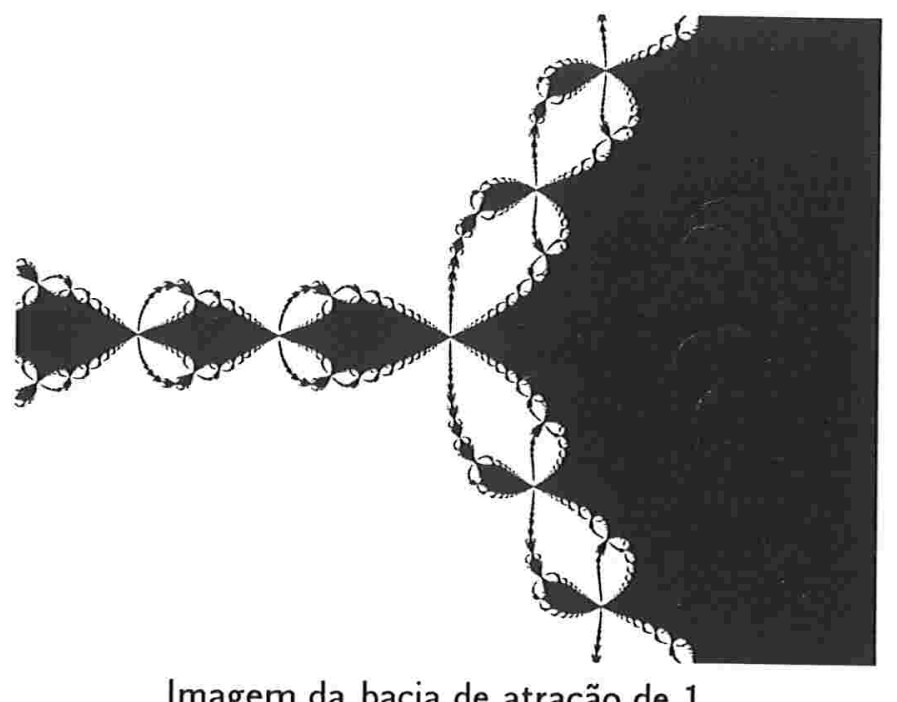

Imagem da bacia de atração de 1.

Apesar da complexidade da fronteira da bacia de atração (idêntica as de $\frac{\sqrt{3}}{2} i-\frac{1}{2}$ e $-\frac{\sqrt{3}}{2} i-\frac{1}{2}$ só que rotacionada $120^{\circ}$ e $240^{\circ}$ respectivamente) a função $f$ não tem atratores estranhos, só atratores: as três raízes cúbicas de 1.

O termo atrator (ou atrator estranho) é largamente utilizado, especialmente em sistemas dinâmicos. A definição neste campo é um pouco mais sofisticada do que a apresentada aqui ${ }^{7}$.

Proposição 1.4 Se A é atrator de uma órbita o $(x)$ então $A$ é um conjunto-fixo de $f$, ou seja, $f(A)=A$

Demo.:

como $A$ é um atrator de o(x) temos que todos $x_{n} \in A$ para $n \leq k$ com qualquer $k \in \mathbb{N}$, dai $f\left(x_{n}\right)=x_{n+1} \in A$ logo temos que $f(A) \subseteq A$, mas por outro lado seja $a \in A$, então necessariamente $a=f\left(x_{p}\right)$ para algum $x_{p}$ em A.

Caso não exista $x_{p}$ desta maneira ${ }^{8}$ existiria um atrator de $o(x): B=A-a$

\footnotetext{
${ }^{7} \mathrm{~A}$ definição aqui apresentada engloba mais do que os ditos "atratores estranhos" naquele campo. A razão desta diferença está no uso de funções com um argumento contínuo (em geral o tempo $t$ ), por exemplo: sistemas de equações diferenciais. Neste caso a órbita é uma trajetória contínua no espaço e o atrator é um conjunto invariante para o qual todas as órbitas de uma dada região se dirigem a medida que o sistema evolui.

A definição física usa de outros requisitos como a sensibilidade as condições iniciais para separar os atratores estranhos de outros atratores infinitos (quasi-periódicos, por exemplo). Estes requisitos derivam de espaços mais equipados e de outro tipo de estudo que não cabe aqui.

${ }^{8}$ Tanto se não existir $x_{p}$, quanto se existir $x_{p}$, mas este não pertencer a $A$.
} 
estritamente contido em A, que não é possivel já que A é atrator.

A volta é similar:

Proposição 1.5 Se A é um conjunto-fixo de $f$, ou seja, $f(A)=A$ então existem $x \in E$ e $k \in \mathbb{N} / A$ é um k-atrator de o(x).

Demo.:

Tomemos qualquer $x \in A, f(x) \in A$, pois $A$ é conjunto-fixo de $f$. Logo podemos escolher qualquer $k$ e teremos: $f^{k}(x) \in A$, logo $A$ é $k$-atrator de $o(x)$.

Definição $1.19 k$-atrator de um conjunto $A$ : assim como no caso de uma órbita. é um conjunto $B \subset E$ tal que $f^{n}(A)=B$ para todos $n \geq k$. Se $B$ for infinito ele é um $k$-atrator estranho do conjunto $A$.

Definição 1.20 atrator de um conjunto A: é o menor elemento do conjunto $\left\{B^{\prime}\right.$ é um k-atrator de $\left.A / k \in \mathbb{N}\right\}$.

Definição 1.21 atrator estranho de um conjunto A: é o menor elemento do conjunto $\left\{B^{\prime} \overline{\text { é um } k \text {-atrator estranho de } A / k} \in \mathbb{N}\right\}$, ou o elemento contido em todos elementos deste conjunto, nem sempre este elemento existe.

Uma vez definidos os termos básicos precisamos de algumas definições para estudar o comportamento das órbitas, ou seja, se elas tem ou não alguma propriedade.

Do conhecimento das propriedades das órbitas podemos, depois, passar a estudar as propriedades das funções iteradas em geral. $f$.

Fixemos para a(s) definição(ões) seguinte(s) um espaço $E$ e uma função

Definição 1.22 Propriedade de uma órbita o: é um procedimento ${ }^{9} h: \mathrm{Orb}(f) \rightarrow$ $R$, onde $R$ é um conjunto chamado de Espaço-Resultado. Este avalia uma dada órbita sob determinado aspecto.

Por exemplo podemos ter um método para determinar se uma órbita dada é ou não periódica. Então temos um $R=\{$ sim, não $\}$ (ou $\{0,1\}$ para computólogos...) e $h(o(x))=$ sim quando a órbita $o(x)$ for periódica e $h(o(x))=$ não quando não for.

\footnotetext{
${ }^{9}$ Definido como uma seqüência de operações matemáticas bem definidas, pode ser encarado como uma funçào.
} 
O procedimento $h$ pode não terminar em tempo finito, logo não é adequado para implementar o estudo de órbitas na prática. Para isso usamos um algoritmo $h^{\prime}: E \rightarrow R$ no lugar do procedimento $h$ ajustado para parar depois de um certo limite de iterações, tempo ou outros critérios. Quando o algoritmo é forçado a parar sem ter chegado a nenhuma conclusão é devolvido o valor indefinido também em $R$. Assim temos $h^{\prime}$ que recebe a semente de uma órbita e devolve, em tempo finito, uma resposta indicando uma característica da órbita.

As propriedades mais comuns de órbitas são:

- É_periódica, com $R=\{$ sim, não, indefinido $\}$ dizendo se a órbita é ou não periódica.

- Periodicidade, com $R=\mathbb{N} \cup\{$ indefinido $\}$ dando o tamanho do período da órbita avaliada.

- Tipo_órbita, com $R=$ \{pontofixo, periodicidadefinita, aperiódica, indefinida $\}$ classifica a orbita,

normalmente é mais fácil classificar a órbita do que calcular o tamanho de seu período (a periodicidade).

\subsection{Em espaços métricos}

Sem estrutura alguma no espaço que operamos fica muito difícil apresentar resultados interessantes, mas por outro lado se tivermos um espaço bastante equipado, fica difícil aplicar os resultados para uma classe ampla de problemas.

Com isso em mente optamos por nos basear em espaços métricos em geral, pois estes fornecem um espaço bastante simples que permite uma coleção bastante ampla de resultados. E em alguns casos (devidamente ressaltados) usa-se espaços métricos completos para garantir a existência de limites e atratores.

Definição 1.23 métrica: função $d: E \times E \rightarrow \mathbb{R}^{+}$que obedece os seguintes axiomas para $\forall x, y, z \in E$ :

1. $d(x, y) \geq 0$ e $d(x, x)=0$

2. $d(x, z) \geq d(x, y)+d(y, z)$

(desigualdade triangular) M2

3. $d(x, y)=d(y, x)$

(reflexividade) M3 
Definição 1.24 espaço métrico: É um par ordenado $(E, d)$ onde $E$ é um conjunto qualquer e dé uma métrica neste conjunto. Quando o contexto não permitir ambigüidades denota-se $(E, d)$ por $E$. Em alguns casos usa-se mais de uma métrica por conjunto, daí indexarmos (ou nomearmos as métricas) para evitar confusões.

Qualquer conjunto pode se tornar um espaço métrico com a métrica $0-1$ dada por $d(x, y)=0$ se $x=y$ ou 1 caso contrário (complementar da função delta). Por isso, deste ponto em diante assumiremos que $E$ é um espaço equipado com uma métrica $d$.

Definição 1.25 convergência de uma órbita: a órbita $o\left(x_{0}\right)$ converge sse $\forall \epsilon \in \mathbb{R}, \epsilon>0 \Rightarrow \overline{\exists m \in \mathbb{N} \text { tal que } d\left(x_{n}, x_{n+p}\right)} \leq \epsilon$ para $\forall n$ e $p \in \mathbb{N}$ e $n \geq m$ (Critério de convergência de Cauchy ${ }^{10}$ ).

Definição 1.26 o(x $x_{0}$ converge $^{11}$ para $z$ : com $z \in E$ quando $\forall \epsilon \in \mathbb{R}, \epsilon>$ $0 \Rightarrow \exists m \in \mathbb{N}$ tal que $d\left(\overline{\left.x_{n}, z\right) \leq \epsilon}\right.$ para $\forall n \in \mathbb{N}$ com $n \geq m$.

Proposição 1.6 Se uma órbita $o(x)$ converge para um ponto $z$ então a órbita o $(x)$ converge.

Demo.:

se o converge então sse $\forall \epsilon \in \mathbb{R}, \epsilon>0 \Rightarrow \exists m \in \mathbb{N}$ tal que $d\left(x_{n}, x_{n+p}\right) \leq \epsilon$ para $\forall n$ e $p \in \mathbb{N}$ com $n \geq m$,

Fixemos então $\epsilon^{\prime}=\epsilon / 2$ e como o converge para z temos que: $\exists m^{\prime} \in \mathbb{N}$ tal que $d\left(x_{n}^{\prime}, z\right) \leq \epsilon^{\prime}$ para $\forall n^{\prime} \in \mathbb{N}$ com $n^{\prime} \geq m^{\prime}$ e $d\left(x_{n}, x_{n+p}\right) \leq d\left(x_{n}, z\right)+$ $d\left(z, x_{p}\right)$ (M3) como ambas parcelas são menores ou iguais a $\bar{\epsilon}^{\prime}$ temos que $d\left(x_{n}, x_{n+p}\right) \leq \epsilon$ para $n^{\prime} \geq m^{\prime}$

Num espaço completo $E$ todas seqüências convergentes são convergentes para algum elemento do espaço, logo todas órbitas convergentes convergem para algum elemento de $E$. Mais ainda, todo espaço métrico pode ser completado, ou seja, ampliado para ser um espaço completo (vide [KA64]).

Definição 1.27 contração é o nome dado à uma função que "aproxima" pontos do espaço $E$, ou formalmente $f: E \rightarrow E$ é contração sse para alguma métrica d do espaço E:

$\forall x, y \in E$ vale $d(f(x), f(y)) \leq c . d(x, y)$ para algum $c \in \mathbb{R}, c<1$

\footnotetext{
${ }^{10} \mathrm{Em}$ textos de análise funcional (como em [KA64]) esta órbita é dita fundamental ou de Cauchy.

${ }^{11} \mathrm{E}$ esta é chamada de convergente pura e simplesmente.
} 
A constante $c$ na definição de uma contração (as vezes chamado de mapeamento contrativo) é conhecida como fator de contração e não é difícil ver que se aplicamos uma contração à um subconjunto de $E$ repetidas vezes convergiremos a um ponto de $E$ no limite. Ou seja o atrator desta função é um ponto! Mas aqui fica um pequeno detalhe: a noção intuitiva de que a função se dirige a um ponto do espaço não é facilmente demonstrada e enunciaremos o teorema que garante isso:

Proposição 1.7 Teorema da Contratividade: seja $f: E \rightarrow E$ uma contração em um espaço métrico completo, então

$f$ tem exatamente um ponto fixo $x_{f} \in E e$

qualquer órbita de $f$ converge para $x_{f}$.

demo: ver [BAR88, na página 76] $\square$

Exemplo 1.6 A iteração inversa do jogo do caos.

A inversa da $f$ definida no exemplo 1.2 não é unívoca: $f_{1}^{-1}(x)=x / 3$ e $f_{2}^{-1}(x)=1-(x / 3)$ em ambas temos uma contração, mas aplicar o teorema em qualquer uma delas não descreve o que acontece com $f$ já que não se leva em consideração a alternância entre as inversas e a multiplicação de pontos nas pré-imagens.

Para resolver isso podemos criar $F(A)=\{f(a) / a \in A\}$ e teremos $F^{-1}$ definida univocamente. Com a métrica de conjuntos $F^{-1}$ é uma contração e seu ponto fixo: $X$ é exatamente $C$ : o conjunto de Cantor Triádico:

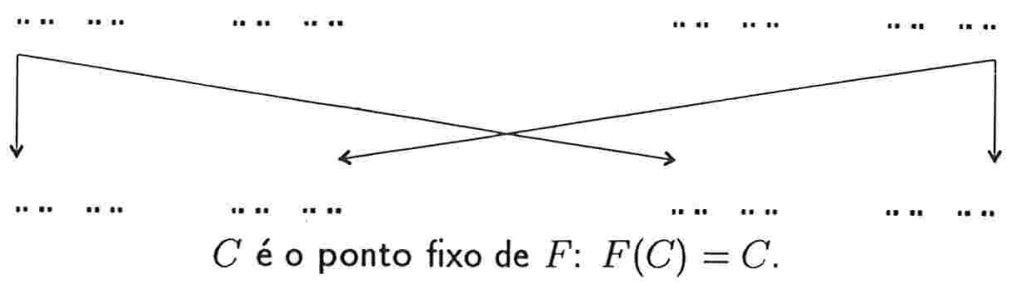

Desta forma percebemos como se calcula o atrator estranho do exemplo 1.4 e nele $f$ tem um conjunto-fixo, neste caso é o conjunto que contém todos os demais.

A noção de atratores é bastante utilizada e fica muito mais interessante quando estuda-se funções em espaços métricos. Mais ainda quando se tratam de espaços métricos completos com cardinalidade infinita, nos quais os atratores estranhos florescem. 
Uma indicação de como espaços equipados podem ser uma fonte rica de resultados interessantes sobre funções iteradas é o teorema de Sarkovsky.

O teorema de Sarkovsky se aplica somente a funções dos reais nos reais, porém é provável que se usarmos outros espaços resultados semelhantes (embora não tão poderosos) possam surgir.

Definição 1.28 Ordenação de Sarkovsky dos números naturais: A ordem:

$$
\begin{aligned}
& 3,5,7,9, \cdots,(2 n+1), \cdots \\
& 2 \times 3,2 \times 5,2 \times 7,2 \times 9, \cdots, 2 \times(2 n+1), \cdots \\
& 2^{2} \times 3,2^{2} \times 5,2^{2} \times 7,2^{2} \times 9, \cdots, 2^{2} \times(2 n+1), \cdots \\
& \vdots \\
& 2^{n} \times 3,2^{n} \times 5,2^{n} \times 7,2^{n} \times 9, \cdots, 2^{n} \times(2 n+1), \cdots \\
& \vdots \\
& 2^{n}, 2^{n-1}, \cdots, 2^{3}, 2^{2}, 2^{1}, 1,0
\end{aligned}
$$

é a ordenação dos naturais de Sarkovsky.

Proposição 1.8 (teorema de Sarkovsky): Seja $f: \mathbb{R} \rightarrow \mathbb{R}$ uma função contínua, se ela tem uma órbita de periodicidade $n$ então

$f$ tem órbitas de períodos com qualquer tamanho $m$ sendo que $m$ sucede $n$ na ordenação de Sarkovsky.

demo:

Ver [DEV92] (na verdade ela está completa em [DEV89])

Exemplo 1.7 0 jogo do caos tem órbitas de qualquer período

Isto é o mesmo que dizer que se $f$ (do exemplo 1.2) tem uma órbita de período 3, o que implica que ela tem órbitas de todos períodos. Em particular tem uma (ou mais) órbita(s) de período infinito.

Uma órbita de período 3 acontece com $f$, em $x_{0}=3 / 13: f(3 / 13)=9 / 13$, $f(9 / 13)=12 / 13$ e $f(12 / 13)=3 / 13$.

O teorema de Sarkovsky só se tornou conhecido no ocidente depois do artigo [LY75] que introduziu versão mais fraca deste teorema: o teorema do período três. Este diz que se uma função tem uma órbita com período de tamanho três então ela tem órbitas com períodos de qualquer tamanho.

Quando se trabalha num espaço métrico a propriedade mais estudada das órbitas (além das que não necessitam da métrica) é a convergência, que 
diz se a órbita converge ou não e no caso afirmativo para que valor. Em muitos casos trabalha-se com a esfera de Riemann $\hat{\mathbb{C}}$ ao invés dos números complexos, pois muitos sistémas ou convergem para um atrator ou divergem completamente, ou seja, "convergem" para $\infty$. Isto nos permite calcular um atrator mais facilmente (a existência do mesmo fica garantida nestes casos).

Exemplo 1.8 Jogo do caos em $\mathbb{R} \cup\{\infty\}$

Tomando $f$ estendida para $\mathbb{R} \cup\{\infty\}$ (com $f(\infty)=\infty$ ) temos agora quatro pontos fixos: $0 ; 0,75,1$ e $\infty$, a melhor forma de se ver isso é pelo diagrama de iteração:

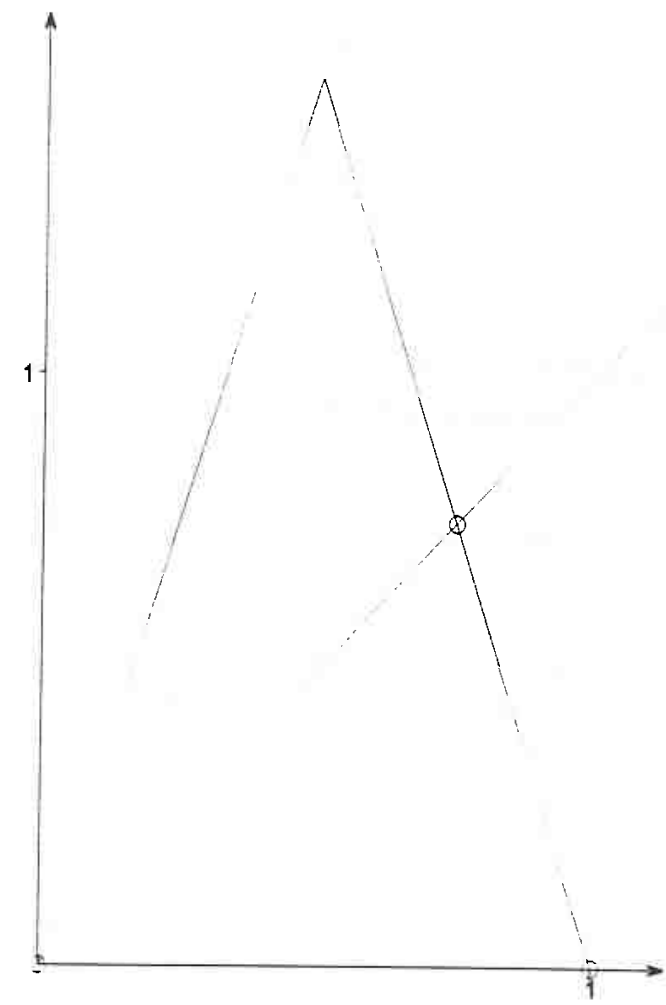

Pontos fixos na transformação em tenda.

A bacia de atração de $\infty$ é muito interessante, constituída dos intervalos: ] $-\infty ; 0[$ e $] 1 ; \infty[$ e trechos dentro do intervalo $[0 ; 1]$.

Os trechos no intervalo $[0 ; 1]$ formam (junto com os extremos acima) o complemento do conjunto de Cantor $C$. Desta forma a bacia de atração de $\infty$ é bastante sofisticada sendo intercalada com pontos do conjunto de Cantor Triádico em todas as escalas. 


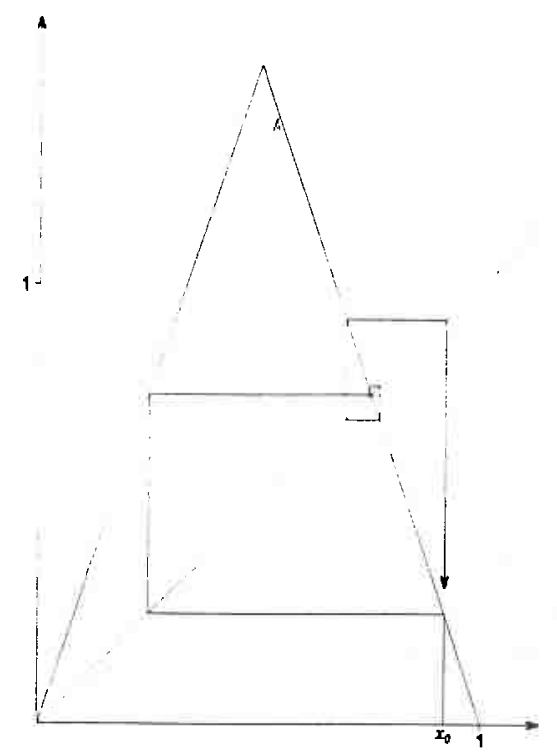

Iteração de um ponto 'prisioneiro'.

Note que o conjunto de Cantor Triádico é um conjunto de pontos "prisioneiros", ou seja aqueles que não "escapam", ou na terminologia adotada aqui: não estão na bacia de atração de $\infty$ ou ainda não divergem.

Retornando a espaços métricos completos temos uma ferramenta extremamente versátil: o expoente de Lyapunov.

Definição 1.29 Expoente de Lyapunov: é uma medida da divergência de orbitas iniciais próximas: então temos o expoente de Lyapunov de uma órbita de semente $x_{0}$ :

$$
\lambda\left(x_{0}\right)=\lim _{x_{0}^{\prime} \rightarrow x_{0}} \lim _{N \rightarrow \infty} \frac{1}{N} \sum_{i=0}^{N} \log _{2}\left(\frac{d\left(f^{i}\left(x_{0}^{\prime}\right), f^{i}\left(x_{0}\right)\right)}{d\left(x_{0}^{\prime}, x_{0}\right)}\right)
$$

Isto é, $\lambda\left(x_{0}\right)$ é o afastamento médio dos pontos em torno de $x_{0}$ pela iteração de $f$. O cálculo do expoente de Lyapunov não é trivial, mas em sistemas dinâmicos pode ser simplificado um pouco pelo uso da derivada da funçāo ${ }^{12}$.

$\mathrm{Na}$ maioria dos casos procura-se um expoente $\lambda$ que caracterize o sistema como um todo (ou limites que valham para um grande número de órbitas),

\footnotetext{
${ }^{12}$ Usando Taylor: $f(x) \approx f\left(x_{0}\right)+\left(x-x_{0}\right) f^{\prime}\left(x_{0}\right)$ portanto temos $\lambda\left(x_{0}\right)=$ $\lim _{n \rightarrow \infty} \frac{1}{n} \sum_{t=0}^{n} \log _{2} f^{\prime}\left(f^{i}\left(x_{0}\right)\right)$
} 
daí se usa o comportamento a longo termo de órbitas que estão na bacia de atração de algum atrator.

A melhor interpretação do expoente de Lyapunov é em termos da teoria da informação. Pode-se pensar na(s) variável(is) do sistema como tendo um número finito de bits de precisão (pela base do logaritmo na definição) e o expoente de Lyapunov representa a quantidade de bits perdidos em cada iteração, em média. Se for positivo indica a sensibilidade às condições iniciais, na terminologia dos físicos: caos; se for negativo indica estabilidade (na verdade é um sistema que ganha precisão exponencialmente); se for nulo a precisão se mantém constante durante a iteração de $f$.

Exemplo 1.9 O expoente de Lyapunov em $(2 x) \bmod 1$.

Tomemos $f(x)=(2 x) \bmod 1$, neste caso o cálculo do expoente de Lyapunov é possível pela aproximação em Taylor (já que a derivada de $f$ é $2 \mathrm{em}$ $[0 ; 1[)$ :

$$
\lambda\left(x_{0}\right)=\lim _{n \rightarrow \infty} \frac{1}{n} \sum_{i=0}^{n} \log _{2} f^{\prime}\left(f^{i}\left(x_{0}\right)\right)=\lim _{n \rightarrow \infty} \frac{1}{n} \sum_{i=0}^{n} \log _{2} 2=\lim _{n \rightarrow \infty} \frac{n+1}{n}=1
$$

isto vale para qualquer $x_{0} \in[0 ; 1[\log \circ$ como $\lambda=1>0$ temos um sistema caótico (ou sensível as condições inicias) no qual duas órbitas próximas divergem, em média, a uma velocidade de $e^{n}$ (ou um bit de imprecisão gerado por iteração) onde $n$ é o número de iterações.

Por exemplo, tomemos $x_{1}=0,05$ e $x_{2}=0,050001$ :

\begin{tabular}{cccc}
$n$ & $x_{1}$ & $x_{2}$ & $\left|x_{1}-x_{2}\right|$ \\
\hline 1 & 0,05 & 0,050001 & 0,000001 \\
2 & 0,10 & 0,100002 & 0,000002 \\
3 & 0,20 & 0,200004 & 0,000004 \\
4 & 0,40 & 0,400008 & 0,000008 \\
5 & 0,80 & 0,800016 & 0,000016 \\
6 & 0,60 & 0,600032 & 0,000032 \\
7 & 0,20 & 0,200064 & 0,000064 \\
8 & 0,40 & 0,400128 & 0,000128 \\
$\vdots$ & $\vdots$ & $\vdots$ & $\vdots$
\end{tabular}

Mesmo com a característica fechada da função (que leva $[0 ; 1[$ em $[0 ; 1[$ as orbitas se afastam exponencialmente com a iteração. 


\section{Capítulo 2}

\section{Mapas}

A idéia usada nos expoentes de Lyapunov - de se estudar o comportamento de um grande número de órbitas a longo prazo - é muito natural neste campo. Para melhor explorar esta idéia vamos introduzir e formalizar o conceito de 'mapa', aqui definido como o 'comportamento' de uma função iterada sobre um espaço dado a longo prazo. Mapa neste contexto, então, se refere muito mais ao conceito usual (geográfico) da palavra, ou seja, um diagrama que descreve características de regiōes do espaço.

Em suma queremos saber como $f^{n}$ se comporta quando $n$ vai para $\infty$, em sistemas tradicionais (como por exemplo cálculo diferencial) estaríamos procurando uma solução fechada para algum problema. Nem sempre esta existe, segundo alguns na maioria dos casos elas não existem, o que é certamente verdade quando se trata de funções iteradas em espaços arbitrários.

\subsection{Geral}

Assim como fizemos com órbitas começaremos com espaços sem nenhuma estrutura e passaremos a seguir para espaços métricos, traçando, onde for pertinente, um paralelo com propriedade e características de órbitas.

Definição 2.1 k-mapa: é uma função $M_{k, f, h}: \operatorname{Orb}(f) \rightarrow R$ que é dada a partir de um procedimento $h$ (em geral um algoritmo), uma função iterada $f$ e uma ordem de iteração $k$. Esta função é dada por:

$$
M_{k, f, h}(o(x))=h\left(\left(x, \cdots, f^{k}(x)\right)\right) \text { para } \forall x \in E
$$

Em muitos casos só se informa a semente da órbita para a função $M \mathrm{e}$ ela passa a semente ao algoritmo $h$. 
Definição 2.2 Mapa: é uma função $M_{f, h}: \operatorname{Orb}(f) \rightarrow R$ que diz o que acontece com cada órbita de E iterada indefinidamente. Definida por:

$$
M_{f, h}(o(x))=h(o(x)) \text { para } \forall x \in E
$$

Normalmente só é usado quando é possível escrever uma forma analítica (fechada) para $M$, caso contrário usa-se um $k$-mapa com um algoritmo $h$ como aproximação. Esta forma é mais adequada para estudos teóricos enquanto a forma dos $k$-mapas é mais útil na prática, com aplicações computacionais.

Definição 2.3 Mapa inverso e mapa direto: Quando o mapa (ou k-mapa) é baseado na $f^{-1}$ é comum referirmo-nos a ele como o mapa inverso. Nestes contextos usa-se o termo mapa direto identificar o de $f$.

Definição 2.4 Mapa de periodicidade: Dado pela propriedade de periodicidade onde $h(o(x))=\operatorname{per}(o(x))$ (a função que devolve a periodicidade de $o(x))$, ou seja, é $M_{f, p e r}: \operatorname{Orb}(f) \rightarrow \mathbb{N} \cup\{\infty\}$ onde $M_{f, p e r}(o(x))$ devolve a periodicidade da órbita $o(x)$. Formalmente:

$$
M_{f, p e r}(o(x))=\operatorname{Tam}\left(o_{p e r}(x)\right)
$$

ou em outras palavras $M_{f, p e r}(o(x))$ dá o tamanho do período de o(x) lembrando que quando o $(x)$ é aperiódica Tam $\left(o_{p e r}(x)\right)=\infty$.

Exemplo 2.1 Mapa de periodicidade de $f(x)=x^{2}+c$ em $\mathbb{R}$

Vamos tomar de $f(x)=x^{2}+c$ em Re verificar como é sua periodicidade quando $x_{0}=0$ e $c$ varia entre -2 e 2 . A função que estamos avaliando é na verdade $f(x, c)=\left(x^{2}+c, c\right)$ e estamos analisando o que acontece com as sementes $(0, c)$.

Com $c=0$ temos um ponto fixo de $f$ e a medida que $c$ aumenta continuamos a convergir para um ponto fixo: 


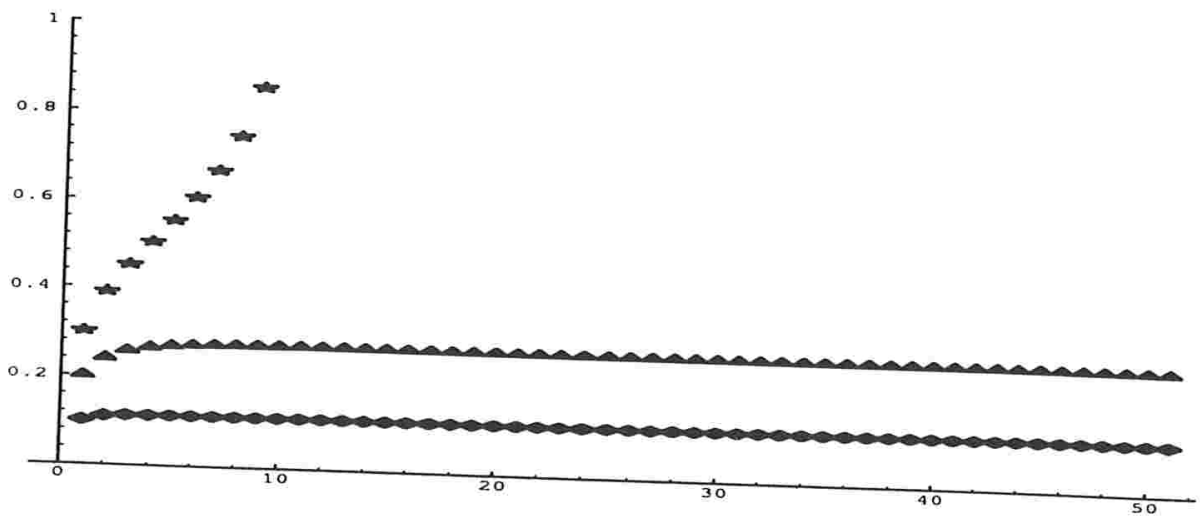

Gráfico de $f$ com $c=0,1,0,2$ e 0,3

$(0,1$ vai para $0,112701664 \ldots$ e 0,2 vai para $0,276393202 \ldots)$, mas com $c>$ $0,25 f$ diverge rapidamente.

Com $c$ decrescendo temos:

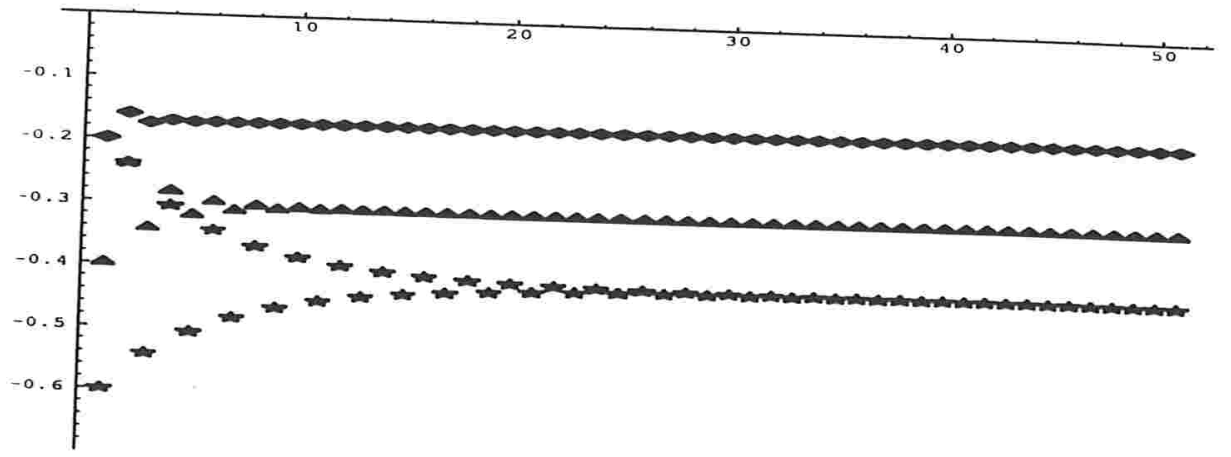

Gráfico de $f$ com $c=-0,2,-0,4$ e $-0,6$

Quando $c=0,75$ temos uma órbita de período 2: 


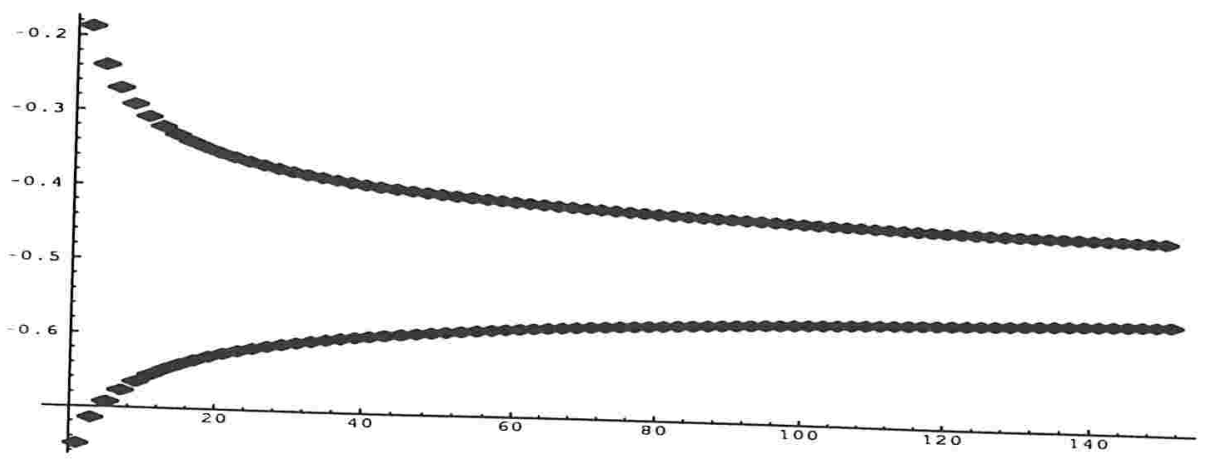

Gráfico de $f \operatorname{com} c=-0,75$

O mapa de periodicidade é dado pelo gráfico do tamanho do período em função de $c$ :

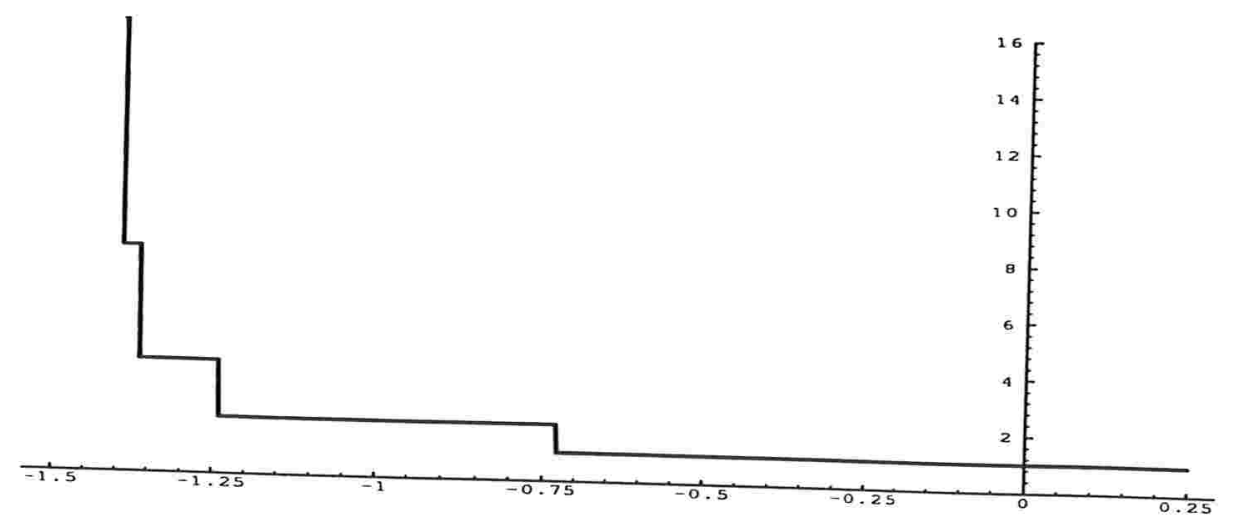

Gráfico da periodicidade $\times c$

Assim vemos como a Periodicidade funciona neste sistema: com $c$ em $[0,25 ;-0,75]$ a função converge para um valor, em $]-0,75 ;-1,25]$ para dois, em ] $-1,25 ;-1.365$ ] para quatro, em ] $-1,365 ;-1.393175$ [ e assim por diante. 
Definição 2.5 Mapa de bifurcação estrita: é uma variante do mapa de periodicidade para estudar as mudanças de periodicidade e os períodos da órbitas. Vele o espaço resultado é $R=P(E)$. É dado por $M_{f, b i f_{e}}: \operatorname{Orb}(f) \rightarrow$ $R$ com funções em E. Sua definição formal é:

$$
M_{f, b i f_{e}}(o(x))=o_{p e r}(x)
$$

ou seja, $M_{f, b i f_{e}}(o(x))$ é o conjunto dos elementos do período para o qual $o(x)$ vai quando $f$ é iterada. E caso este conjunto não exista, costuma-se adotar $M_{f, b i f_{e}}(o(x))=E$.

Os mapas de bifurcação estrita têm utilidade limitada, pois só em alguns casos atinge-se efetivamente os pontos de uma órbita periódica. Quando a função converge assimptoticamente para os pontos de convergência (como no exemplo acima) é mais útil o mapa de bifurcação (não estrita) ou dos pontos de convergência. Como este depende de uma métrica no $E$ será introduzido na próxima seção.

\subsection{Em espaços métricos}

Mas o mapa de bifurcação estrita nem sempre é suficiente, as órbitas podem demorar muito ou mesmo nunca chegarem a uma periodicidade definida, mas se aproximarem disso assintopticamente.

Ou seja voltamos à necessidade de avaliar a convergência das órbitas e seu preço: as métricas.

Nesta seção apresentaremos definições de mapas em espaços métricos explorando sobretudo a noção de convergência.

O mapa principal neste caso é o

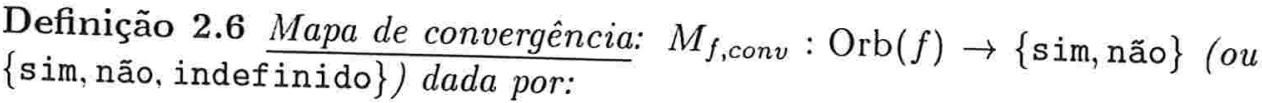

$$
M_{f, \text { conv }}(o(x))= \begin{cases}\text { sim } & \text { se o }(x) \text { converge } \\ \text { não } & \text { caso contrário }\end{cases}
$$

isto é, $M_{f, c o n v}$ diz simplesmente se uma órbita converge ou não. Quando aplicado na prática usa-se o espaço resultado $\{\mathrm{sim}$, não, indefinido $\}$ para
limitar o cálculo a tempos razoáveis. 
Este é um dos mapas mais importantes, normalmente usado em espaços métricos completos para prever tendências de comportamento.

\section{Exemplo 2.2 Conjunto de Sierpinsky}

Se tomamos uma função que age no plano, que depende de um triângulo isósceles $A B C$ (por exemplo, com $A$ em $(0,0)$ e tamanho 1), dada por: Seja $P$ o vértice mais próximo do ponto $x$, seja $r$ a semi-reta com origem em $P$ e que passa por $x$, o valor de $f$ é o ponto $x^{\prime}$ em $r$ tal que $\overline{P x^{\prime}}=2 \overline{P x}$

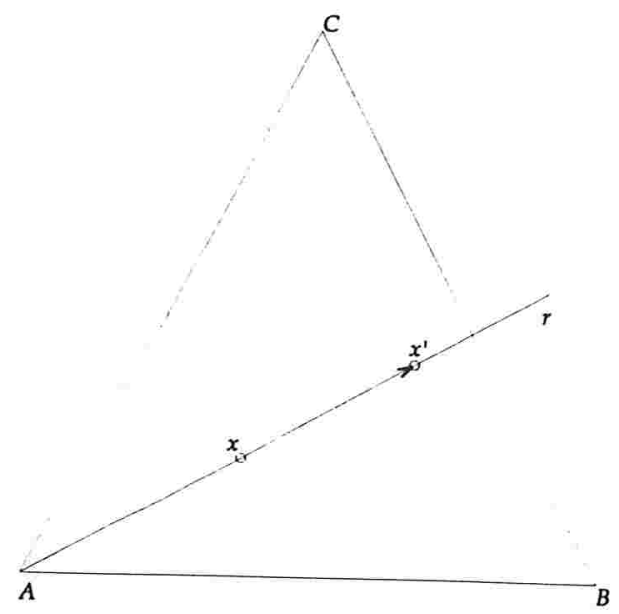

A iteração de $f$.

Esta função tem um conjunto de pontos prisioneiros interessante (caracterizado por Sierpinsky):

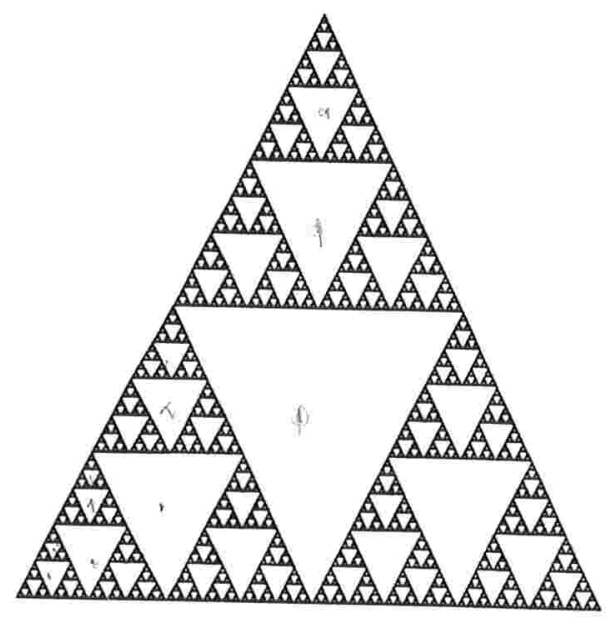

A iteração de $f$. 
Este é o conjunto de Sierpinsky, que demonstrou que qualquer curva unidimensional é topologicamente equivalente a um subconjunto dele.

Uma extensão natural do mapa de convergência é o mapa de pontos de convergência. Este é muito útil (e só faz sentido) em espaços completos, já que todas seqüências convergentes convergem para algum valor específico do espaço. Este é uma versão "aproximada" do mapa de bifurcação estrito:

Definição 2.7 Mapa de pontos de convergência ou de bifurcação: é o mapa definido por: $M_{f, b i f}: \operatorname{Orb}(f) \rightarrow P(E)$ onde

$$
M_{f, b i f}(o(x))=\{y \in E / y \in B \text { e B é atrator de } o(x) .
$$

Em outras palavras é o ponto para o qual a órbita o(x) converge, se a órbita convergir ou convenciona-se que $M_{f, b i f}(o(x))=E$ caso contrário.

Exemplo 2.3 Mapa de bifurcação de $f(x)=x+\lambda x(1-x)$

Um exemplo clássico de mapa de bifurcação estrito - em geral bastante mal interpretado - é o da função $f:[0 ; 1] \rightarrow[0 ; 1]$ dada por: $f(x)=x+\lambda x(1-x)$ onde $\lambda$ é uma parâmetro dado - uma equação simples de modelagem do crescimento populacional. Tomemos $\lambda=3,75$ a evolução de um ponto $x_{0}=$ 0,2 é:

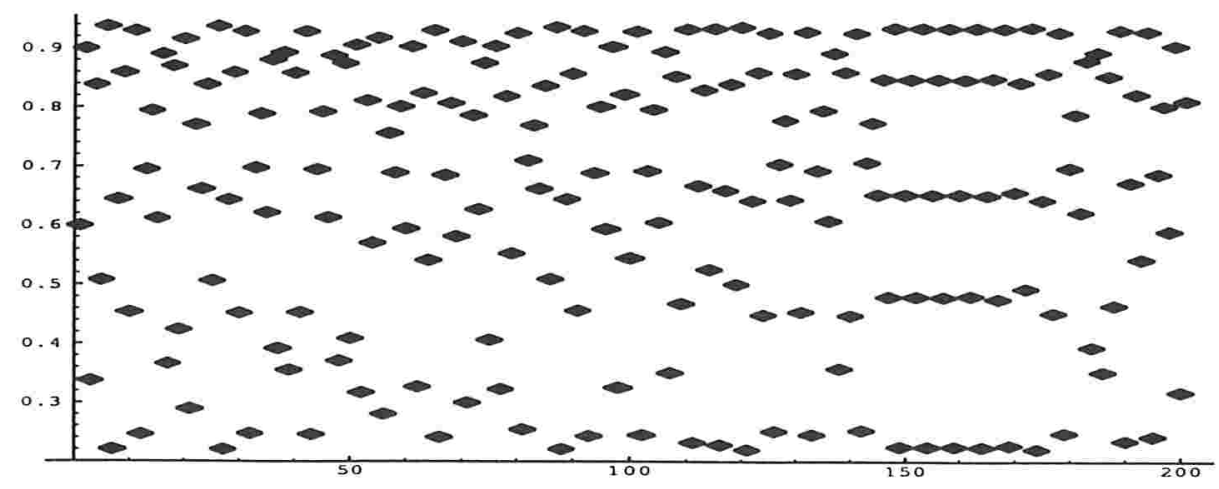

Iteração de $f$ com $\lambda=3,75$ e $x_{0}=0,2$ 
A ausência de regularidade é bastante comum, mesmo perto de pontos fixos como 0:

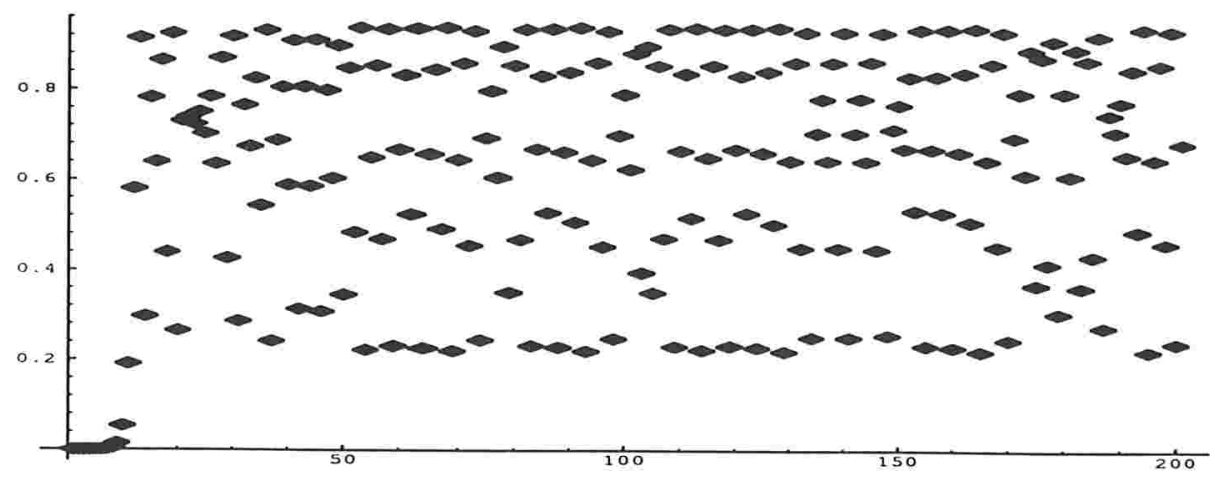

Iteração de $f \operatorname{com} \lambda=3,75$ e $x_{0}=0.0000001$

Em todos valores de $\lambda$ temos 0 e 1 como pontos fixos, e qualquer ponto entre eles tem periodicidade igual aos demais, só dependendo de $\lambda$, por exemplo com $\lambda=3,5$ :

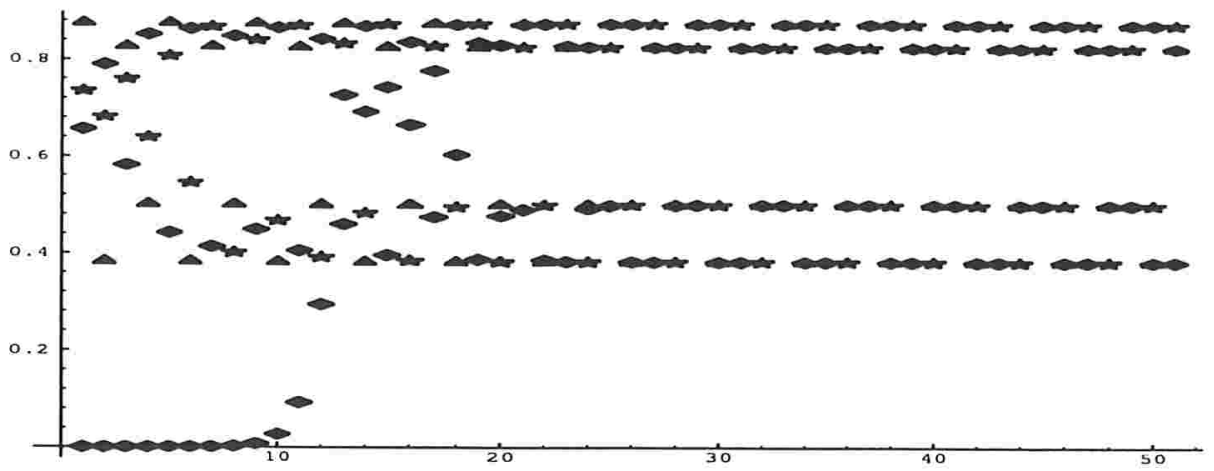

Iteração de $f$ com $\lambda=3,5$ e $x_{0}=0,0000001 ; 0,5 ; 0,3 ; 0,75$ 
Essa característica de controle sobre o sistema do parâmetro de crescimento populacional $\lambda \circ$ torna mais interessante do que a semente escolhida, aí surge uma confusão que pode ser resolvida simplesmente. A confusão é considerar que o mapa de bifurcação depende sempre de algum parâmetro (como $\lambda$ ).

Que figura é aquela comumente dita então como mapa de bifurcação da $f$ dada acima? É o mapa de bifurcação com uma semente fixa (algo como 0,2 ) e o parâmetro $\lambda$ variando! ou seja estamos considerando a função:

$$
f^{\prime}\left(\begin{array}{c}
x \\
\lambda
\end{array}\right)=\left(\begin{array}{c}
x+\lambda x(1-x) \\
\lambda
\end{array}\right)
$$

com um dado $x_{0}$ onde $f^{\prime}$ é uma função iterada. Depois de considerar o mapa de periodicidade de $f^{\prime}$, toma-se sua projeção na primeira componente $(x)$, uma representação gráfica disto é o conhecido diagrama:

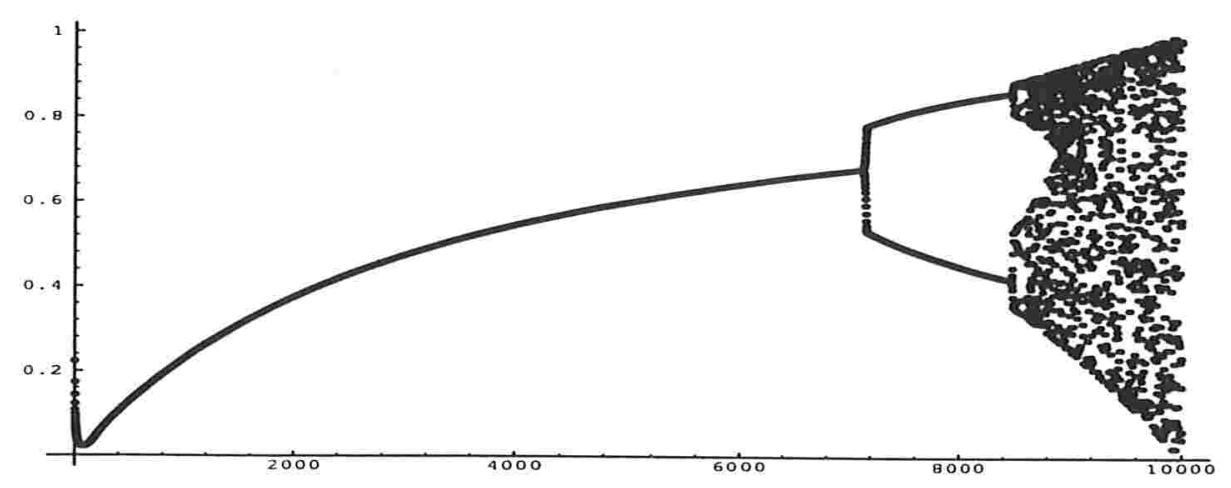

Mapa de bifurcação de $f^{\prime} \operatorname{com} \lambda \in[1 ; 4]$

onde o valor do período é dado no eixo $y$ (e no eixo $x$ temos números proporcionais ao número de iteraç̃es usadas). Uma ampliação: 


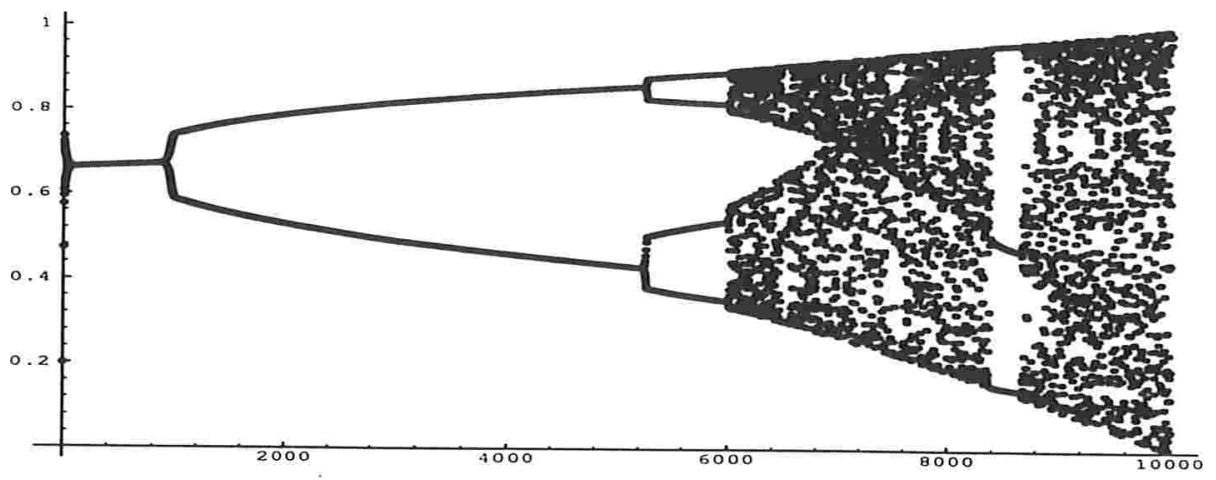

Mapa de bifurcação de $f^{\prime} \operatorname{com} \lambda \in[2,95 ; 4]$

Podemos ver ainda a relação entre as órbitas de $f$ (não $f^{\prime}$ ) e este diagrama:

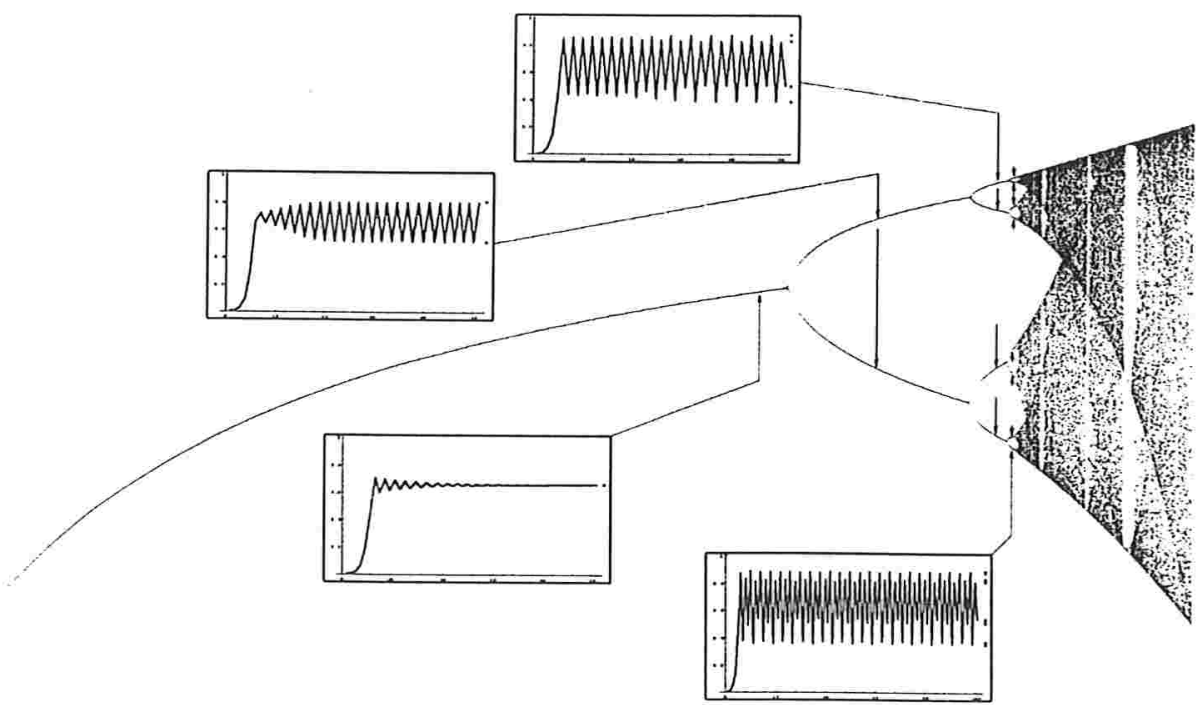

Mapa de bifurcação de $f^{\prime} \operatorname{com} \lambda=\epsilon[1 ; 4]$ e iterações de $f$ com $\lambda=2,9 ; 3,2 ; 3,5 ; 3,55$ e periodicidades $1 ; 2 ; 4$ e 8 respectivamente.

E porquê o nome 'bifurcação'? O diagrama acima mostra a razão: normalmente os sistemas apresentam o fenômeno de bifurcação (multiplicação do tamanho do período) a medida que uma variável (ou parâmetro) é variado. 
Vale a pena notar que no caso de funções deriváveis temos uma característica muito interessante, presente em uma grande classe de funções. Nas funções de $[0 ; 1]$ em $[0,1]$ com derivada schwarziana $D s_{f}$ negativa, esta é definida por:

$$
D s_{f}(x)=\frac{f^{\prime \prime \prime}(x)}{f^{\prime}(x)}-\frac{3}{2}\left(\frac{f^{\prime \prime \prime}(x)}{f^{\prime}(x)}\right)^{2}
$$

que têm um máximo em $x_{m}$ quadrático $\left(f^{\prime \prime}\left(x_{m}\right) \neq 0\right)$ e são monótonas em $\left[0 ; x_{m}[\mathrm{e} \mathrm{em}] x_{m} ; \infty\right]$ temos o seguinte resultado: os pontos de bifurcação estão espaçados numa seqüência em progressão geométrica de razão $1 / \delta$ onde $\delta$ é fixo e não varia a cada função! Seu valor aproximado é de $\delta=$ $4,6692016148 \ldots$.

Pesquisas foram feitas em torno de $\delta$ para determinar se ele é resultado de manipulações de constantes matemáticas mais conhecidas como $\pi, e \mathrm{e}$ também algumas constantes físicas. O resultado foi negativo, parece que existe uma nova constante matemática associada às funções que apresentam bifurcação com a derivada schwarziana negativa. Essa constante também aparece em diversos experimentos físicos indicando que o comportamento de funções simples pode ser um bom modelo para fenômenos naturais.

Voltando aos mapas, também é interessante perceber o quão rapidamente pontos divergem, ou seja, "escapam" de um dado atrator conhecido (numa esfera de Riemann isto seria equivalente a velocidade de aproximação ao $\infty$ ). Isto é dado pelo:

Definição 2.8 Mapa de tempo de escape: dado por $M_{f, \text { escap }}: \operatorname{Orb}(f) \rightarrow \mathbb{N}$ onde

$$
M_{f, \text { escap }}(o(x))=n \text { sse } d\left(f^{n}(x)=x_{n}, x\right) \geq r
$$

( $r$ é um raio previamente fixado), em outras palavras: $M_{f, \text { escap }}(o(x))$ devolve a iteração na qual a órbita escapa da bola de raio $r$ centrada na semente da órbita.

Este tipo de mapa é muito empregado no estudo de funções quadráticas iteradas nos complexos, pois estas sempre têm (vide [PS88]) dois atratores: um conjunto limitado em torno da origem e o infinito quando vistos na esfera de Riemann.

Graficamente costuma-se associar uma cor a cada valor de $n$ ao desenhar o mapa. Um exemplo é o da função: $f(x)=x^{2}-1,25$ que avaliada em $\mathbb{C}$ nos dá o seguinte mapa de tempo de escape: 


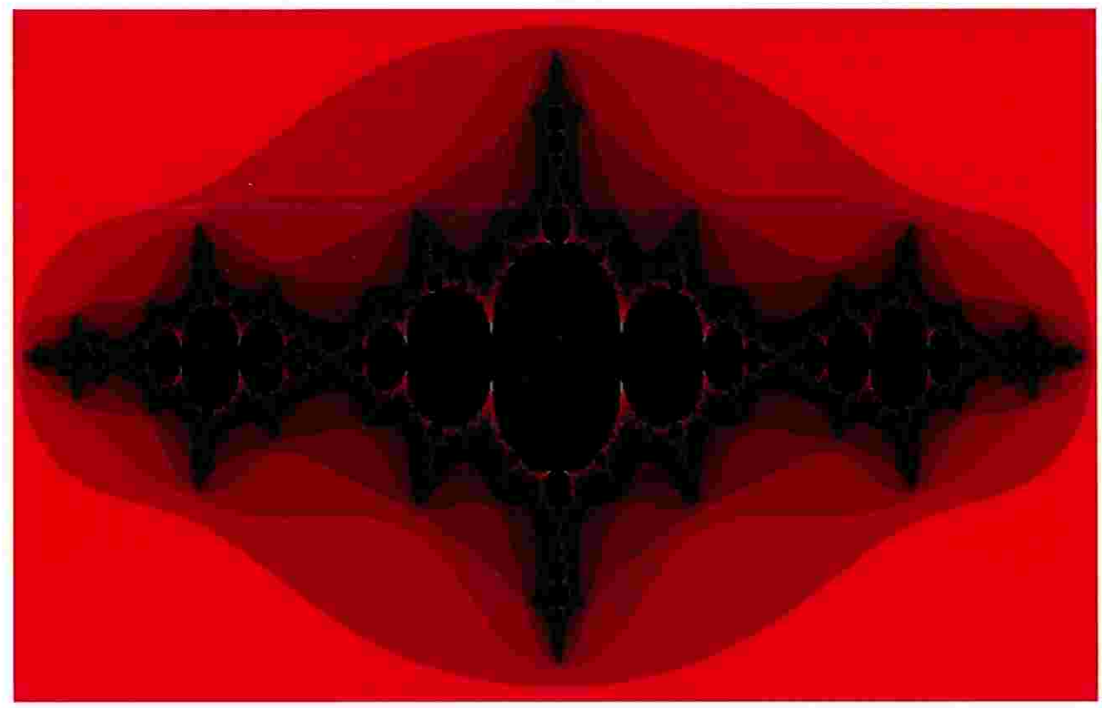

Mapa de tempo de escape para $f(x)=x^{2}-1,25$.

A região central (em preto) é de um dos:

Definição 2.9 Conjuntos de Julia-Fatou: dada uma função $f(x)$ qualquer, é o conjunto dado por:

$$
J(f)=\left\{x \in E / \lim _{n \rightarrow \infty} d\left(x, f^{n}(x)\right)<\infty\right\}
$$

$\hat{E}$ o conjunto de todas as sementes que geram órbitas não-divergentes.

Muitas vezes, porém, usamos a definição dos conjuntos de Julia-Fatou no contexto das funções de uma variável e um parâmetro $f_{c}$. Neste caso o conjunto de Julia-Fatou resultante também é indexado pelo parâmetro $c$ : $J\left(f_{c}\right)$ (às vezes abreviado por $J_{c}$ ) dado por:

$$
J(f, c)=\left\{x \in E / \lim _{n \rightarrow \infty} d\left(x, f_{c}^{n}(x)\right)<\infty\right\}
$$

Neste contexto podemos perguntar o que acontece se fixarmos a variável e variarmos o parâmetro. Ou seja: fazemos $g_{x}(c)=f_{c}(x)$ e calculamos um conjunto de Julia-Fatou para um $x_{0}$ que seja de relevância para o sistema, daí temos os conjuntos de Mandelbrot.

Originalmente Mandelbrot ([MAN83]) usou isso para a família de funções quadráticas: $f_{c}(x)=x^{2}+c$ nos complexos ${ }^{1}$, e o conjunto $M$ ou de Mandelbrot, pura e simplesmente é o conjunto de Julia-Fatou obtido pela variação

\footnotetext{
${ }^{1}$ No caso da família de funçôes quadráticas $F(z)=\alpha z^{2}+\beta z+\gamma \operatorname{com} \alpha$ não nulo em $\mathbb{C}$, sempre é possível simplificá-las com a transformação dada por: $z \mapsto \frac{1}{\sqrt{\alpha}}\left(x-\frac{\beta}{2 \alpha}\right)$ para a forma: $f_{c}(x)=x^{2}+c$.
} 
do $c$ e o $x$ é fixado em 0 , pois este é um ponto crítico $^{2}$ das funções desta família.

O estudo dos pontos críticos de uma função nos diz o que acontece com o conjunto de Julia-Fatou associado, no caso de funções com um ponto crítico (como as quadráticas, acima) temos um resultado interessante de Julia e Fatou: se a órbita do ponto crítico (no caso das quadráticas $x_{0}=0$ ) for divergente então o conjunto Julia-Fatou da função é totalmente desconexo, formando uma poeira de Cantor, caso contrário é conexo.

Este resultado transforma o conjunto de Mandelbrot (especialmente no caso das funções quadráticas) num sofisticado mapa! Nele estão todos os pontos que não convergiram, portanto contém todos os valores de $c$ que originam conjuntos de Julia-Fatou conexos!

Vejamos a forma do conjunto $\mathrm{M}$ nos complexos ${ }^{3}$ :

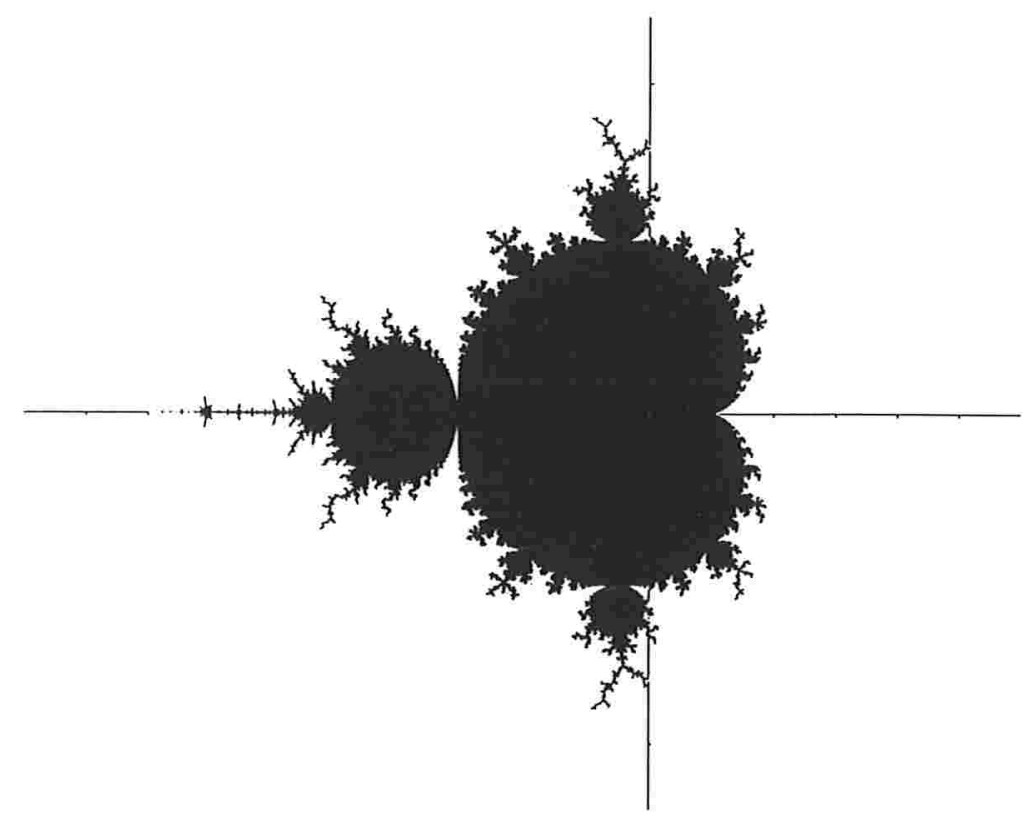

Conjunto de Mandelbrot em $\mathbb{C}$ de $f(x)=x^{2}+c$ com os eixos assinalados.

Temos os pontos do interior e borda do conjunto de Mandelbrot de em preto. A partir de um parâmetro tomado na região preta consegue-se um conjunto de Julia-Fatou conexo como o que fica no interior da figura acima (para $c=1,25)^{4}$ :

\footnotetext{
${ }^{2}$ Ponto onde a derivada da função se anula

${ }^{3}$ Aqui alargado por um algoritmo de estimar distâncias ao conjunto desenvolvido por Yuval Fisher em [PS88, pag. 287]

${ }^{4}$ Desenhado com o mesmo método do anterior.
} 


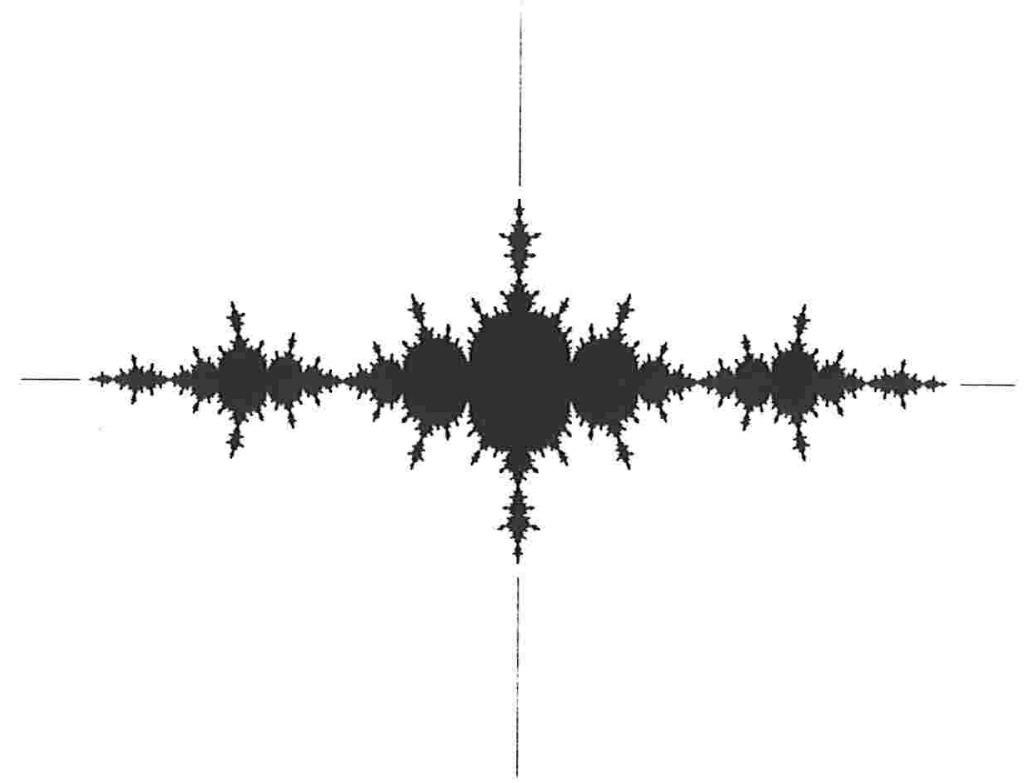

Conjunto de Julia-Fatou conexo em $\mathbb{C}$ de $f(x)=x^{2}-1,25$.

Ou se for na parte branca ele será desconexo $(\operatorname{com} c=0.3+0.6 i)$ :

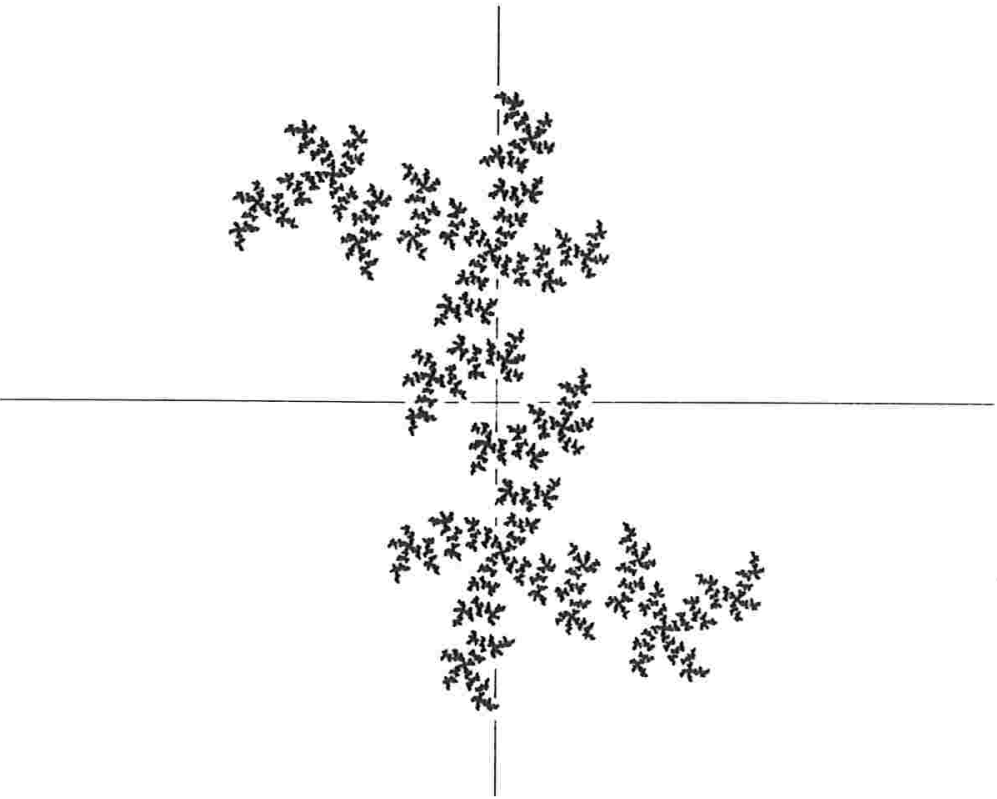

Conjunto de Julia-Fatou desconexo em $\mathbb{C}$ de $f(x)=x^{2}+(0,3+0,6 i)$.

E finalmente uma pequeno "guia" da geração dos conjuntos de Julia- 
Fatou nos complexos ${ }^{5}$ :

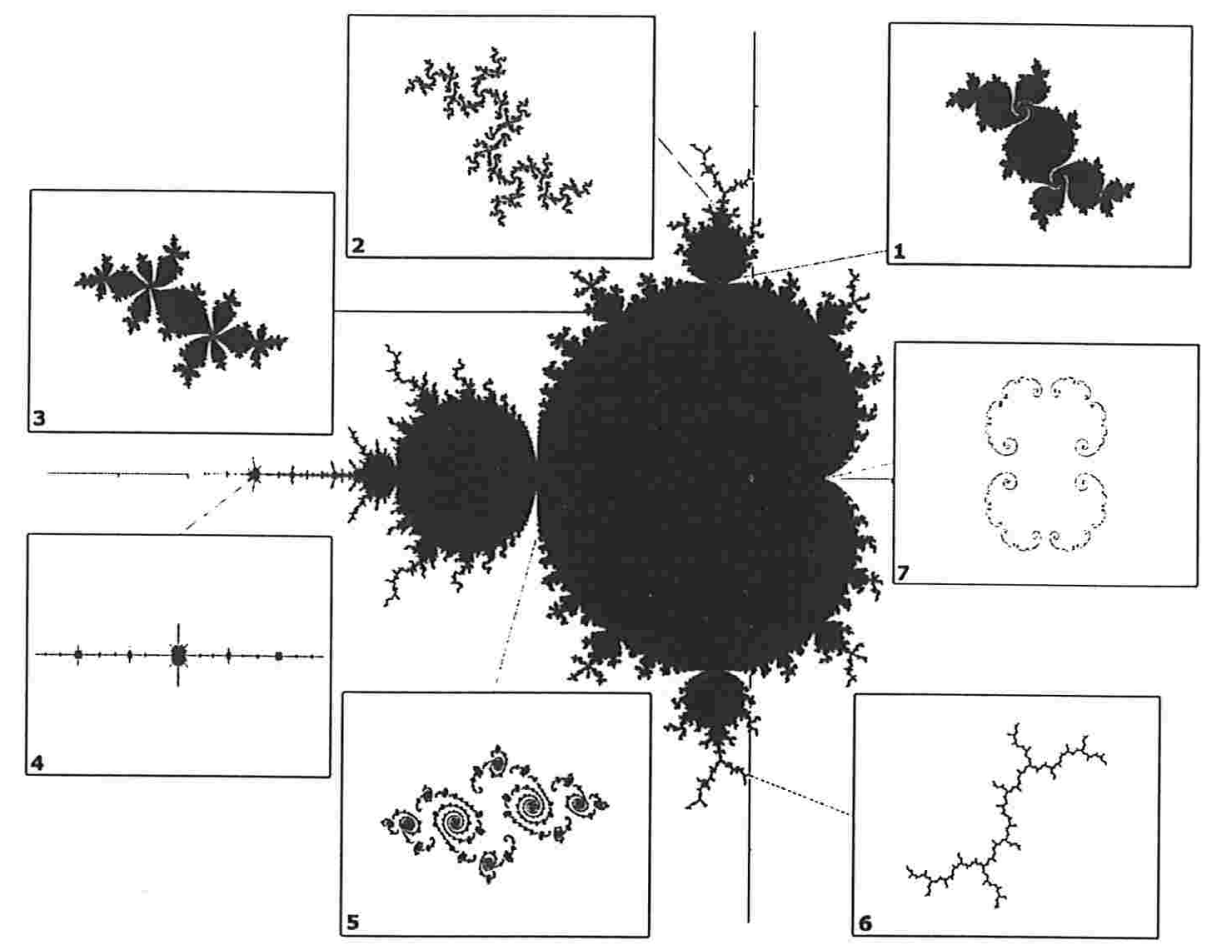

$M$ e alguns conjuntos de Julia-Fatou associados.

Devemos notar que a borda do conjunto $\mathrm{M}$ é muito intrincada tendo dimensão de Hausdorff-Besicovich igual a 2 (mais sobre dimensões a partir da página 45 na próxima seção), e todos conjuntos de Julia-Fatou associados à pontos dela não têm interior (são um filamento, como no caso de $c=i$ ) enquanto os pontos internos correspondem a conjuntos com interior estritamente maior que zero.

Definição 2.10 Mapa de decomposição: dada uma função $f(x)$ em $\mathbb{C}$, iterada até a iteraçẫo $n$ (em um caso de teste de convergência, por exemplo) define-se a propriedade:

$$
p(x)= \begin{cases}0 & \text { se }\left(2^{k} \alpha\right) \bmod 1 \leq \frac{1}{2 \pi} \arg (x) \leq\left(2^{k} \alpha+\frac{1}{2}\right) \bmod 1 \\ 1 & \text { caso contrário }\end{cases}
$$

onde $\alpha$ é um ângulo de referência (normalizado entre $[0 ; 1]$. A expressão

\footnotetext{
${ }^{5}$ Os valores de $c$ são: $1 \rightarrow(-0,11+0,6557 i), 2 \rightarrow(0,75 i), 3 \rightarrow(-0,5+0,55 i)$, $4 \rightarrow(-1,75), 5 \rightarrow(-0,75-0,2 i), 6 \rightarrow(i)$ e $7 \rightarrow(0,3)$.
} 
avalia se o ângulo do ponto (também normalizado) é mais próximo de $\alpha$ pelo sentido anti-horário (0) ou horário (1).

Esta avaliação é muito interessante para a decomposição dos pontos nas órbitas divergentes em mapas em $\mathbb{C}$, veja mais detalhes na seção de visualização (pag. 101). 


\section{Capítulo 3}

\section{Fractais}

A noção de fractal é muito mais intuitiva do que objetiva. Até hoje isso tem sido suficiente, mas as conseqüências da falta de definição estão começando a ser sentidas. Nesta seção abordaremos uma rápida tipologia dos fractais como são vistos hoje (intuitivamente). A seguir discutiremos dimensões, medidas e leis de potência e suas relações com fractais.

Para uma melhor compreensão, tanto por parte daqueles que já trabalham no campo quanto novos ingressantes, é necessário ver o campo dos fractais e todas "correntes" e "escolas" e como seu pensamento molda o conceito de fractais.

Mais do que só ver quais são as origens do conceito é importante uma visão abrangente que transcenda as fronteiras de cada campo de aplicação para conseguirmos uma definição ao mesmo tempo versátil, ampla e aplicável.

Depois de termos um quadro mental dos conceitos de fractal poderemos ver com uma postura crítica mais madura as antigas tentativas de definição e apresentar uma definição objetiva de fractal. Outras possibilidades são discutidas. Na última parte desta seção apresentamos as principais linhas de pesquisa e o futuro do campo.

\subsection{Tipologia revisitada}

O que se entende por fractal se não existe uma definição definitiva do termo? A resposta é: não se sabe. Ou mais precisamente: fractal é uma noção intuitiva, uma sugestão de características comuns que unem objetos de naturezas totalmente diversas.

Para podermos compreender o conceito intuitivo de fractal e ir além 
definindo-os objetivamente é interessante classificar os fractais conhecidos atualmente em categorias. Para isto montamos uma tipologia diferente para apresentar os fractais. Diferente, pois não pretende ser uma classificação definitiva já que fala pouco da gênese dos fractais temporalmente. mas prefere dividi-los em categorias. Estas, por se apoiarem em conceitos intuitivos, podem ter elementos em comum (não-disjuntas).

Podemos separar os objetos matemáticos que tocam e estão no centro do conceito de fractal em quatro categorias:

1. Algébricos ou Simbólicos

2. Afins

3. Não-lineares

4. IFS

5. Probabilísticos

Muitos membros desta família podem ser considerados de duas ou mais categorias, pois têm homólogos em outros espaços. Estes homólogos (por bijeções) são muito comuns e permitem, por exemplo, um 'fractal' não-linear ser estudado como um algébrico e assim por diante. Porém em alguns casos os artifícios matemáticos utilizados para 'converter' objetos de uma categoria para outra são tão sofisticados ou complexos que fica difícil dizer que se trata do mesmo objeto. Em casos mais raros não se conhece nenhuma maneira de encontrar homólogos de certos objetos.

No futuro poderemos ter mais desenvolvimentos que mostrem que cada um dos 'fractais' atuais pode ter pelo menos um homólogo em cada um destas categorias, daí esta classificação se transformará em uma série de possíveis interpretações para o mesmo objeto.

\subsubsection{Algébricos ou Simbólicos}

Nesta categoria temos objetos gerados por regras de transformação sobre símbolos (como em linguagens formais), autômatos (finitos ou não) etc. daí o outro nome desta categoria: simbólicos. Basicamente são baseados em espaços de cadeias de símbolos, ou em bases numéricas quando alguma relação com $\mathbb{R}$ (ou outro espaço mais conhecido) é desejada. Formalmente utiliza-se a noção de linguagens sobre símbolos por regras de transformação. 
Um exemplo é o conjunto de Cantor algébrico dado pela iteração das transformações:

$$
\begin{array}{lll}
0 & \mapsto & 000 \\
1 & \mapsto & 101
\end{array}
$$

Começando com a semente '1' no espaço de seqüências infinitas dos símbolos ' 0 ' e ' 1 ' temos:

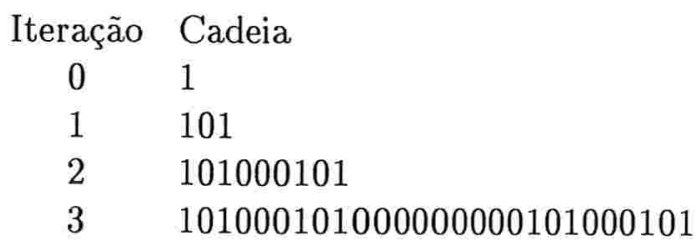

Levando a iteração ao limite temos uma versão simbólica do conjunto de Cantor. Se começamos com uma cadeia "0" o resultado é uma seqüência infinita de zeros, mas com outras cadeias a evolução fica interessante:

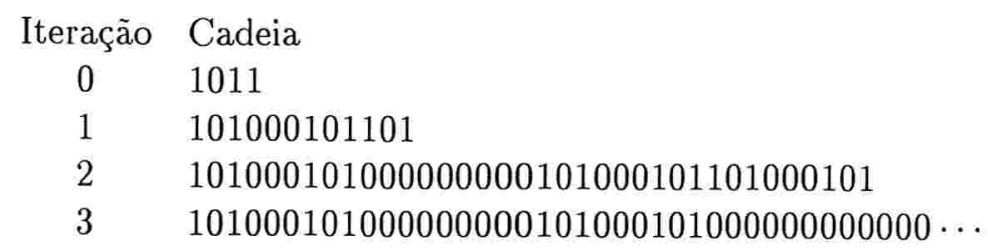

Todas cadeias geradas têm um aspecto semelhante: contêm cópias de si mesmas. Esta característica é normalmente evocada intuitivamente sob o nome de "auto-semelhança", embora seja de difícil definição em outros tipos de fractais - nominalmente aqueles que contêm cópias aproximadas de si mesmos.

Quando existe uma transformação "afim"1 que transforma um subconjunto do objeto no objeto todo diz-se que há a auto-semelhança estrita. Quando os subconjuntos são deformados (por exemplo por uso de funções não lineares), mas ainda retêm semelhança com o objeto inteiro, usa-se simplesmente auto-semelhança.

Muito importante é a utilização de bijeções entre em espaços genéricos com seqüências infinitas de símbolos, pela sua capacidade de endereçamento.

Exemplo 3.1 Endereçamento no conjunto de Cantor Triádico

O conjunto $C$ (de Cantor Tríadico) definido como o conjunto dos pontos que não divergem pela iteração de:

\footnotetext{
${ }^{1}$ Aqui vista como uma combinação de translações, rotações e mudanças de escala.
} 


$$
f(x)= \begin{cases}3 x & \text { Se } x \leq 0,5 \\ 3-3 x & \text { caso contrário }\end{cases}
$$

Pode ser muito bem descrito pelo endereçamento de transformações, tomemos a função $f$ na base 3 :

$$
f(x)= \begin{cases}10_{3} x & \text { Se } x \leq 0,5_{10}=0, \overline{1}_{3} \\ 10_{3}(1-x) & \text { caso contrário }\end{cases}
$$

Para números em $[0 ; 1]$ dizer $1-x$ é o mesmo que inverter os dígitos de sua expansão em alguma base. Portanto as operações acima são ${ }^{2}$ :

$$
f(x)= \begin{cases}\operatorname{shift}_{3}(x) & \text { Se } x \leq 0,5_{10} \\ \operatorname{shift}_{3}(\bar{x}) & \text { caso contrário }\end{cases}
$$

Logo avaliemos as três possibilidades: $x \in[0 ; 1 / 3[, x \in[1 / 3 ; 2 / 3[$ e $x \in$ $[2 / 3 ; 1]$. Elas podem ser escritas como: $x=0.0 \ldots 3, x=0.1 \ldots 3$ e $x=0.2 \ldots 3$ respectivamente. Ou seja a expansão de $x$ na base 3 começa por 0,1 ou 2 . Caso a caso:

Dígito 0 neste caso $x \leq 0,5$ logo $f(x)=\operatorname{shift}_{3}(x)$ e tomaremos o próximo dígito de $x$ na próxima iteração.

Dígito 1 com este dígito temos duas possibilidades: $x \leq 0,5$, portanto $f(x)=$ $\operatorname{shift}_{3}(x)$ de onde temos que $f(x)=1, \ldots 3$. Por outro lado se $x>0,5$ então $f(x)=\operatorname{shift}_{3}(\bar{x})$ portanto $\left(\operatorname{como} \overline{1_{3}}=1_{3}\right)$ temos $f(x)=1, \ldots 3$ também.

Dígito 2 com isto sabemos que $x>0,5$ então $f(x)=\operatorname{shift}_{3}(\bar{x})$ portanto (como $\left.\overline{2_{3}}=0_{3}\right)$ temos $f(x)=0, \ldots 3$.

O que significa dizer $f(x)=0, \ldots 3$ ? Isto nos diz que $f(x)$ continua em $[0 ; 1]$ e não escapa. E $f(x)=1, \ldots 3$ diz que ${ }^{3} f(x)>1$ logo a função diverge.

Visto isso temos a seguinte conclusão: $x$ só diverge se tiver um dígito $1 \mathrm{em}$ sua expansão na base 3 ! Portanto todos números em $[0 ; 1]$ que só tem dígitos 0 e 2 em suas expansões na base 3 são pertencentes ao conjunto de Cantor Triádico!

\footnotetext{
${ }^{2}$ Aqui 'shift' quer dizer mover o ponto fracionário uma casa para a direita (ou 'empurrar' os dígitos de $x$ uma casa para a esquerda)

${ }^{3}$ Se trocarmos a representação de 1 como $1.0000 \ldots 3$ por $0.2222 \ldots 3$.
} 
Por uma bijeção simples ${ }^{4}$ vê-se que a cardinalidade de $C$ é igual a de $[0 ; 1]$ portanto é igual a de $\mathbb{R}$ ! Isto contrasta fortemente com o fato de $C$ ser totalmente desconexo e ter dimensão topológica 0 !

Outro fractal bastante conhecido desta categoria é o autômato finito bidimensional conhecido como "Life" de John Conway (apresentado ao público por Martin Gardner em [GAR70]). O autômato consiste de uma grade bidimensional infinita onde cada posição (ou célula) pode assumir dois valores: 0 (morta) 1 (viva). As regras de transformação são:

1. Uma célula viva com menos de dois vizinhos morre (solidão?)

2. Uma célula viva com mais de três vizinhos morre (superlotação?)

3. Uma célula viva aparece se a posição tem exatamente três vizinhos vivos (triplóides?)

Estas regras na verdade são uma simplificação bastante sintética de todos padrões de transformação que podem ser aplicados na grade (seriam $2^{9}$ ou 512 padrões).

Assim percebe-se a função iterada $F$ que leva um estado da grade no estado seguinte. A $F$ pode ser simplificada pela aplicação de uma mesma $f$ que sintetiza as três regras acima e quando aplicada em todos pontos da grade ao mesmo tempo reproduz $F$.

Muitas questões são interessantes neste "jogo" simples. Uma delas é que todos padrões eventualmente entram em "ciclos repetitivos", ou seja, todas órbitas são periódicas (no que se conta as situações que todas as células morrem). A resposta neste caso é negativa pois existem padrões que se repetem, mas deslocados (transladados) da posição original. Um exemplo do "jogo da vida" em ação:

\begin{tabular}{|c|c|c|c|c|}
\hline $\begin{array}{l}00000 \\
00000 \\
00000 \\
00000 \\
00000\end{array}$ & 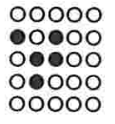 & $\begin{array}{l}00000 \\
00000 \\
00000 \\
00000 \\
00000\end{array}$ & $\begin{array}{l}\text { O0000 } \\
\text { O甲000 } \\
\text { O0000 } \\
00000 \\
00000\end{array}$ & $\begin{array}{l}00000 \\
00000 \\
00000 \\
00000 \\
00000\end{array}$ \\
\hline Ger. 0 & Ge & Ger & Ger & $\mathrm{Ge}$ \\
\hline
\end{tabular}

A questão principal levantada por Conway era se existia um padrão que crescesse indefinidamente. Aparentemente não havia, mas foi descoberto um padrão que tem esta propriedade: "Machine Gun"

\footnotetext{
${ }^{4}$ Especificamente tomando-se os dígitos da expansão de $x$ na base três e substituindo: 0 por 0 e 2 por 1 obtém-se um número $y$ na base 2 também em $[0 ; 1]$.
} 


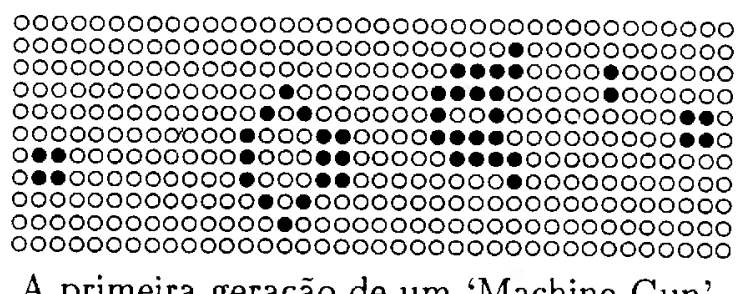

A primeira geração de um 'Machine Gun'.

\subsubsection{Fractais Afins}

Quando trabalhamos com funções iteradas afins, ou seja: $f(x)=A x+b$ em algum espaço vetorial, temos os 'fractais' afins. Estes normalmente são estudados em espaços euclidianos $\left(\mathbb{R}^{n}\right)$ e podem ter uma única função, ou várias funções componentes.

Em espaços euclidianos usa-se uma matriz de transformações $A$ e um vetor de translação $b$. $f$ pode ser vista como uma rotação, uma mudança de escala e uma translação compostas.

Por exemplo:

$$
f\left(\begin{array}{l}
x \\
y
\end{array}\right)=\left(\begin{array}{ll}
\alpha & \beta \\
\gamma & \delta
\end{array}\right)\left(\begin{array}{l}
x \\
y
\end{array}\right)+\left(\begin{array}{l}
a \\
b
\end{array}\right)
$$

Com valores apropriados de $\alpha, \beta, \gamma, \delta, a$ e $b$, temos imagens como:

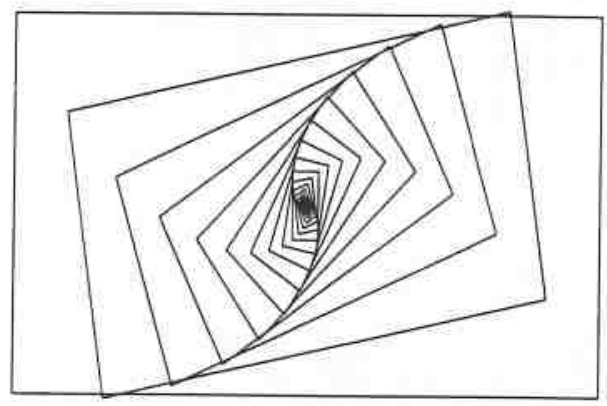

Exemplo de transformação afim

\subsubsection{Fractais Não-Lineares}

Sob este título reúnem-se todo tipo de função não-linear (na terminologia matemática: não afins) de um espaço nele mesmo. A origem da divisão entre "afins" (ou lineares em outros campos) e não lineares é bastante útil no estudo de aplicações físicas onde a ordem da função é muito importante para a estabilidade e previsibilidade nos sistemas estudados. 
Em alguns casos temos sistemas de funções não lineares que deveriam ser classificados nesta categoria, mas que pelo tratamento acabam sendo classificados como IFS. Neste caso as funções têm restrições adicionais (têm que ser contrações no espaço sob alguma métrica) que não se aplicam a esta categoria.

\section{Exemplo 3.2 O Método de Newton}

Vamos retomar o exemplo 1.5 , no qual a equação $x^{3}-1=0$ tem suas raízes em $\mathbb{C}$ aproximadas pelo método de Newton que consiste na iteração da fórmula:

$$
x=f\left(x_{0}\right)=x_{0}-\frac{f\left(x_{0}\right)}{f^{\prime}\left(x_{0}\right)}=x_{0}-\frac{x_{0}^{3}-1}{3 x_{0}^{2}}
$$

Agora perguntamos: se tomamos cada ponto do plano complexo como ponto inicial o método convergirá para alguma raiz da equação? Se sim qual delas? E quanto o método demorará para convergir? A imagem abaixo mostra:

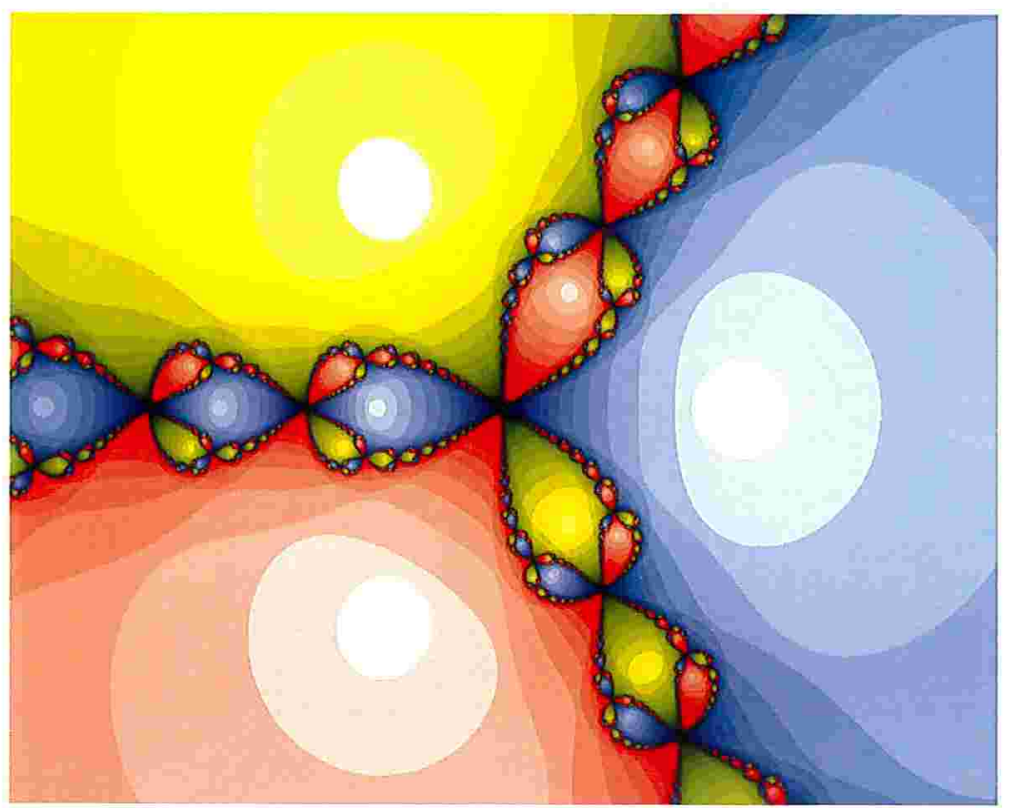

Imagem de tempo de escape e bacias de atração para $x^{3}-1=0$

Pontos nas áreas claras convergiram mais rápido, enquanto os pontos em áreas escuras convergiram mais devagar. ( $\mathrm{O}$ conjunto de pontos que não converge pelo método para esta equação tem medida nula). Além disto Cada ponto é colorido com um tom que corresponde a raiz para qual o método convergiu. Nas fronteiras das bacias de atração percebe-se os padrões intrincados 
que surgem neste fractal.

\subsubsection{IFS}

Em muitas outras situações usam-se várias funções, ou seja, sistemas de funções iteradas (Iterated Function Systems, abreviados por IFS). Neste caso temos várias $f_{i}: E \rightarrow E$. Cada uma das $f_{i}$ deve ser uma contração (vide seção de órbitas), mas a composição delas não é necessariamente uma contração em $E$ (será na verdade uma contração em $P(E)$ )!

Esta definição também parece não ser a de uma função iterada, mas se considerarmos:

$F(X): P(E) \rightarrow P(E)$ (uma função de conjuntos de pontos do espaço em conjuntos de pontos do espaço)

teremos:

$$
F(X)=\bigcup_{\forall i}\left\{f_{i}(x) / x \in X\right\}
$$

onde $F$ é uma função iterada. E podemos começar as iterações com $F(\{x\})$, ou mesmo $F(A)$ onde $A$ é um conjunto limitado em $E$.

Normalmente trata-se de IFS compostos por funções afins, mas nada impede o uso de outros tipos de funções. Pela facilidade computacional de IFS afins foram desenvolvidas muitas ferramentas para este tipo de sistema, inclusive com aplicações comerciais interessantes. Mas é importante lembrar que a condição de contratividade ainda se mantém ${ }^{5}$.

Um resultado de Hutchinson, que Barnsley demonstra habilmente em [BAR88] diz que se temos um espaço métrico $E$ completo e um IFS nele, então a função $F$ no espaços $P(E)$ é uma contração e $P(E)$ é um espaço métrico completo com a métrica de Hausdorf ${ }^{6}$ derivada da métrica de $E$. $F$ é conhecida como operador de Hutchinson.

Com isso se temos um IFS em $E$ ele pode ser visto como uma contração em $P(E)$ e pelo teorema da contratividade ele convergirá à um único ponto

\footnotetext{
${ }^{5}$ Mesmo que não seja em métricas comuns, como a euclidiana, mas em alguma métrica de $E$.

${ }^{6}$ Seja $d$ a métrica original (em $E$ ), $A, B \subset E$, definimos $d_{p}(x, B)=\min \{d(x, y) / y \in B\}$ como a distância entre um ponto em um conjunto. A distância entre dois conjuntos é dada por: $d_{c j}(A, B)=\max \{d(x, B) / x \in A\}$. Para ser uma métrica só nos falta a reflexividade (normalmente $d_{c \jmath}(A, B) \neq d_{c \jmath}(B, A)$ ) logo definimos a métrica de Hausdorff $(\mathrm{em} P(E)$ ) como:

$$
h_{d}(A, B)=\max \left\{d_{c \jmath}(A, B), d_{c \jmath}(B, A)\right\}
$$
}


de $P(E)$ (e não de $E$ ). Este conjunto (o ponto fixo do IFS em $P(E)$ é o atrator do IFS em $E$, em geral um atrator estranho.

\section{Exemplo 3.3 Sierpinsky por IFS}

Uma maneira de construir o triângulo de Sierpinsky visto no exemplo 2.2 é usar um IFS em $\mathbb{R}^{2}$ que calcula as pré-imagens da função daquele exemplo:

$$
\begin{gathered}
f_{1}\left(\begin{array}{l}
x \\
y
\end{array}\right)=\left(\begin{array}{cc}
1 / 2 & 0 \\
0 & 1 / 2
\end{array}\right)\left(\begin{array}{l}
x \\
y
\end{array}\right)+\left(\begin{array}{l}
0 \\
0
\end{array}\right) \\
f_{2}\left(\begin{array}{l}
x \\
y
\end{array}\right)=\left(\begin{array}{cc}
1 / 2 & 0 \\
0 & 1 / 2
\end{array}\right)\left(\begin{array}{l}
x \\
y
\end{array}\right)+\left(\begin{array}{c}
1 / 2 \\
0
\end{array}\right) \\
f_{3}\left(\begin{array}{l}
x \\
y
\end{array}\right)=\left(\begin{array}{cc}
1 / 2 & 0 \\
0 & 1 / 2
\end{array}\right)\left(\begin{array}{l}
x \\
y
\end{array}\right)+\left(\begin{array}{c}
1 / 4 \\
\sqrt{3} / 4
\end{array}\right)
\end{gathered}
$$

$F(X)$ construída pela composição destas três funções faz o seguinte: encolhe o conjunto $X$ para $1 / 2$ de seu tamanho original, tira três cópias, colocando a primeira na localização original de $X$, a segunda $1 / 2$ deslocada para esquerda e a terceira $1 / 4$ deslocada para a esquerda e $\sqrt{3} / 4$ para cima, graficamente:

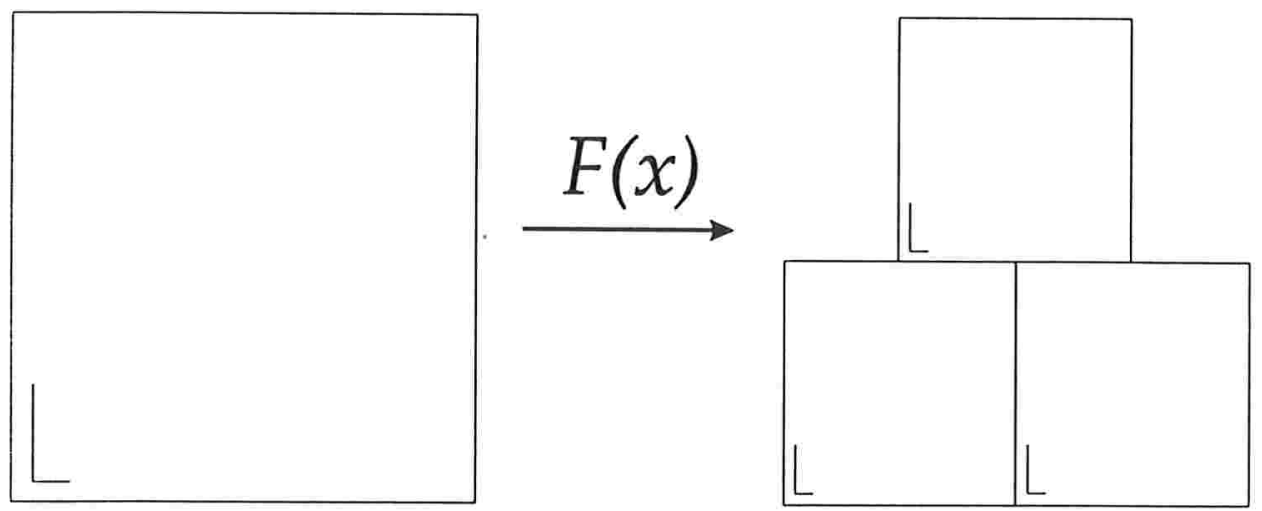

Uma aplicação de $F$ em um quadrado.

E algumas iterações de $F$ em um conjunto arbitrário: 

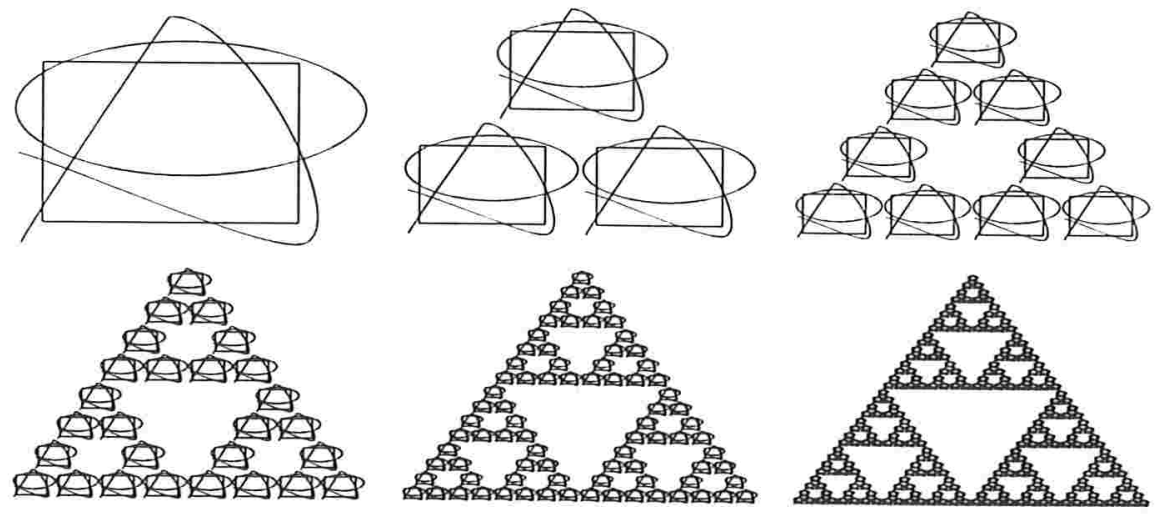

Aplicação de $F$.

Já é possível perceber como $\circ F^{n}$ se aproxima rapidamente do triângulo de Sierpinsky.

Apesar desta propriedade de convergência extremamente forte é somente na estrutura do espaço métrico $P(E)$ e da métrica de Hausdorff que se baseou Michael Barnsley para tentar definir os fractais (em [BAR88, página 35]), mas ela acaba sendo muito ampla (mais sobre isso adiante).

Um dos resultados mais importantes do trabalho de Barnsley: o Teorema da Colagem. A 'colagem' é entendida como a primeira aplicação (iteração) do IFS $F$ em alguma semente. O teorema nos fornece um limitante da distância (de Hausdorff) entre uma dada semente e o atrator baseado na distância entre a semente e sua colagem e no fator de contração do IFS.

Quando estuda-se uma função mais sofisticada, pode-se tentar usar as órbitas inversas (pelo cálculo de funções inversas da original) para avaliar o comportamento das órbitas na bacia de atração do $\infty$, mas surge um problema: normalmente uma função tem várias inversas. Para resolver isso constrói-se um IFS com cada $f_{i}$ sendo uma inversa e por ele pode-se entender como a função original se comporta. O fato de estarmos na bacia de atração do infinito nos permite mostrar mais facilmente que cada $f_{i}$ é contração.

Exemplo 3.4 IFS de um conjunto de Julia

Tomemos a fórmula $f(x)=x^{2}+c$ suas inversas são $f_{1}(y)=+\sqrt{y-c}$ e $f_{2}(y)=-\sqrt{y-c}$ e iteramos a partir de pontos distantes da origem para encontrar o conjunto de pontos não divergentes (ou sua fronteira). 

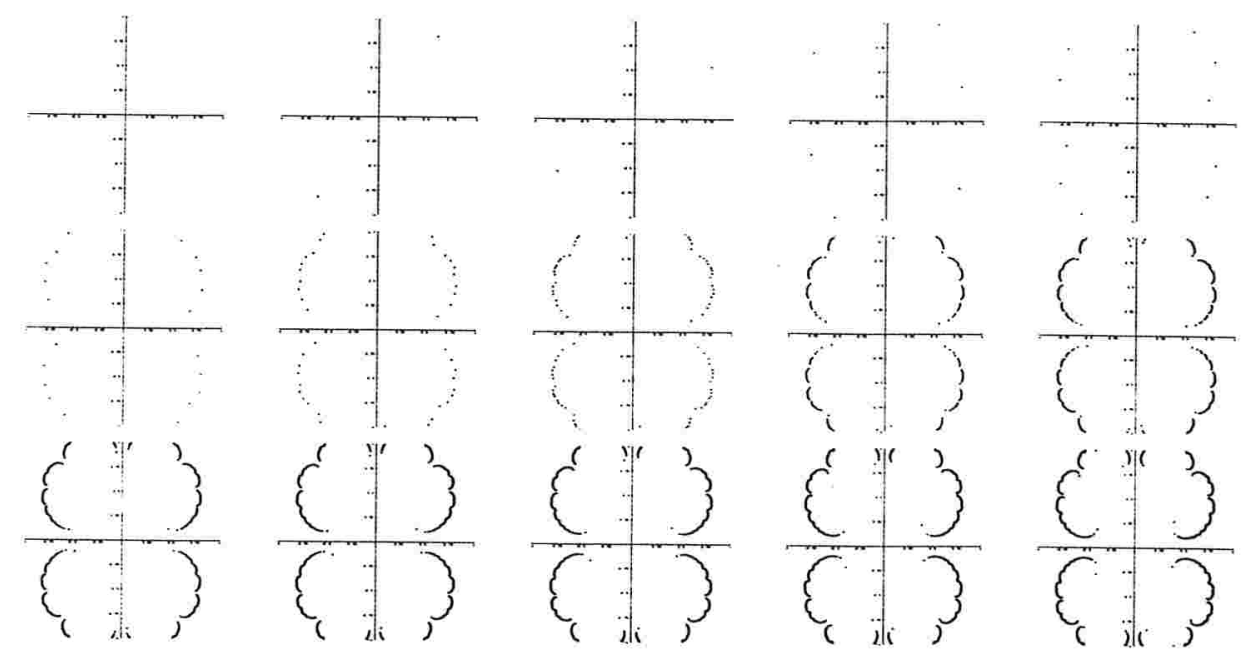

Nesta seqüência, tomamos $c=+0,3$ e começamos com $X_{0}=\{i\}$ e são obtidos no último quadro 16384 pontos $\left(2^{14}\right)$.

O problema com IFS é a "explosão" de pontos nos conjuntos iterados. O número de elementos em cada conjunto cresce a cada iteração. Sendo o número total proporcional a $I^{n}$, onde $I$ é o número de funções iteradas no sistema e $n$ é a iteração atual. Para tratar disso existem técnicas computacionais específicas, as mais importantes são tratadas na última seção.

A autosemelhança nos conjuntos gerados por IFS nem sempre é um bom modelo, em alguns casos é necessário um método que gere de formas diferentes as partes de um IFS: os IFS hierárquicos.

Nestes diversas transformações (operadores de Hutchinson, mais formalmente) são intercalados na iteração para formar uma nova transformação contrativa em $P(E)$. A vantagem de se utilizar IFS hierárquicos é que se pode tratar diversas formas de auto-semelhança em um mesmo atrator de uma função. A hierarquia é normalmente associada a um multigrafo ${ }^{7}$ onde os vértices são representantes dos componentes do IFS hierárquicos e os arcos são as transformações (ou os IFS componentes). Duas referências são [EDG90] e [PJS92].

\subsubsection{Fractais Probabilísticos}

Este é o nome que normalmente identifica fractais baseados em funções iteradas que tem um comportamento não-determinístico, sendo modeladas como funções com uma ou mais variáveis aleatórias que obedecem alguma

\footnotetext{
${ }^{7} \mathrm{Um}$ grafo dirigido que pode ter múltiplas arestas de um vértice a outro.
} 
distribuição probabilística. Estas variáveis aleatórias são a fonte da variação a cada iteração da função.

Para modelagem de sistemas naturais e interpolação, estes fractais são muito úteis, mas resta-nos dúvidas se o comportamento deles é realmente aleatório ou não. Pela complexidade exibida por outros sistemas determinísticos a resposta negativa parece mais provável.

Tomemos $f(x)=A x+c$ onde $c$ é fixo e $A$ é uma variável aleatória que muda a cada iteração. Quando estudada, esta função é modelada por um gerador de números pseudo-aleatórios $G$ que devolve um novo valor para a variável aleatória $A$ a cada iteração. Temos na realidade:

$$
F(x, A)=(f(x), g(A))
$$

Ou seja: $F(x, A)=(A x+c, g(A))$ é uma função iterada e todas implementações práticas são baseadas em $g$ determinísticos atingindo resultados muito bons. Parece-nos que o uso de variáveis "aleatórias" não passa de um disfarce para uma função um pouco mais complexa totalmente determinística!

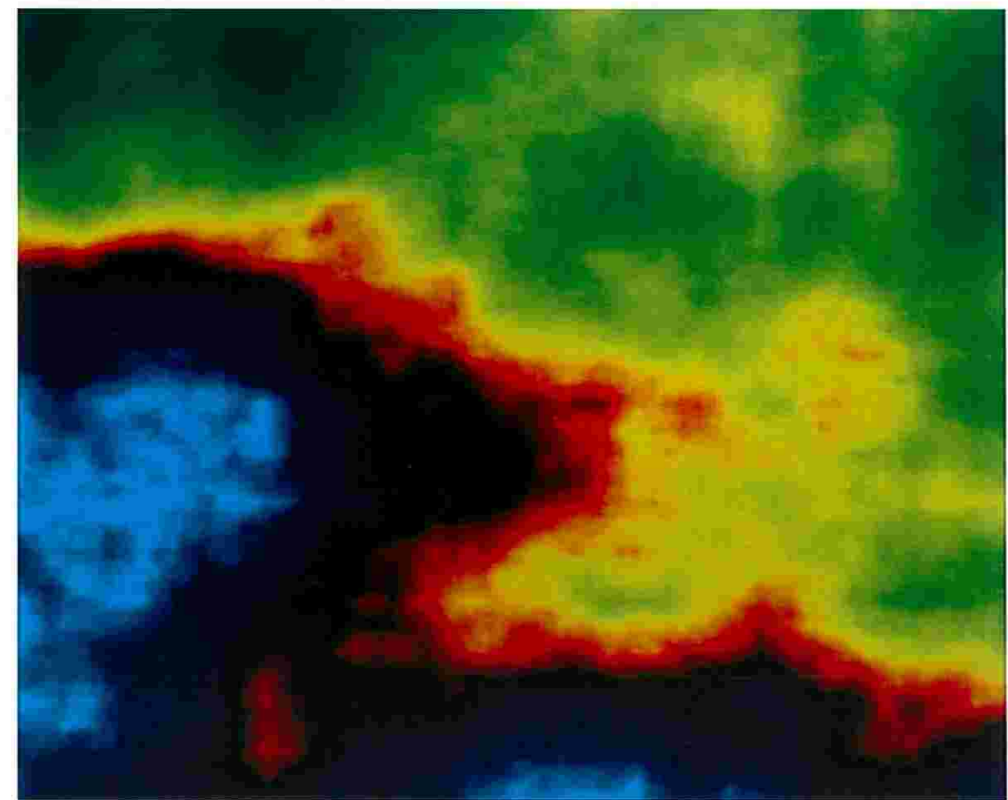

Nuvem de plasma criada por deslocamento aleatório do ponto médio.

Algumas implementações de IFS afins fazem uso de uma forma intermediária que é na verdade uma função iterada com uma variável aleatória, para poder calcular atratores em tempos razoáveis. 


\subsection{Dimensões, Potências e Medidas}

A definição original de fractais utilizava fortemente da dimensão de Hausdorff-Besicovich e apesar de não ter sido uma definição duradoura foi a maior fonte de ferramentas para avaliar o comportamento de objetos "fractais" até hoje.

Infelizmente o cálculo de dimensões (já que existem inúmeras definições) é normalmente complicado e de difícil implementação computacional, restringindo o seu uso em aplicações embora possa dar informações valiosas sobre a geometria dos objetos estudados.

\subsubsection{Medidas}

É um objetivo muito útil poder encontrar uma "função característica" que devolve um único número que descreve o comportamento de um sistema complexo ou que o classifica bem. A noção de medida é servir como 'alavanca` para este tipo de função.

Esta é uma apresentação muito breve e simplificada de medidas ${ }^{8}$ mas que contém o essencial para podermos definir as dimensões a seguir.

Medida é uma função do tipo:

$$
\mu: P(E) \rightarrow \mathbb{R}^{+}
$$

a qual precisa ter um comportamento razoável, isto é, se tomarmos um conjunto e o medirmos, e depois tomarmos suas partes e medirmos, a soma das medidas das partes deve ser a medida do conjunto. Barnsley dá a visão intuitiva de 'massa' de um conjunto para a sua medida. Esse comportamento é descrito por:

$$
\mu\left(\bigcup_{i=1}^{\infty} A_{i}\right)=\sum_{i=1}^{\infty} \mu\left(A_{i}\right)
$$

\subsubsection{Dimensões}

O termo dimensão remonta a matemática grega (como número de medidas (não no sentido apresentado acima, mas como medições) mínimo para limitar

\footnotetext{
${ }^{8}$ Formalmente as medidas vão de um campo (field - conjunto de subconjuntos de $E$ fechado por união e complementarão por $E$ ) nos reais positivos. A teoria de medidas é muito bem apresentada em [FED69]. No caso de estudo de fractais ou IFS a apresentação feita em [BAR88, pag. 334 em diante] é bastante acessível e detalhada e para aqueles que realmente querem estudar o campo em profundidade [HAL74].
} 
um objeto), classificando os objetos desta, mas a noção era intuitiva. A primeira definição explícita ${ }^{9}$ vem com Poincarè ${ }^{10}$ (vide histórico sucinto em [MAN83, pag. 409]):

"Quando dizemos que um espaço tem dimensão três, o que queremos dizer? Se para dividir um continuum $\mathcal{C}$ basta considerar como cortes um certo número [finito] de elementos [pontos] então dizemos que este continuum tem dimensão um [...] Se ao contrário [...] para dividir um continuum basta usar cortes que formam um ou mais continua de dimensão um então dizemos que $\mathcal{C}$ tem dimensão dois. Se cortes que formam continua de dimensão dois são suficientes então dizemos que $\mathcal{C}$ tem dimensão três; e assim por diante."

Esta definição é a base da definição da dimensão topológica, e aqui um pouco diferente da noção grega. Estes aplicavam a noção de dimensão aos objetos e não aos espaços como Poincarè.

\section{Dimensão Topológica}

A noção grega do menor número de medidas (números ou medições) de um objeto foi transposta à matemática contemporânea como o menor número de parâmetros necessários para localizar um ponto no espaço, e daí definindo a dimensão do espaço.

Então Cantor - com a construção da correspondência entre os pontos do plano e reta - e Peano - pela construção da curva que preenche o plano mostram como isso pode ser perigoso, o primeiro é um exemplo de função bijetora entre plano e reta, o segundo é uma função injetora e contínua entre plano e reta. Se as duas fossem reunidas teríamos um homeomorfismo entre espaços de dimensões diferentes, e assim a dimensão não seria a invariante topológica desejada.

Brower deu prova que isso não era real, mas com Lebesgue tivemos a primeira demonstração que a dimensão é uma invariante topológica, bem como a primeira definição de dimensão topológica (muitas vezes usamos somente a 'dimensão' de um espaço). Segundo [NAG, pag. 9]:

Definição 3.1 Dimensão topológica (de Cobertura ou de Lebesgue): Seja U uma cobertura de $A$ por abertos, contável. $\operatorname{Ord}(A, U)=\sup \left\{\operatorname{ord}_{p} U / p \in A\right\}$ $e$ ord $_{p} U$ é o número de abertos de $U$ que contém $p$.

\footnotetext{
${ }^{9}$ Embora hoje não fosse considerada formal.

${ }^{10}$ Numa tradução livre de [MAN83]
} 
Se dada qualquer cobertura finita $U$ de $A$ existe uma cobertura $V$ de $A$ que esta contida em $U^{11}$, e $\operatorname{Ord}(A, V) \leq n+1$ para algum $n \in \mathbb{N}$ então

$$
D_{T}(A) \leq n
$$

Se $D_{T}(A) \leq n$ e ainda $D_{T}(A) \not n-1$ então $D_{T}(A)=n$ e caso $D_{T}(A) \not$ $n$ dizemos que $D_{T}(A)=\infty$.

Mas esta noção ainda não leva em conta a geometria do objeto avaliado, e sim é uma formalização do conceito de invariante topológica. Duas outras definições: a de dimensão indutiva forte (Urysohm-Menger) coincide com a de cobertura em espaços métricos e são usadas no lugar dela em muitos casos. Apresentaremos a indutiva forte (maiores detalhes em [HW41] e [NAG]), também, pois apesar de não ser necessária aqui, representa de maneira mais fiel a idéia de Poincaré:

Definição 3.2 Dimensão Indutiva Forte (de Čech-Brower's): denotada por Ind. Se $A=\emptyset$ então $\operatorname{Ind}(A)=-1$, caso contrário se para quaisquer que sejam os fechados $F, G \subset A$ existe um aberto $U$ tal que: $F \subset U \subset A-G e$ $\operatorname{Ind}(\operatorname{Borda}(U)) \leq n-1$ então:

$$
\operatorname{Ind}(A) \leq n
$$

Valem as mesmas observações feitas para a dimensão topológica.

\section{Dimensão de Auto-Semelhança}

A geometria do objeto pode ser capturada pela noção de medida, mas uma medida não é necessariamente uma dimensão, no sentido de ser uma caracterização de uma classe de objetos semelhantes, em particular as medidas são afetadas por acréscimos ou remoções que não alteram a geometria de um objeto.

A chave por trás da utilização das dimensões para caracterização dos fractais é a noção de auto-semelhança (estrita ou não) ${ }^{12}$. Podemos definir uma dimensão de auto-semelhança para objetos que são formados por cópias reduzidas de si mesmos.

\footnotetext{
${ }^{11} \mathrm{Ou}$ seja $\forall u \in U \Longrightarrow \exists v \in V / v \subset u$

${ }^{12}$ Auto-semelhança estrita é quando um conjunto é um conjunto fixo dele mesmo por uma composição de transformações afins, não estrita é quando não há uma composição de transformações afins que leve o conjunto nele mesmo, mas as propriedades estatísticas deste permanecem as mesmas em diversas escalas.
} 
Tomemos um quadrado como exemplo:

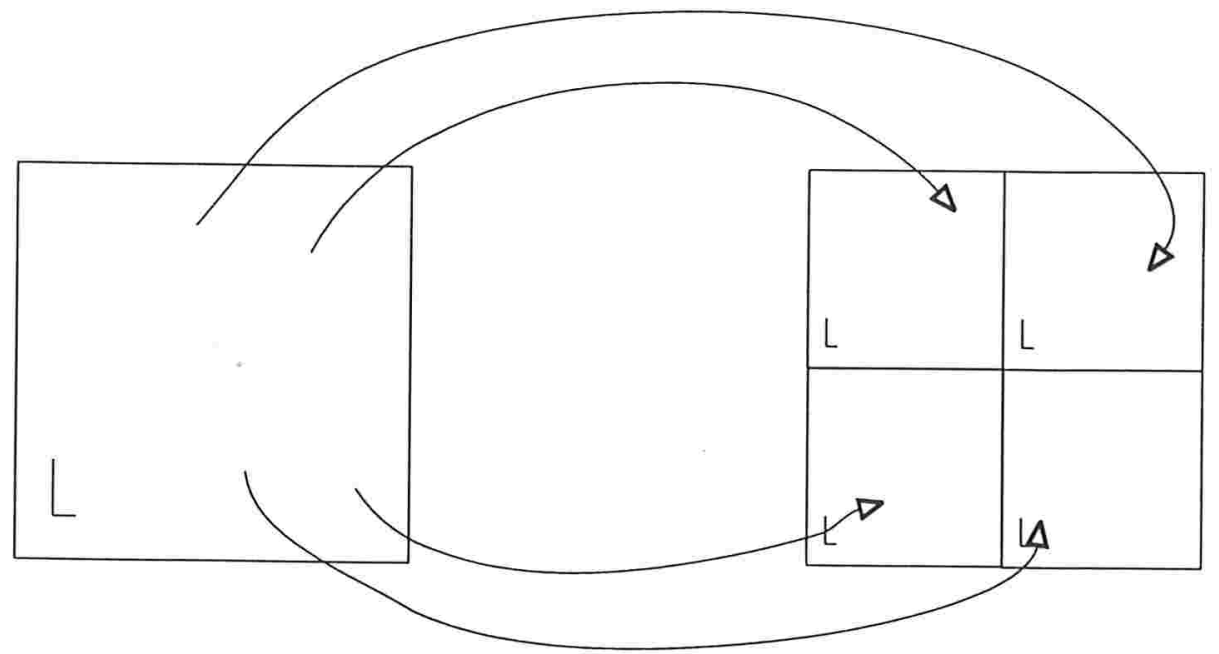

Um quadrado composto de quatro cópias de si mesmo.

São quatro cópias reduzidas do quadrado original, cada uma com metade do lado do original. Se formos dividindo o quadrado sucessivas vezes em quadradinhos de lado $L_{n}=\frac{1}{2^{n}}$ teremos $N_{n}=4^{n}$ quadradinhos. Ou seja o número de quadradinhos segue uma lei de potência:

$$
N_{n}=\left(\frac{1}{L_{n}}\right)^{2}
$$

daí concluímos que o quadrado é bidimensional (pelo expoente 2), isolando o exponente:

Definição 3.3 dimensão de auto-semelhança: Se um objeto $A$ é dividido em $N$ partes exatamente iguais a ele só que de tamanho $L$ então a dimensão de auto semelhança $D_{A S}$ é:

$$
D_{A S}=-\frac{\log N}{\log L}
$$

\section{Exemplo 3.5 Conjunto de Cantor:}

Por exemplo, a dimensão de auto semelhança da Poeira de Cantor é calculada notando que cada metade do conjunto é igual ao conjunto inteiro reduzido a $1 / 3$ do tamanho original: 


\section{O conjunto de Cantor ('esticado' para podermos vê-lo).}

Daí a dimensão é: $D_{A S}=-\frac{\log 2}{\log (1 / 3)}=\log _{3} 2$ que fica entre 0 e 1 conforme uma noção 'intuitiva' de dimensão esperaria, pois o conjunto é totalmente desconexo (comprimento 0 ) e logo tem dimensão topológica 0 , mas tem tantos pontos quanto o intervalo $[0 ; 1]$ ou mesmo $\mathbb{R}$.

\section{Dimensão de Hausdorff-Besicovich}

Para a generalização da noção de dimensão para conjuntos arbitrários (e não necessariamente auto-semelhantes) é necessário o uso de uma medida indexada por escala ${ }^{13}$, para obtermos uma medida da geometria do objeto em várias escalas.

Isso é feito quando medimos áreas, volumes, hiper-volumes ou o 'conteúdo' $C_{r}$ de uma bola $n$-dimensional de raio $r$ :

$$
C_{r}=\gamma(n) r^{n} \quad \text { onde } \quad \gamma(n)=\frac{(\Gamma(1 / 2))^{n}}{\Gamma(1+n / 2)}
$$

onde $\Gamma$ é a função de Euler ${ }^{14}$. No caso de um disco bidimensional teríamos, por exemplo: $C_{r}=\pi r^{2}$.

A idéia de Hausdorff foi perceber que esta medida é um pouco 'exagerada' em alguns casos e pode ser melhorada. Com isso em mente substituiu $n$ por s. um expoente arbitrário, na expressão acima e o deixa variar de 0 a $\infty$ usando $C_{r}^{s}$ para calcular o conteúdo de uma cobertura de conjuntos arbitrários. Formalmente com Lebesgue tínhamos a medida externa de um conjunto $A$ dada por:

$$
\mu(A)=\lim _{r \rightarrow 0} \mu_{r}(A)
$$

com

$$
\mu_{r}(A)=\inf \left\{\sum_{i=0}^{\infty} C_{r_{i}} / \begin{array}{l}
\text { para todas coberturas } \cup B_{i} \supset A \\
\text { onde } r_{i} \text { é o diâmetro de } B_{i} \text { e todos } r_{i} \leq r
\end{array}\right\}
$$

${ }^{13}$ Ou seja uma medida que usa uma escala como parâmetro para sua avaliação.

${ }^{14}$ É a generalização feita por Euler da função fatorial para os reais, dada por:

$$
\Gamma(x)=\lim _{m \rightarrow \infty} \frac{m^{x} m !}{x(x+1)(x+2) \ldots(x+m)}
$$

e está definida para todos reais exceto os inteiros negativos aonde o limite não existe. 
Ou seja $\cup B_{i}$ é uma cobertura enumerável de $A$ por abertos que têm diâmetro $^{15}$ menor ou igual ao limite $r$ dado. Levando o limite a zero e somando os conteúdos das 'menores' coberturas medimos o conteúdo do conjunto em relação a dimensão topológica do espaço. Mas as alterações de Hausdorff transformam esta expressão em:

$$
h^{s}(A)=\lim _{r \rightarrow 0} h_{r}^{s}(A)
$$

com

$$
h_{r}^{s}(A)=\inf \left\{\begin{array}{ll}
\sum_{i=0}^{\infty}\left(r_{i}\right)^{s} / & \text { para todas coberturas } \cup B_{i} \supset A \\
\text { onde } r_{i} \text { é o diâmetro de } B_{i} \text { e todos } r_{i} \leq r
\end{array}\right\}
$$

E $h^{s}(A)$ é a medida de Hausdorff do conjunto $A^{16}$. Variando o $s$ obtemos uma função decrescente, e que tem um 'pulo' abrupto de $\infty$ a zero em um valor específico $s_{c}$ este valor crítico é a dimensão de Hausdorff-Besicovich.

Definição 3.4 dimensão de Hausdorff-Besicovich: é dada por:

$$
D_{H B}(A)=\inf \left\{s / h^{s}(A)=0\right\}=\sup \left\{s / h^{s}(A)=\infty\right\}
$$

Com isso a definição de Mandelbrot [MAN83, pag. 15] faz sentido: fractais são aqueles conjuntos que têm dimensão de Hausdorff-Besicovich diferente de sua dimensão topológica, ou seja, não são adequadamente medidos pela dimensão topológica.

A dimensão $D_{H B}$ também agrupa os conjuntos em classes de equivalência, só que atualmente somente temos um resultado válido para objeto auto-semelhantes ([DK88, no artigo An Introduction to Fractals $]$ ). Os objetos auto-semelhantes de mesma dimensão de Hausdorff-Besicovich são mapeados entre si por quase-isometrias ${ }^{17}$ e se classificam assim de uma maneira mais refinada do que a dimensão topológica, já que leva-se em consideração a estrutura dos objetos. Resta saber se entre quaisquer conjuntos de mesma dimensão de Hausdorff-Besicovich existe sempre alguma quase-isometria, ou algum outro tipo de homeomorfismo.

\footnotetext{
${ }^{15}$ Definido como a maior distância (segundo a métrica do espaço) entre todos os pontos do conjunto.

${ }^{16} \mathrm{Na}$ verdade nem todos conjuntos $A$ são mensuráveis por esta medida, somente aqueles em que $h^{s}(A)=h^{s}(A \cap T)+h^{s}\left(A \cap T^{C}\right)$ para qualquer $T \subset E$. Na prática normalmente usam-se conjuntos fechados que são $h^{s}$-mensuráveis.

${ }^{17}$ Tipo especial de homeomorfismo. São funções contínuas, inversíveis e que cuja inversa seja Lipschitz $\left(d\left(f^{-1}(x), f^{-1}(y)\right) \leq K d(x, y)\right.$ para todos $x, y \in E$ e algum $\left.K \in \mathbb{R}^{+}\right)$.
} 


\section{Dimensões generalizadas}

Pode-se usar toda uma classe de dimensões baseada no mecanismo de Hausdorff, escolhemos alguma função $m_{s}(r)$ que vai a zero com $r$ e fazemos a mesma localização do ponto de corte nos reais:

$$
M_{s}(A)=\lim _{r \rightarrow 0} M_{r, s}(A)
$$

com

$$
M_{r, s}(A)=\inf \left\{\sum_{i=0}^{\infty} m_{s}\left(r_{i}\right) / \begin{array}{l}
\text { Para todas coberturas } \cup B_{i} \supset A \\
\text { onde } r_{i} \text { é o diâmetro de } B_{i} \text { e todos } r_{i} \leq r
\end{array}\right\}
$$

A função $m_{s}(r)$ pode ser ajustada para cada conjunto de uma maneira bem particular pela escolha do $s$ crítico, por exemplo temos conjuntos com bom ajuste por: $m(r)=1 / \log |r|$ etc. Mandelbrot [MAN83, pag. 364] chama uma função bem a justada de função-teste intrínseca do conjunto. Um exemplo é o movimento Browniano no plano que têm função-teste intrínseca $m(r)=r^{2} \log \log (1 / r)$.

\section{Dimensão de Bouligand-Minkowsky}

Uma variante da dimensão de Hausdorff-Besicovich é a de Minkowsky refinada por Bouligand: nela tomamos discos de raio exatamente $r$ e usamos a medida de Hausdorff para esta classe de coberturas:

$$
B M_{s}(A)=\lim _{r \rightarrow 0} B M_{r, s}(A)
$$

com

$$
B M_{r, s}(A)=\inf \left\{\begin{array}{ll}
\sum_{i=0}^{\infty} r^{s} / & \begin{array}{l}
\text { Para todas coberturas } \cup B_{i} \supset A, \\
\text { onde o raio } B_{i}=r
\end{array}
\end{array}\right\}
$$

Definição 3.5 dimensão de Bouligand-Minkowsky: é dada por:

$$
D_{B M}(A)=\inf \left\{s / B M_{s}(A)=0\right\}=\sup \left\{s / B M_{s}(A)=\infty\right\}
$$

Como estamos restritos a bolas de raio $r$ podemos ter valores maiores do que os observados na dimensão de Hausdorff-Besicovich e lembrando que a dimensão topológica é o arredondamento da $D_{H B}$ para o inteiro mais próximo que não a ultrapassa, sempre vale a desigualdade para qualquer conjunto $A \subset E$ ( $D_{E}$ é a dimensão topológica do espaço $E$ ): 


$$
D_{T} \leq D_{H B} \leq D_{B M} \leq D_{E}
$$

Um conjunto $A$ que tem $D_{H B}=D_{B M}$ é dito muito regular e pode ser usado para decompor conjuntos mais complexos pois $D_{H B}(A \times B)=$ $D_{H B}(A)+D_{H B}(B)$ para qualquer conjunto $B$.

\section{Dimensão de Contagem de Caixas}

As definições de dimensão, ficam um tanto quanto longe de uma técnica prática para a sua computação numérica. Questões como "todas as coberturas possíveis" são simplesmente intratáveis em computadores, mas se nos restringimos a uma classe qualquer de coberturas cujos elementos têm tamanho que vai a zero e calculamos uma dimensão $D^{*}$ então podemos dizer com segurança que $D_{H B} \leq D^{*}$.

A técnica mais popular (embora nem sempre dê bons resultados) é conhecida como 'dimensão de contagem de caixas', alguns autores preferem chamá-la de 'dimensão de grade'. Enquanto seu nome original parece ser dimensão de entropia ou então dimensão de Schnirelman-Komolgorov.

Trata-se de um problema simples de contagem, usamos uma grade de hiper-cubos de tamanho $r$ e contamos o número de cubos que contém pelo menos um ponto do conjunto avaliado. Após isso reduz-se o tamanho da grade e repete-se o processo. a dimensão é dada por:

$$
D_{C C}(A)=\lim _{r \rightarrow 0} \frac{\log N(r)}{\log (1 / r)}
$$

onde $N(r)$ é o número de hiper-cubos contendo ponto(s) do conjunto $A$.

Como esta definição se encaixa nas anteriores? É baseada na seguinte medida $r^{d} N(r)$, e notando que: $d=\inf \left\{d^{\prime} / \lim _{r \rightarrow 0} r^{d^{\prime}} N(r)=0\right\}$.

Normalmente o método é usado com sucessivas divisões de $r$ (por potências de 2 por exemplo) e usa-se um gráfico log-log para fazer uma regressão linear e da inclinação da reta obtida estimar a dimensão de contagem de caixas.

Exemplo 3.6 Dimensão de contagem de caixas da costa inglesa

Podemos calcular qual é a dimensão de contagem de caixas da costa da Inglaterra usando grades progressivamente mais finas e para cada uma, contando o número de caixas necessárias para cobrir a costa. 

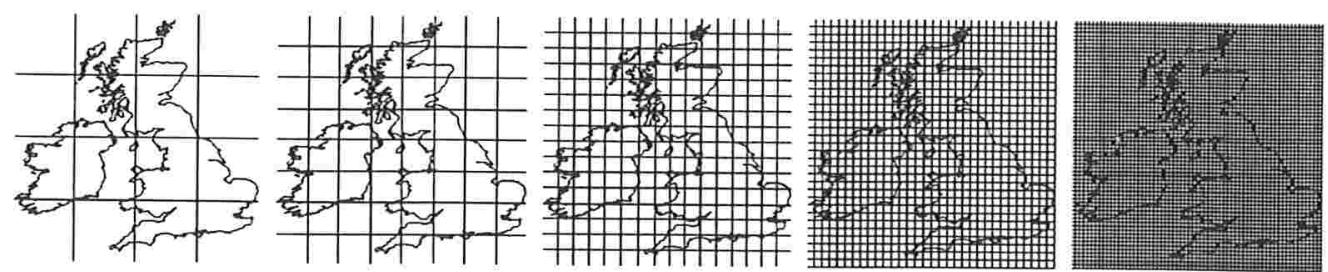

E o número de caixas cobrindo a costa em cada escala:

\begin{tabular}{r|c|c|c|c|c} 
Escala & $1 / 4$ & $1 / 8$ & $1 / 16$ & $1 / 32$ & $1 / 64$ \\
\hline Número de caixas & 13 & 47 & 138 & 362 & 944
\end{tabular}

Isto em um gráfico log-log:

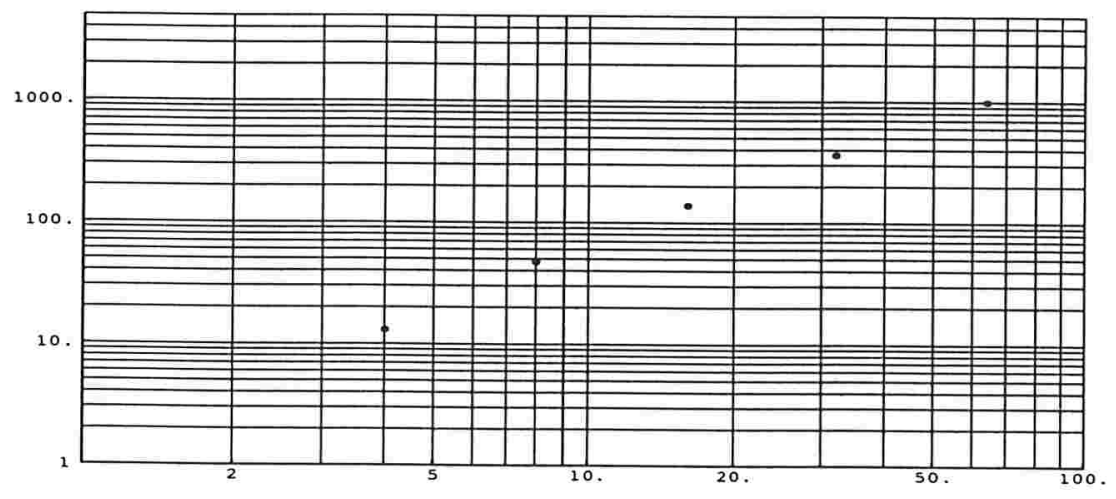

Gráfico log-log da escala versus a contagem de caixas.

A inclinação da reta interpolada entre os pontos é de aproximadamente 1,4, e este valor é a dimensão de contagem de caixas da costa da Inglaterra (nas escalas consideradas aqui): $D_{C C} \approx 1,4$.

É importante notar que este método tem limitações intrínsecas, por exemplo, ele irá dar dimensão um a qualquer subconjunto denso de $\mathbb{R}$, enquanto muitos destes subconjuntos podem ter dimensão de HausdorffBesicovich igual a zero (por exemplo, os números racionais). 


\section{Dimensões de Informação}

Também conhecidas como dimensões generalizadas de Renji, são muito úteis na física ([FFP94]), e atualmente em matemática no estudo de multifractais ([PJS92, no artigo de Mandelbrot, pag. 921]).

Inicialmente tomamos uma medida invariante numa grade de tamanho $\epsilon$ na qual cada caixa tem probabilidade $p_{i}$ associada (ligada a 'quantidade' de pontos do conjunto contidos na caixa). Então definimos:

Definição 3.6 dimensão generalizada de Renji de ordem $q$, onde $q \in \mathbb{R} e$ $q \neq 1$ é dada por:

$$
D_{q}=\frac{1}{1-q} \lim _{\epsilon \rightarrow 0} \frac{\log _{2} \sum_{i} p_{i}^{q}}{\log _{2} \epsilon}
$$

Esta definição nos dá um espectro de dimensões quando $q$ varia. Normalmente é usada em sistemas com atratores, tomando-se órbitas define-se:

$$
p_{i}=\lim _{\varepsilon \rightarrow 0} \frac{N_{i}}{N}
$$

Onde $N_{i}$ é o número de pontos da órbita que estão na $i$-ésima caixa e $N$ é o número de pontos total da órbita. Quando $N$ é grande a órbita esta percorrendo várias vezes o atrator, logo as diferenças de 'densidade' do mesmo estão bem representadas pelos $p_{i}$ s daí pode-se aplicar a definição de dimensão cima para calcular as dimensões de Renji do sistema.

Alguns valores de $q$ são particularmente relevantes: 0,1 e 2. Vejamos $D_{0}=\lim _{\epsilon \rightarrow 0} \frac{\log _{2} \sum_{i} 1}{\log _{2} \epsilon}$ agora $\sum_{i} 1$ é exatamente o número de pontos na caixa $i$, ou seja $N_{i}(\epsilon)$ daí ficamos com:

$$
D_{0}=\lim _{\epsilon \rightarrow 0} \frac{\log _{2} N_{i}(\epsilon)}{\log _{2} \epsilon}
$$

Que é exatamente a definição da dimensão de contagem de caixas, ou seja: $D_{C C}=D_{0}$ !

Com $q=1$ temos uma pequena dificuldade técnica na definição, mas pode ser contornada. Reescrevemos $D_{q}$ como:

$$
D_{q}=-\lim _{\epsilon \rightarrow 0} \frac{I_{q}(p)}{\log _{2} \epsilon}
$$


Onde $I_{q}(p)$ é a informação generalizada de Renji de ordem $q^{18}$ definida por:

$$
I_{q}(p)=\frac{1}{1-q} \log _{2} \sum_{i} p_{i}^{q}
$$

Esta tem um limite definido quando $q \rightarrow 1$ que é [FFP94, pag. 151]: $-\sum p_{i} \log _{2} p_{i}$ que é exatamente a quantidade de informação (por Shannon) do sistema. Daí temos:

$$
D_{1}=\lim _{\epsilon \rightarrow 0} \frac{\sum_{i} p_{i} \log _{2} p_{i}}{\log _{2}(1 / \epsilon)}
$$

Que é chamada de dimensão de informação. E por fim o caso onde $q=2$ :

$$
D_{2}=\lim _{\epsilon \rightarrow 0} \frac{\log _{2} \sum_{i} p_{i}^{2}}{\log _{2} \epsilon}
$$

é a dimensão de correlação que é de fácil cálculo em sistemas complexos pelo algoritmo de Grassemberger-Procaccia (mais sobre isso na próxima seção).

Uma propriedade interessante das dimensões de Renji é:

$$
D_{q} \leq D_{q^{\prime}} \text { sse } q \geq q^{\prime} \text { onde } q, q^{\prime} \in \mathbb{R}
$$

a igualdade vale com conjuntos auto-semelhantes e homogêneos (todos os pontos são equiprováveis). Se houver a desigualdade temos um conjunto hoje denominado multifractal, pois possui diferentes dimensões considerando-se diferentes 'densidades' do conjunto. As dimensões $D_{q}$ com $q$ indo a $-\infty$ correspondem a uma caracterização das partes mais esparsas e quando vai a $\infty$ as partes mais densas.

\subsubsection{Antigas Definições}

Mas porque esta série de definições de dimensão, uma definição não seria suficiente? Infelizmente não, como veremos abaixo, Mandelbrot tenta dar a princípio [MAN83] uma definição formal de fractal usado a dimensão de Hausdorff-Besicovich, mas já nota que é uma definição provisória. Depois

\footnotetext{
${ }^{18}$ A teoria da informação é extremamente bela e rica, mas fica um pouco fora do escopo desta tese, para resultados gerais [HAM80] e para detalhes aplicados a fractais [FFP94, em II.II e III.III.C].
} 
reconhece que não deveria ter fixado uma dimensão em particular, mas que o conceito de dimensão é o que conta, para cada situação uma dimensão.

Barnsley [BAR88] por outro lado usa outra aproximação montando um espaço métrico de subconjuntos compactos de outros espaços métricos com a métrica de Hausdorff. Isso é exatamente o que é necessário para o trabalho dele em particular.

\section{Mandelbrot}

Retomemos agora a definição de Mandelbrot:

"Whenever we work in the Eucliedean span $R^{E}$, both $D_{T}$ [dimensão topológica] and $D$ [dimensão de Hausdorff-Besicovitch] are at least 0 and to most $E$. But the resemblance ends here. The dimention $D_{T}$ is always an integer, but $D$ need not to be an integer. And the two dimentions need not concide; they only satisfy the Szpilrajn inequality $D \geq D_{T}$. For All Euclid, $D=D_{T}$. But nearly all sets in this Essay satisfy $D>D_{T}$. There was no term to denote such sets, which led me to coin the term fractal, and to define it as it folows:

A fractal is by definition a set for which the Hausdorff Besicovitch dimention strictly exceeds the topological dimention." 19

Agora fica mais claro a intenção de Mandelbrot ao definir como fractal aquele conjunto em que $D_{T}<D_{H B}$, pois com isso podemos ter uma distinção geométrica entre os objetos, em um o comportamento é euclidiano no outro não é. Daí a necessidade de cunhar um temo novo: fractal - da aparência quebrada, fracionada dos objetos.

Quão fácil é classificar um objeto como fractal nestes termos? Depende muito do objeto. Para formas euclidianas é fácil, para objetos em geral não há bons métodos, pois a medida de Hausdorff é muito teórica o termo 'todas possíveis coberturas' invalida o uso direto da definição.

\footnotetext{
19 "Sempre que trabalhamos no espaço euclidiano $R^{E}$, ambas $D_{T}$ [dimensão topológica] e $D$ [dimensão de Hausdorff- Besicovitch] são no mínimo zero e no máximo $E$. Mas a similaridade termina aí. A dimensão $D_{T}$ é sempre um número inteiro, enquanto $\mathrm{D}$ não precisa ser um inteiro. E ambas não precisam coincidir tampouco; elas somente tem que satisfazer a desigualdade de Szpilrajn: $D \geq D_{T}$. Para todas formas euclidianas $D=D_{T}$. Mas quase todos conjuntos neste Ensaio satisfazem $D>D_{T}$. Não havia nome para tais conjuntos, o que me levou a cunhar o nome fractal, e a defini-lo como segue:

Um fractal é por definição um conjunto cuja dimensão de Hausdorff-Besicovitch excede estritamente sua dimensão topológica."
} 
A solução em geral adotada é usar outra definição de dimensão no lugar de $H_{H B}$ de cálculo mais fácil no problema em questão. Mas nem sempre é tomado o cuidado necessário e não fica claro para os leitores que se está usando uma aproximação ou limitante superior (como a $D_{C C}$ ), fato que o próprio Mandelbrot lamenta no final da edição revisada de seu livro [MAN83]. Após isso ele reforça que a idéia de dimensão e não sua definição formal é que deve ser usada para classificar objetos. Depois de quase duas décadas de trabalhos no campo é hora de retomarmos esse problema e dar uma definição formal abrangente.

Pela dificuldade de cálculo da dimensão a definição raramente é usada como crivo para classificar objetos. Em vez disso normalmente se ouve (de autores cuidadosos): 'o sistema apresenta características fractais', 'o objeto é de natureza fractal', etc. E quando cálculos com alguma variante de dimensão funcionam diz-se imediatamente que o objeto é fractal, embora isso não garanta que sua dimensão de Hausdorff-Besicovich seja estritamente maior que a topológica.

Pior ainda em muitos problemas mostra-se que fractais clássicos tem dimensão inteira e às vezes igual à sua dimensão topológica. Por exemplo os conjuntos de Cantor 'gordos'

Exemplo 3.7 Um conjunto de Cantor gordo:

Um conjunto de Cantor gordo é construído aqui pela remoção dos segmentos centrais de tamanho que decresce relativamente (um ao outro) com $1 / 3^{2^{k}}$. Na figura temos o terço central removido, daí são removidos os nonos centrais dos segmentos restantes, então são removidos os $1 / 81$ etc.

$1 / 81$

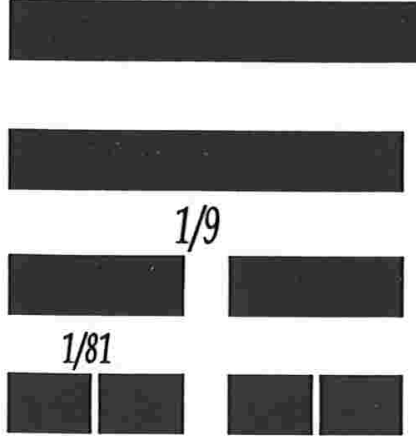

$1 / 3$

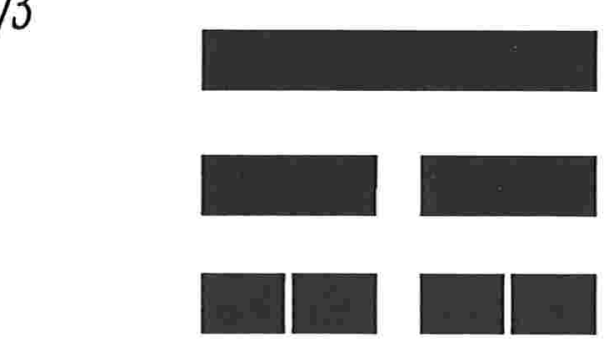

...

Primeiros passos na construção de um conjunto de Cantor gordo.

Neste caso o conjunto tem infinitos buracos, mas seu comprimento final é maior que zero! Calculemos: 


$$
L_{n}=1-\prod_{k=0}^{n}\left(1-3^{2^{k}}\right)
$$

Que possui limite para $n \rightarrow \infty: L_{\infty}=0.41482 \ldots$

e também em particular a fronteira do conjunto $M$ (conjunto de Mandelbrot para $\left.f_{c}(z)=z^{2}+c\right)$ tem $D_{H B}(\sigma M)=2$ [SHI91]! Notamos também que em [EDG90, pg. 180] é citado um melhoramento da definição de Mandelbrot por James Taylor que adiciona mais uma restrição: " $F$ é fractal se $\operatorname{dim}_{T}(F)<\operatorname{dim}_{H B}(F)=\operatorname{dim}_{P}(F)$ "20. Essa sugestão ainda falha ao deixar objetos conhecidos de fora herdando as dificuldades de cálculo da original, porém ela elimina objetos que não se parecem nem são construídos como fractais (Mandelbrot os chama de 'verdadeiro caos geométrico').

Isso mostra que apesar da construção idêntica muitos objetos, supostamente fractais, não são fractais por esta definição. Portanto parece-nos que a dimensão cai melhor como uma das propriedades de conjuntos fractais, mas não como definição: é uma importante ferramenta para entender os fractais, mas não é suficiente para defini-los.

\section{Barnsley}

Em seu livro [BAR88] Michael Barnsley aproveita esta situação de indefinição em relação à dimensão e cria uma nova definição. Não é uma proposta para substituir a antiga, mas simplesmente o que o autor entende por fractal em seu livro, e especialmente aquilo que se encaixa melhor nas necessidades das ferramentas desenvolvidas por ele.

Retomemos a definição:

"We refer to $(H(X), h)$ [espaço métrico de subconjuntos de $X$ com a métrica de Hausdorff $h$ induzida] as 'the space of fractals'. It is too soon to be formal about the exact meaning of 'a fractal'. At the present stage of development of science and mathemathics, the idea of a fractal is most useful as a broad concept. Fractals are not defined by a short legalistic statement, but by the many pictures and contexts which refer to them. For us [...] any subset of $(H(X), h)$ is a fractal. However as with the

\footnotetext{
${ }^{20}$ Aqui aparece mais uma dimensão: a de Empacotamento (Packing no original).
} 
concept of 'space' more meaning is suggested than is formalized." 21

O que Barsley define como $(H(X), h)$ é o espaço métrico da união conjuntos compactos de $X$ com a métrica de Hausdorff induzida $h$ sobre o espaço métrico original $X$. Mas um ponto de $X$ é um conjunto compacto, logo $H(X)$ é na verdade $P(X)$ (o conjunto da partes de $X$ ), logo a definição engloba todos subconjuntos de $X$ !

Desta forma não se limita o que são os fractais (e sempre trabalhamos com espaços métricos completos). Parece-nos uma definição muito abrangente, criada para satisfazer as necessidades do trabalho do próprio Barnsley.

\subsection{Definição}

Se não existe uma solução completa, uma possibilidade é retomar a noção de fractais à procura de uma nova definição. O que identifica um fractal antes de calcularmos sua dimensão ou sabermos se ele é compacto etc.? Uma característica é clara: auto-semelhança (estrita ou não). Ter partes semelhantes ao todo é essencial.

Aqui devemos fazer uma pausa na nossa linha de raciocínio e notar explicitamente aquilo que Mandelbrot defende como a 'volta da geometria' como ramo importante do desenvolvimento matemático.

Como saber se um conjunto é auto-semelhante? Pela definição teórica é um pouco difícil, com a possível exceção de alguns exemplos de livros didáticos. A maneira corrente introduzida por Mandelbrot ${ }^{22}$ é fundamentalmente importante até hoje: visualização computadorizada. Sem 'ver' um conjunto não temos como dizer algo sobre sua auto-semelhança. Aqui temos um divisor de águas: a visualização computadorizada passa a ser ferramenta importante para a matemática no estudo de fractais.

Isso é uma corrente de volta ao 'visual' na matemática. Aonde nossa visão geométrica passa a exercer um papel importante. Outro fato importante é a sugestão de fatos a serem provados (conectividade de $M$, universa-

\footnotetext{
21 "Nos referimos a $(H(X), h)$ [espaço métrico de subconjuntos de $X$ com a métrica de Hausdorff $h$ induzida] como "o espaço dos fractais". É muito cedo para sermos formais sobre o significado exato de "um fractal". No estagio atual de desenvolvimento da ciência e da matemática, a idéia de fractal é mais útil como um conceito amplo. Os fractais não são definidos por uma curta definição "legal", mas pelas inúmeras imagens e contextos que se referem a eles. Para nós [...] qualquer subconjunto de $(H(X), h)$ é um fractal. Porém assim como com o conceito de 'espaço' mais é sugerido do que realmente formalizado."

${ }^{22} \mathrm{Nem}$ ele acreditou na sofisticação das primeiras imagens, atribuindo o resultado à algum erro de cálculo, fato que ele rapidamente descobriu ser incorreto.
} 
lidade da constante $\delta$ etc.) e a inspiração de pesquisadores pela investigação das imagens de fractais.

Outro ponto que é comum a todos fractais - tanto quanto a autosemelhança - sendo presença obrigatória na gênese dos fractais, é a iteração. Disto percebe-se a grande importância do computador como ferramenta ideal para estudar fractais.

Praticamente todos fractais são gerados por funções iteradas, e todos foram descobertos ou inventados a partir de funções iteradas ${ }^{23}$. Com isso vai ficando mais claro a importância de funções iteradas e o porquê de termos apresentado-as no início deste trabalho. Retomemos as três características fundamentais dos fractais em ordem de aparição:

\section{Iteração}

2. Auto-semelhança

3. Dimensionalidade

Ou seja a idéia de Mandelbrot é a última na seqüência. Ela tem problemas que já discutimos e a vantagem de ser sintética e eficiente ao tentar descrever estrutura dos objetos. A segunda é a essência de um fractal, mas tem definição formal muito difícil. Algumas possibilidades são de aplicação limitada e no caso de fractais não-lineares não se tem boas definições para o que seria a auto-semelhança não estrita. $\mathrm{O}$ conceito serve realmente melhor como um guia intuitivo.

Nos resta então a primeira: a iteração, como forma de definição, temos duas possibilidades, então.

Primeiro podemos chamar a própria função iterada de fractal, isso cairia bem no estudos de sistemas, pois eles são definidos em temos de equações ou funções iteradas. Porém não é uma forma geométrica como mencionamos há pouco.

Temos como segunda possibilidade: o conceito de lugar geométrico influenciando a definição. Normalmente estamos tratando de uma função iterada que tem órbitas que vagam por um espaço apresentando ou não alguma característica de nosso interesse. Estes dois conceitos são unificáveis e fractal pode ser dito como o lugar geométrico dos pontos que compartilham uma mesma propriedade de uma função iterada. Formalmente temos:

\footnotetext{
${ }^{23}$ Com a exceção do conjunto de Cantor Triádico que pode ser definido em termos de números em $[0 ; 1]$ na base três e da seleção de todos que não apresentam o dígito 1 na expansão. Este exemplo também pode ser encarado como iterado.
} 
Definição 3.7 Fractal: dada uma função iterada $f: E \rightarrow$ $E$, um mapa $M: \operatorname{Orb}(f) \rightarrow R$ e um valor $r \in R$ (onde $R$ é um espaço-resultado de $M$ ) é um conjunto $A$ tal que: $A=\{x \in E / M(o(x))=r\}$.

Assim qualquer conjunto formado por pontos com a mesma propriedade (quando transformados por $f^{n}$ ) é um fractal. Isto coincide com a definição de fractais clássicos e com alguns famosos que não eram fractais pela definição original, como o conjunto de Mandelbrot de $f(z)=z^{2}+c$.

Esta definição é mais abrangente que a de Mandelbrot e mais ajustada ao campo como um todo do que a de Barnsley. A experiência acumulada no campo pela iniciativa de pesquisadores como estes acaba nos levando a uma definição que incorpora a origem dos fractais - a iteração - e a noção geométrica - de lugar geométrico - num único conceito. As noções de autosemelhança de dimensionalidade são então propriedades a serem estudas, presentes (como eram encaradas) na vasta maioria dos fractais.

\subsection{Novas direções}

O campo de fractais têm se expandido por dois caminhos: o das aplicações e o da teoria. O primeiro é muito rico e não cabe aqui uma revisão exaustiva dele. No segundo temos uma pequena confusão reinante pela dificuldade de definição e pelas características pouco convencionais dos fractais. Porém é importante frisar que muitos têm contribuído significativamente para a própria matemática por ferramentas que usam fractais. Alguns chegam a desenvolver teorias belíssimas ampliando conceitos atuais pelos fractais. Como exemplos disso temos [MÉH91] como grande trabalho teórico e [DK88, no artigo de Jenny Harrison] como amostras das possibilidades dos fractais na matemática pura. 


\section{Capítulo 4}

\section{Técnicas de Cálculo e Visualização}

As técnicas de cálculo e visualização de fractais sofrem também com a falta de organização do campo. Aqui apresentamos uma organização e referências para as técnicas mais importantes e utilizadas. A visualização é um caso particular do cálculo, mas é de fundamental importância para o estudo dos fractais, por isso é tratada com maior atenção aqui.

Três categorias de cálculo descrevem o que é possível com fractais: síntese, transformação e análise. Na síntese temos uma função iterada sendo estudada (e alguma propriedade sendo avaliada) gerando um fractal - se considerarmos este uma imagem estamos falando de visualização. Com transformação descrevemos a mudança de um fractal para outro, muitas vezes é vista como um acoplamento análise-síntese. Com a análise buscase encontrar elementos que resumam as características do fractal estudado - dimensões, expoentes característicos etc. - no caso mais geral se coloca talvez o problema mais difícil: dado um fractal encontrar a função iterada e a propriedade que o gerou (também conhecido como o problema inverso).

Sintetizar um fractal é a ferramenta mais comum, porém que apresenta menos aplicações práticas diretamente. Uma grande variedade de programas gera fractais somente por sua beleza estética, mas a similaridade entre muitos fractais e elementos da natureza os torna ótimas fontes para programas que imitam o comportamento natural. Como exemplos temos os programas de ilustração que simulam texturas, pincéis, etc. com fractais e também temos simuladores de vôo e jogos que simulam superfícies e texturas por fractais. O cálculo eficiente de um fractal não depende somente da função e da propriedade estudadas, diversas técnicas de otimização podem 
ser utilizadas para obtenção de resultados muito próximos (senão iguais) do obtido pelo uso da "força bruta".

$\mathrm{Na}$ transformação temos a primeira aplicação comercial de fractais: a compressão de imagens. Nela uma imagem é codificada como um fractal (IFS afim para ser exato) e este ocupa um espaço muito reduzido em comparação com a imagem original. Na restauração a imagem obtida não é exatamente igual à original (compressão com perdas) mas a diferença é controlada ${ }^{1}$. Mas este método aponta algumas das possibilidades de transformações fractais: a imagens restaurada não precisa ser do mesmo tamanho (nem resolução) da original. Se mais pontos forem necessários o fractal calculado serve de função de interpolação gerando resultados interessantes e melhores do que os obtidos com qualquer outro método. Apesar do pioneirismo este tipo de cálculo é bastante difícil, provavelmente devido a parte de análise de conjuntos. Alguns desenvolvimentos são mostrados em [VIN93].

Com a análise extrai-se informações relevantes de um dado fractal. Este em geral é um conjunto de propriedades que desejamos conhecer melhor. É sem dúvida o tipo de pesquisa mais explorado no campo. Desde a introdução do termo por Mandelbrot calcula-se a dimensão fractal de imagens, objetos naturais, sistemas etc. $\mathrm{O}$ objetivo maior neste tipo de cálculo seria encontrar uma função iterada e uma determinada propriedade a partir de um fractal dado. Este é conhecido como o problema inverso, e é na realidade o problema de todas ciências experimentais: dado um fenômeno fornecer um modelo que o explique. Desnecessário dizer que pouco sucesso foi obtido no problema geral, mas em casos específicos temos boas descrições e explicações geométricas baseadas, por exemplo, na dimensão calculada.

Esta seção está dividida em quatro partes: Cálculo e precisão; Órbitas; Mapas; Cálculo de dimensões e outros indicadores. A primeira comenta algumas questões relativas aos métodos básicos utilizados para se calcular fractais e órbitas. Estes são muito relevantes pois os sistemas fractais apresentam freqüentemente comportamento caótico e sensibilidade às condições iniciais, daí a necessidade de tratamento cuidadoso do uso do computador na avaliação dos mesmos. Teoria da informação, caoticidade e expoentes de Lyapunov são temas que não só se referem a métodos de cálculo, mas auxiliam em outras áreas como a avaliação de dimensões.

Órbitas é a parte que se concentra mais no estudo dos cálculo relativos às órbitas de funções iteradas e a avaliação de suas propriedades. Mapas faz o mesmo para fractais incluindo técnicas de varredura e outras questões

\footnotetext{
${ }^{1}$ Quanto mais diferença maior a compressão obtida. Similar a outros métodos de compressão com perdas, em particular o JPEG (também para imagens).
} 
pertinentes. Ambas se concentram mais no aspecto sintético do que no analítico do cálculo.

Já a última parte: Cálculo de dimensões e outros indicadores trata da parte sintética. Indica-se como avaliar indicadores a partir de fractais dados e como ajustar parâmetros de meta-modelos para obter modelos funcionais de fenômenos observados.

\subsection{Cálculo e precisão}

$\mathrm{Na}$ síntese de fractais por computadores encontramos muito freqüentemente problemas associados à precisão finita destas máquinas. A caoticidade (definida e comentada mais adiante) inerente nestes sistemas introduz ruídos que muitas vezes atingem proporções semelhantes ao do sistema todo em pouco tempo. Nesta seção nos concentraremos em espaços métricos, já que sem uma métrica não conseguimos conceituar a informação nem o erro cometido.

A teoria da informação de Shannon nos auxilia a limitar estes efeitos e, quando isso não for possível, avaliar o grau de significância do sistema num determinado ponto.

\subsubsection{Noção da quantidade de informação}

Pode-se avaliar a quantidade de informação pelo número de bits [HAM80] (dígitos binários) necessários para representar um objeto. Na teoria da informação usa-se a noção de eventos com probabilidades $p$ associadas (como na avaliação das dimensões de Renji) e define-se a informação como:

$$
I(s)=\log _{2}\left(\frac{1}{p}\right)
$$

ou seja, o símbolo $s$ que tem probabilidade $p$ de aparece em um canal "carrega" $I(s)$ bits de informação. Neste contexto a informação é tratada como "novidade" ou "surpresa" associada a um evento/símbolo. Quanto mais improvável um evento, mais sua aparição nos diz (informação).

Numa codificação ótima (Huffmann) cada símbolo requer $\lceil I(s)\rceil$ bits para ser representado, quanto mais improvável, mais bits o símbolo requer. Como corolário temos que esta codificação comprime (ou armazena de forma comprimida) uma mensagem otimamente (embora quando implementado este método não seja ótimo).

Porém o conceito básico que utilizaremos mais fortemente é:

$$
I(s)=\log _{2}|s|
$$


onde consideramos $|s|$ o 'tamanho' do símbolo $s$. No caso de probabilidades e no caso de espaços métricos usamos

$$
I(\overline{s p})=\log _{2} d(s, p)
$$

onde avaliamos a distância entre dois elementos de $E$ pelo número de bits que necessitamos para armazená-la.

Outro conceito que utilizaremos (embora não na extensão que Shannon apresenta) é a entropia. Ela é a resposta à pergunta: se temos um símbolo $s$ com informação $I(s)$, quantos bits de informação recebemos na média? Para cada símbolo $s$ com probabilidade $p$ a resposta é: $p_{i} I(s)=p_{i} \log _{s}\left(1 / p_{i}\right)$. E para todo o sistema? Temos a entropia:

$$
H=\sum_{i} p_{i} \log _{2} \frac{1}{p_{i}}
$$

O que a entropia significa no contexto da teoria da informação? Basicamente é a quantidade de bits média de cada símbolo. Ou seja quantos bits ${ }^{2}$ são necessários para armazenar cada símbolo daquele sistema.

Por exemplo, tomemos um dado honesto, com $p_{i}=1 / 6$ a quantidade de informação de cada face é constante: $I($ face $)=\log _{2}(6) \approx 2,5849 \ldots$ e a entropia do sistema (o dado) todo é dada por:

$$
H=\sum_{i} \frac{1}{6} \log _{2} \frac{1}{\frac{1}{6}}=6\left(\frac{1}{6} \log _{2} 6\right)=\log _{2} 6
$$

Neste caso (e em qualquer outro onde todas probabilidade forem iguais) temos a entropia igual a quantidade de informação de cada face, agora vamos supor que o dado foi viciado. Com isso somente duas faces aparecem (digamos 5 e 6 ) com probabilidades desiguais ( $1 / 4$ e $3 / 4$ respectivamente). Estas faces 'prediletas' tem quantidade de informação: $I$ (face 5$)=\log _{2} \frac{1}{1 / 4}=0,5$ e $I($ face 6$)=\log _{2} \frac{1}{3 / 4}=0,415 \ldots$ Já as outras faces: $I$ (face ruim) $=\log _{2} \frac{1}{0}$ que podemos dizer que é infinita, já que não podem ocorrer estas faces. Agora a entropia deste dado é (supondo que não se somam as faces com $p=0)$ :

$$
H=\frac{1}{4} \log _{2} \frac{1}{\frac{1}{4}}+\frac{3}{4} \log _{2} \frac{1}{\frac{3}{4}}=\frac{1}{8}+\frac{3}{4} \log _{2} \frac{4}{3} \approx 0,6783 \ldots
$$

logo este dado é mais 'bem comportado' que o dado honesto! Isso quer dizer que o dado viciado não apresenta tantas surpresas (quatro faces não

\footnotetext{
${ }^{2}$ Arredondados para o inteiro superior.
} 
aparecem, pelo menos) que o dado honesto (que pode mostrar qualquer face quando jogado).

Bits de informação e bits de armazenamento são grandezas distintas, que podem ser confundidas (como fiz acima) somente quando se tem a distinção clara: bits de informação são unidades (não necessariamente inteiras) de quantidade de informação; bits de armazenamento (ou transmissão) são símbolos, dígitos binários utilizados para representar um evento. Ambos podem ser confundidos quando se pensa na codificação de Huffmann e na quantidade de informação levada ao próximo inteiro.

\subsubsection{Representação numérica}

Como representar órbitas (ou mapas) em espaços arbitrários? Começamos avaliando a ordem de grandeza necessária: $M=\left\lceil\log _{2}|E|\right\rceil$ ou seja o número de bits necessários para armazenar os elementos de $E$. No caso de espaços infinitos ou com $M$ muito grande usamos aproximações. Mas no caso de espaços finitos pequenos usa-se uma representação exata.

Como numa representação exata não existem erros, e nossas funções iteradas são determinísticas temos um controle perfeito (embora nem sempre eficiente) da evolução do sistema.

Em espaços 'grandes' complica-se a situação. Especialmente se a métrica for a única estrutura existente, pois a representação dos elementos será muito difícil.

Consideramos aqui como paradigma de espaços 'grandes' $\mathbb{R}^{n}$ quando forem não-enumeráveis e $\mathbb{Z}^{n}$ quando forem enumeráveis. Se usarmos $\mathbb{Z}^{n}$ normalmente nos restringimos à alguma ordem de grandeza $M$ e usamos $\mathbb{Z}_{2 M}$. Neste caso estamos falando de um espaço 'pequeno' se não houver órbitas que extrapolam esta ordem de grandeza, caso contrário a representação é inadequada. A referência básica para isso é [KNU81, Cap. 4].

\section{Inteiros}

No caso das representações de $\mathbb{Z}$ podemos usar: $\mathbb{Z}_{p}$ ou usar uma alocação dinâmica que acomoda tantos dígitos dos números quanto sejam necessários. Sempre tentando manter-nos dentro da capacidade do computador em questão. Em casos onde os valores ficam muito altos muda-se para a representação de ponto flutuante para os inteiros, conforme discutiremos abaixo. 


\section{Reais}

No caso dos números reais $\mathbb{R}$ temos um problema sério: é um conjunto infinito, denso e não-enumerável. Como toda representação em computadores digitais $^{3}$ é finita acontece o inevitável: usa-se aproximações. Estas juntamente com sistemas determinísticos são a fundação do caos determinístico. Vejamos alguns métodos:

Ponto fixo Aproximações por inteiros, ou ponto fixo são o método mais simples de representar números reais numa região específica da reta. Por exemplo se temos um computador de 32 bits (ou seja é capaz de fazer contas com inteiros de 32 bits) podemos representar os números em [0,1[, tomamos a palavra:

$$
w_{0} w_{1} w_{2} \cdots w_{31}
$$

e imagina-se uma vírgula decimal antes dela:

$$
0, w_{0} w_{1} w_{2} \cdots w_{31}
$$

A soma e a subtração não são afetadas por este artifício, mas a multiplicação e a divisão são, é só lembrarmos que estamos vendo na verdade o valor $\frac{w}{2^{32}}$ onde $w$ é o valor inteiro da palavra:

$$
\begin{gathered}
\frac{a}{2^{32}}+\frac{b}{2^{32}}=\frac{a+b}{2^{32}} \\
\frac{a}{2^{32}} \times \frac{b}{2^{32}}=\frac{a \cdot b}{2^{64}}=\left(\frac{a \cdot b}{2^{32}}\right) / 2^{32}
\end{gathered}
$$

$\mathrm{Na}$ multiplicação somente multiplicar os inteiros $a$ e $b$ não multiplica os reais por eles representados é necessário dividir o resultado por $2^{32}$ ainda para obter o valor correto. Um ajuste semelhante vale para a divisão ${ }^{4}$.

Este método é rápido pois lida com operações básicas em geral embutidas no hardware do computador, e prático pois não necessita de muita programação adicional para ser realizado.

A desvantagem é clara: somente números num intervalo são representados e muito cuidado deve ser tomado para não ultrapasar os limites da máquina.

\footnotetext{
${ }^{3}$ Em oposição aos analógicos, hoje quase extintos, mas que parecem resolver alguns problemas que são inviáveis em computadores digitais.

${ }^{4}$ Além de cuidados para nenhuma destas passagens ultrapassarem a capacidade do computador, fato que ignoraremos neste trabalho.
} 
Ponto Flutuante A extensão natural deste método é aplicar ao computador a representação conhecida como ponto flutuante (ou notação científica em outros campos). Nela o expoente é armazenado alem de um número em $[0 ; 1[$ :

$$
x=(-1)^{s} 0, w_{0} w_{1} w_{2} \cdots w_{63} \times 2^{e_{0} e_{1} \cdots e_{15}-B}
$$

Neste caso eu utilizei o padrão 'double extended' da IEEE, nele temos um bit de sinal $s, 64$ para a mantissa e 15 para o expoente deslocado (artifício para não armazenar no sinal do expoente é deslocá-lo de $B$ unidades, neste exemplo $B=16383$ ).

Os limites neste caso são: 64 bits na mantissa, ou seja, quase 20 casas decimais depois da vírgula e 15 bits no expoente deslocado que vai de -16383 à +16384 .

As operações são bem mais complicadas, pois envolvem o tratamento com os expoentes também. Resultado: é um método mais lento, porém muito preciso, só que certos números não são representáveis assim como no ponto fixo. A vantagem do expoente é poder 'deslizar' a representação por um trecho muito maior da reta real.

Racionais Outra possibilidade muito interessante é usar um par de inteiros (do computador) para representar números racionais da forma $p / q$ (em geral normalizada, isto é $p$ e $q$ são primos entre si). Os cálculos não são difíceis e bastante eficientes, mas os problemas surgem em dois pontos: na limitação de alcance imposta pelo tamanho dos inteiros no computador, e pelo uso de funções transcendentais que fornecem respostas não representáveis por racionais muito facilmente. Porém em sistemas que atuam com as quatro operações básicas é uma boa alternativa.

Precisão arbitrária Quando não se sabe de antemão qual será a precisão necessária há a possibilidade de se implementar algoritmos de precisão arbitrária que vão expandindo o espaço ocupado pelos números à medida do necessário. Problemas: complexidade de implementação lentidão e em muitos casos consumo de memória exagerado. Vantagens: repostas muito precisas.

Apesar de fornecerem mais precisão o ganho teórico é nulo. Ainda são números em ponto flutuante, só que a mantissa (e às vezes o expoente) têm tamanho variável, mas ainda são finitos. Por exemplo funções transcendentais também extrapolam a capacidade deste sistema. 
Híbridos Alguns programas matemáticos como o Mathematica adotam uma estratégia mista: eles detectam a representação mais adequada (no sentido de minimizar as perdas de precisão) e convertem entre elas quando necessário. O resultado é um sistema muito interessante para matemáticos, no qual números como $\pi$ são devolvidos na tela como Pi. E somente são explicitamente calculados se o usuário quiser (neste caso permitindo quantos dígitos de precisão forem desejados). Funções transcendentais ficam, em geral, não avaliadas e números inteiros muito grandes são armazenados por inteiro (por exemplo é trivial calcular 10000! com todos os dígitos de precisão). Essa flexibilidade tem seu preço: tempo. O sistema é de longe o mais lento de todos sendo somente adequado quando o volume de cálculos é baixo.

Influência nos cálculos $\mathrm{O}$ fato de se utilizar um número finito de bits para armazenar os números causa um problema sutil: a introdução de ruído à medida que iteramos alguma função.

\subsubsection{Problemas de trabalho com precisão finita}

Como detectar as imprecisões ou ruídos introduzidos em cada iteração de uma função? A idéia básica é tomar duas órbitas de sementes muito próximas (mas ainda distintas na representação escolhida) e acompanhar sua evolução. Ou seja estamos querendo avaliar:

$$
\Delta_{i}=d\left(x_{i}, x_{i}^{\prime}\right)
$$

como uma avaliação do erro que se introduzirá ou não ao iterarmos a função. Iniciando com $\Delta_{0}=d\left(x_{0}, x_{0}^{\prime}\right)=\epsilon$ vamos comparar este valor com um $\Delta_{i}$ no futuro para dizer se o sistema introduziu mais imprecisão ou não. Pelo afastamento das órbitas percebemos que um erro pequeno tende a se ampliar podendo comprometer os dados avaliados num ponto futuro. Com órbitas que mantém o afastamento constante ou que se aproximam temos um sistema que conserva sua precisão (ou mesmo a melhora) com o passar do tempo e pequenos erros não afetarão o sistema significativamente no futuro.

\subsection{4 'Segurança' nos cálculos}

Quando lidamos com vários atratores (os casos mais interessantes) tem-se a pergunta: como lidar com a imprecisão inerente a representação numérica entre as bacias de atração de atratores diferentes? 
Para isso usa-se uma definição e algumas propriedades de sistemas fractais: dado um ponto $x$ e uma precisão $s \in \mathbb{R}^{+}$dizemos que o ponto é inseguro se existe outro ponto $y \in B(x, s)$ que converge para um atrator diferente do que $x$.

A fronteira entre as bacias de atração tem (hiper-)volume:

$$
V(s) \approx N(s) s^{d}
$$

onde $N(s)$ é o número de caixas cobrindo a fronteira e $d$ é a dimensão do espaço.

Mas se tomamos como $D$ a dimensão (por exemplo a de contagem de caixas) da fronteira das bacias dos atratores, então $N(s) \propto 1 / s^{D}$. Logo

$$
V(s) \approx s^{d-D}=s^{\alpha}
$$

Onde $\alpha$ é chamado de expoente de incerteza. Como $D$ fica entre $d$ e $d-1$ temos que $0 \leq \alpha \leq 1$.

A partir disto pode-se estimar quantos dígitos a mais precisa-se para reduzir a região de incerteza: supondo que deseja-se uma redução de $r$ vezes de $V(s)$, então a nova precisão $s^{\prime \alpha}=s^{\alpha} / r$ logo:

$$
\log _{r} s^{\prime}=\log _{r} s-\frac{1}{\alpha}
$$

Ainda podemos ver isso como:

$$
s^{\prime}=\frac{s}{r^{\frac{1}{\alpha}}}
$$

Logo se $\alpha$ for se aproximando de 0 teremos um fronteira que se aproxima da dimensão (logo do hiper-volume associado) do espaço todo, assim conseguir mais precisão é difícil. Por outro lado quando $\alpha$ aproxima-se de 1 temos uma fronteira suave que tem volume proporcional à precisão, logo reduzir a fronteira é como reduzir a precisão proporcionalmente.

Por exemplo: seja $D=2,5$ a dimensão de uma fronteira em $\mathbb{R}^{3}(d=3)$ e seja $s=10^{-3}$ temos que $\alpha=0,5$, logo para reduzir $H(s)$ por um fator de 1000 teríamos que:

$$
s^{\prime}=\frac{10^{-3}}{1000^{2}}=10^{-3-6}=10^{-9}
$$

Ou seja, seriam necessários mais seis dígitos na precisão de nossos cálculos para reduzir a região de incerteza por um fator de 1000. Agora se a fronteira fosse mais rebuscada $(D=2,75)$ : 


$$
s^{\prime}=\frac{10^{-3}}{1000^{4}}=10^{-3-12}=10^{-15}
$$

Neste caso se quiséssemos a mesma redução de volume teríamos que melhorar a precisão por 12 casas significantes (decimais).

\subsubsection{Caoticidade e expoentes de Lyapunov}

Vamos introduzir uma medida do afastamento das órbitas: o expoente de Lyapunov. Ele é largamente utilizado em física para avaliar a caoticidade de sistemas e ajudar no cálculo de dimensões e outros indicadores.

A noção é simples: quanto as órbitas do sistema todo se afastam entre si na média? (ver para uma introdução mais detalhada: [PJS92] e [FFP94])

Comecemos por calcular o expoente de Lyapunov de uma órbita com imprecisão $\epsilon$, ou seja com uma bola centrada em $x_{0}$ de raio $\epsilon / 2$, neste caso $\Delta_{i}=\left|f^{i}\left(b\left(x_{0}, \epsilon / 2\right)\right)\right|$ ou seja é o diâmetro do conjunto resultante da $i$-ésima iteração de $f$ na bola centrada em $x_{0}$.

$$
\lambda(x)=\lim _{N \rightarrow \infty} \frac{1}{N} \sum_{i=0}^{N-1} \log _{2} \frac{\Delta_{i}}{\epsilon}
$$

ou seja, se este limite existir quer dizer que as órbitas que iniciam em torno de $x_{0}$ seguem uma lei exponencial de afastamento. Se o expoente for zero, então a separação entre as órbitas mantém sua ordem de grandeza, se for negativo quer dizer que a separação tenderá a zero muito rapidamente. Se o expoente for positivo então as separação entre as órbitas cresce exponencialmente e temos a presença do caos determinístico.

Tomando-se a média dos expoentes de Lyapunov de todas as órbitas de um sistema obtemos o expoente do sistema $\lambda$.

$\mathrm{Na}$ verdade podemos, em espaços multidimensionais, obter tantos expoentes de Lyapunov quanto são as dimensões do espaço, mas a definição já depende de mais estrutura do que somente a métrica. E a avaliação e aplicação são bem mais complexas, vide por exemplo [FFP94].

\section{Espectro de expoentes de Lyapunov}

No caso de funções contínuas e diferenciáveis em $\mathbb{R}^{n}$ é possível calcular-se o espectro de expoentes de Lyapunov. Toma-se um hiper-elipsóide em torno de um ponto e observando-se sua evolução pela função. Neste caso avalia-se a extensão (linear) de maior crescimento $\left(\lambda_{1}\right)$, a seguir avalia-se a área de 
maior crescimento $\left(\lambda_{1}+\lambda_{2}\right)$, a seguir o volume $\left(\lambda_{1}+\lambda_{2}+\lambda_{3}\right)$, etc. Assim obtém-se $n$ expoentes do espectro de Lyapunov.

Em outros termos pode-se dizer que os expoentes do espectro são as velocidades de afastamento em direções independentes ordenados da maior velocidade para a menor. Maiores detalhes podem ser encontrados em [FFP94].

Definição 4.1 Sensibilidade as condições iniciais é quando dada uma órbita $x$ tem-se $\lim _{i \rightarrow \infty} \Delta_{i}=\infty$ logo as imprecisões são amplificadas sem limites.

Esta sensibilidade é encontrada em muito sistemas naturais em certos pontos críticos, mas o mais interessante (observado inicialmente com Lorentz) é que muitos sistemas têm sensibilidade às condições iniciais em todas as órbitas do sistema (ou na maioria delas).

Sistemas dinâmicos $\mathrm{Na}$ física o uso de expoentes de Lyapunov é comum em sistemas definidos por equações diferenciais. A técnica computacional básica utilizada é a adoção de um passo finito (embora pequeno) e o tratamento das equações como funções iteradas, ou ainda pode-se usar cortes de Poincaré que na verdade transformam um sistema contínuo num discreto como as funções iteradas.

Porém o fato de termos equações diferenciais e portanto: funções diferenciáveis permite uma simplificação da definição dos expoentes de Lyapunov. Onde utilizamos o $\Delta_{i} / \epsilon$ usa-se a derivada da função: $\left|d\left(F^{i}\left(x_{0}\right)\right) / d x\right|$ ou ainda melhor: $\left|d\left(F\left(x_{i}\right)\right) / d x\right|$ (notada como $\left.\left|F^{\prime}\left(x_{i}\right)\right|\right)$ :

$$
\lambda(x)=\lim _{N \rightarrow \infty} \frac{1}{N} \sum_{i=0}^{N-1} \log _{2}\left|F^{\prime}\left(x_{i}\right)\right|
$$

No caso multidimensional a situação é um pouco mais complicada numericamente ${ }^{5}$.

Precisão O expoente de Lyapunov nos dá uma medida das imprecisões geradas pela iteração da função. Uma interpretação muito adequada é das casa de precisão: vamos supor que uma função iterada tem a variável $x$ descrita por um número finito de bits:

$$
x=w_{0} w_{1} \cdots w_{k}, w_{k+1} \cdots w_{n}
$$

\footnotetext{
${ }^{5}$ Recomendamos [FFP94].
} 
e também um expoente de Lyapunov $\lambda>0$ associado. A cada iteração $\lambda$ bits são comprometidos por imprecisões que são menores que a representação adotada. Ou seja a cada iteração perdemos $\lambda$ bits de precisão. Se o expoente for zero manteremos nossa precisão e se for negativo esta aumentará (eliminando ruídos rapidamente).

\section{Como evitar a imprecisão caótica}

A imprecisão denotada por expoentes de Lyapunov positivos é difícil de ser evitada. Uma estratégia possível é estimar o número de iterações desejados e se adotar representações com $k+\lambda . n$ bits de precisão, onde $k$ é o número final de bits de precisão desejado e $n$ é o número de iterações.

Para expoentes grandes a técnica acima pode ser inviável, daí podemos lançar mão da função(ões) inversa(s) de $f$ para avaliar trajetórias. Estas terão seus expoentes revertidos e ganharão precisão em cada iteração. O problema está na multiplicidade das inversas e na explosão exponencial de possibilidades para as iterações anteriores. Porém lidar com um número de soluções ou possibilidades que cresce exponencialmente é uma atividade muito mais comum em ciência da computação do que com uma perda de precisão exponencial.

No [PS88] vemos este método usado para os conjuntos de Julia-Fatou (MIIM no texto referido) para evitar o cálculo de órbitas divergentes.

\section{Considerações adicionais}

Se tivermos um sistema com expoente de Lyapunov positivo a pergunta natural é: "faz sentido calcularmos numericamente comportamentos a longo prazo neste sistema?" A resposta não é imediata, mas parece apontar na direção da negativa, pois as imprecisões tendem a destruir a informação original das órbitas estudas. Ou em outras palavras: se começamos com semente $x_{0}, x_{n}=f^{n}\left(x_{0}\right)$ terá tantos erros acumulados (para $n$ grande) que dificilmente pode-se avaliar alguma propriedade de $x_{0}$.

Porém existe uma característica adicional: o lema da sombra (Shadowing Lemma). É um princípio que nos permite um ataque, pelo menos estatístico em espaços métricos completos, ao problema da perda de precisão.

Proposição 4.1 (lema da sombra) [PJS92] Seja o(x) uma órbita e $f$ uma função com $\lambda>0$ então depois de um número suficiente de iterações $n$ a função $f$ calculada com uma precisão finita causará: $\tilde{x}_{k}=f^{k}(x) \neq x_{k}$ (onde $x_{k}$ é o valor correto, calculado com precisão infinita), mas o $\tilde{x}_{k}$ calculado é 
uma boa aproximação de $z_{k}\left(d\left(\tilde{x}_{k}, z_{k}\right)<\epsilon\right)$ onde $z_{k}$ é elemento da órbita $o\left(z_{0}\right)^{6}$.

Em outras palavras o lema nos diz que o ponto que calculamos com precisão finita não corresponde à $k$-ésima iteração da semente, mas corresponde a $k$-ésima iteração de outra órbita! Daí pode-se trabalhar com a avaliação da órbita (mesmo com precisão finita) para fins estatísticos.

Porém quando o expoente de Lyapunov é grande a finitude do sistema de representação se manifesta muito rápido e todas as órbitas serão periódicas.

\subsection{Visualização e cálculo de órbitas}

O cálculo de órbitas apresenta uma complexidade semelhante à do cálculo da função $f$ em si. Para permitir um estudo de comportamentos a médio e longo prazo privilegiamos funções fáceis de serem calculadas, com isso os pontos mais interessantes são a avaliação de propriedades e a visualização. Quer como cálculos de elementos de mapas, forma de avaliação de orbitas individuais, ou ainda como maneira de reconstruir um atrator estranho o cálculo de órbitas tem uma estrutura simples: iterar a função dada.

Algumas órbitas apresentam interesse maior (por exemplo o destino de pontos críticos) enquanto em outros sistemas a avaliação de uma órbita em particular não nos diz nada pela perda de precisão do sistema, mas todas as órbitas acabam convergindo a um atrator, logo como ferramenta de levantamento de um atrator podemos utilizar a avaliação direta de órbitas em sistemas com expoentes de Lyapunov positivos.

Quando avaliadas em mapas as órbitas precisam de condições auxiliares de parada ou de um limite de iterações baixo (neste caso o $k$-mapa pode não aproximar bem o mapa em questão). As condições de parada são uma ferramenta largamente utilizada, especialmente na avaliação da convergência (mais abaixo).

\subsubsection{Questão numérica}

$\mathrm{Na}$ avaliação numérica da evolução de órbitas indicadores como o expoente de Lyapunov são técnicas específicas para lidar com problemas de perdas de precisão intrínsecas. Em espaços menos sofisticados (em relação a $\mathbb{R}^{n}$ ) não se deve tentar usar o espectro de Lyapunov, e sim somente seu maior expoente.

\footnotetext{
${ }^{6}$ Mais formalmente, para qualquer $\epsilon>0$ existe um $z_{0}$ tal que $z_{k}=f^{k}\left(z_{0}\right)$ (com $f$ calculada com precisão infinita) é próximo do $\tilde{x}_{k}$ dado: $d\left(\tilde{x}_{k}, z_{k}\right)<\epsilon$.
} 
Uma forma interessante e eficiente de se combater a perda de precisão em funções com expoente de Lyapunov é:

\section{Iteração Inversa}

A técnica de iteração inversa resolve o caso de funções que divergem rapidamente e funções com sensibilidade às condições iniciais. O problema principal fica com a obtenção da inversa, que em si já é muito complicado.

Vamos supor o caso que $f$ admite $n$ inversas: $f_{1}^{-1}, f_{2}^{-1}, \ldots, f_{n}^{-1}$. Se a inversa é única, podemos encará-la como uma função inversa normal e iterar sem problemas. Agora quando $n>1$ como lidar com a 'explosão' do número de caminhos possíveis? Vamos considerar a árvore $(\operatorname{com} n=2)$ :

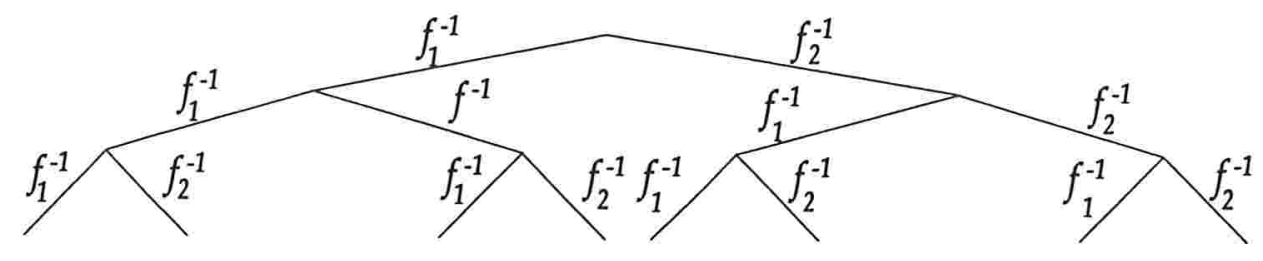

Arvore de possibilidades da $f^{-1}$

Nela podemos utilizar varreduras (ou passeios) para percorrer os ramos. A utilidade deste sistema é mais evidente em sistemas divergentes, pois então temos um critério de corte (ou parada): quando os pontos na órbita inversa não se distanciam mais do que $\epsilon$.

Em outros casos limita-se a profundidade ou desenvolve-se um outro critério de parada adequado à função em questão. Vejamos como percorrer a árvore:

Varredura Aleatória Pode-se decidir quais ramos percorrer por uma varredura aleatória: a cada iteração sorteia-se qual será a inversa adotada e ignora-se as alternativas. Este método não costuma ser eficiente ou mesmo razoável. Deve ser usado com muito cuidado, pois os resultados não caracterizam bem o comportamento do sistema.

Varredura em Profundidade Este método costuma dar bons resultados com pouco gasto de memória, mas a condição de parada tem que ser bem escolhida para não prolongar demais os cálculos. 
Varredura em Largura Também gera bons resultados, tem a vantagem de ser menos dependente de condições de parada especiais, problemas: volume muito grande de pontos armazenados nos cálculos (na fila de espera).

Técnicas de varredura organizadas funcionam muito bem em sistemas conhecidos e de inversa bem definida (mesmo que seja múltipla).

Uma das características mais importantes da técnica é o ponto de início (um $x_{k}$ arbitrário). Como escolher? Depende de novo do sistema: se houverem conjuntos de não divergência vale a pena cercá-los com pontos e estudar o destino de cada um destes. Para certos conjuntos esta técnica foi muito bem estudada como em [PS88]. Em casos de funções divergentes na maioria dos pontos basta tomar um ponto inicial afastado da bacia de atração do atrator finito.

\subsubsection{Visualização}

A visualização de órbitas e/ou de suas propriedades, pode parecer à primeira vista um campo bem acabado onde todos os problemas de interesse já foram resolvidos, mas não há dúvidas quanto a capacidade das imagens geradas de suscitarem dúvidas, sugerirem propriedades de sistemas etc. A força destas imagens, que atingem igualmente pesquisadores e leigos, já levou alguns matemáticos menos remunerados a abandonarem a carreira pela de artistas plásticos, com exposições que dão voltas no mundo.

Afastando-nos do efeito das imagens, temos a utilização das mesmas como ferramenta, para avaliar o comportamento de um sistema de maneira sintética e global. Permitindo uma proximidade maior dos modelos de equações e dos fenômenos estudados (nas ciências naturais) e fornecendo um modelo visual de comportamento em sistemas abstratos (na matemática, por exemplo), onde às vezes não se tem nenhuma visualização do comportamento do sistema disponível.

Além de ser uma ferramenta de visualização científica, a visualização das órbitas apresenta alguns desafios computacionais interessantes, que não aparecem em um exame menos minucioso. A questão da precisão (já apresentada teoricamente) e técnicas de combate a caoticidade; a constante batalha contra a explosão exponencial; procedimentos de varredura especiais para geração de imagens são apenas alguns tópicos que podem ser estudados neste campo.

Além das possibilidades de desenvolvimento de pesquisa o conhecimento sobre as técnicas de geração das imagens permite uma interpretação mais aprofundada dos mesmos. 


\subsubsection{Eficiência espaço-temporal}

O estudo da eficiência dos algoritmos de avaliação e visualização de órbitas ainda é pouco explorado. Parte pela avaliação das órbitas ficar em segundo plano em relação ao cálculo das funções iteradas propriamente ditas. Por exemplo na matemática aplicada privilegia-se funções que convergem em poucas iterações, estas são bastantes sofisticadas, as órbitas aí não tem tanto significado quando nos fixamos em poucas iterações e uma característica específica das funções iteradas: a convergência.

Em outros casos vale a pena desenvolver algoritmos para avaliar órbitas, embora normalmente as questões sejam simples o tipo de avaliação às vezes nos leva a problemas específicos.

\section{Armazenar x Iterar}

A avaliação de órbitas com um número considerável de iterações pode ser feita armazenado-se todos os pontos da órbita ou iterando-a até a obtenção do resultado desejado.

Tomemos como exemplo uma órbita tridimensional que deve ser mostrada em uma tela bidimensional. Em muitos casos não vale a pena armazenar os pontos da órbita, pode-se recalculá-la sempre que necessário, pois o número de pontos a serem armazenados e tratados é muito grande. Já se os pontos da órbita forem pré-processados para alguma estrutura de dados mais sintética aí podemos manipular o resultado da iteração diretamente.

Num caso mais concreto podemos ter um sistema de equações diferenciais ordinárias com solução aproximada por uma função iterada. Neste caso a variação suave no caminho das órbitas (mesmo que a imprevisibilidade esteja presente) nos sugere a possibilidade de utilizar curvas (como splines) para aproximar um grande número de pontos na órbita. Uma vez avaliadas estas curvas a manipulação da órbita calculada é bastante facilitada.

\subsubsection{Cálculo de propriedades}

O cálculo de propriedades depende muito de algoritmos específicos a cada propriedade estudada. As mais comuns: convergência/divergência e periodicidade. 


\section{Detecção de divergência}

Muitos sistemas de funções iteradas tem um limite claro a partir do qual o sistema diverge certamente, um exemplo claro é o conjunto de Mandelbrot de $f(x)=x^{2}+c$, para o qual as órbitas divergem sempre que $x$ ou $c$ tiverem módulo maior ou igual à 2 .

Outro recurso é usar números muito grandes (próximos da precisão utilizada) para limites de parada, pois as funções que divergem costumam, fazê-lo exponencialmente. Ou ainda o afastamento entre pontos da órbita pode ser usado, assim que ele atinge um passo de crescimento exponencial é muito difícil que a órbita não divirja.

\section{Deteç̧ão de periodicidade}

Este caso é mais sofisticado, dependendo se estamos lidando (teoricamente falando) com espaços como $\mathbb{R}^{n}$ ou $\mathbb{Z}^{n}$. No primeiro caso a aproximação finita feita no computador pode no máximo sugerir a periodicidade, sendo que todos testes devem ser encarados como uma indicação e não uma certeza de periodicidade da órbita.

Nos espaços discretos a deteç̧ão é mais fácil (Se estes forem representados exatamente), mas ainda temos o problema de qual método é o mais adequado, especialmente levando em conta que o número de pontos a serem testados é grande.

Caso seja escolhido o método imediato: de guardar todos os pontos da órbita e comparar cada novo com os anteriores podemos ter um tempo elevado: podemos simplesmente comparar cada ponto com os anteriores sem nenhum preparo: $\mathrm{O}\left(n^{2}\right)$; mesmo que com técnicas consiga-se reduzir este tempo o gasto de memória será $O(n)$ ou mais.

Como comparação apresentamos um algoritmo que descobre a periodicidade em tempo finito e usando memória constante:

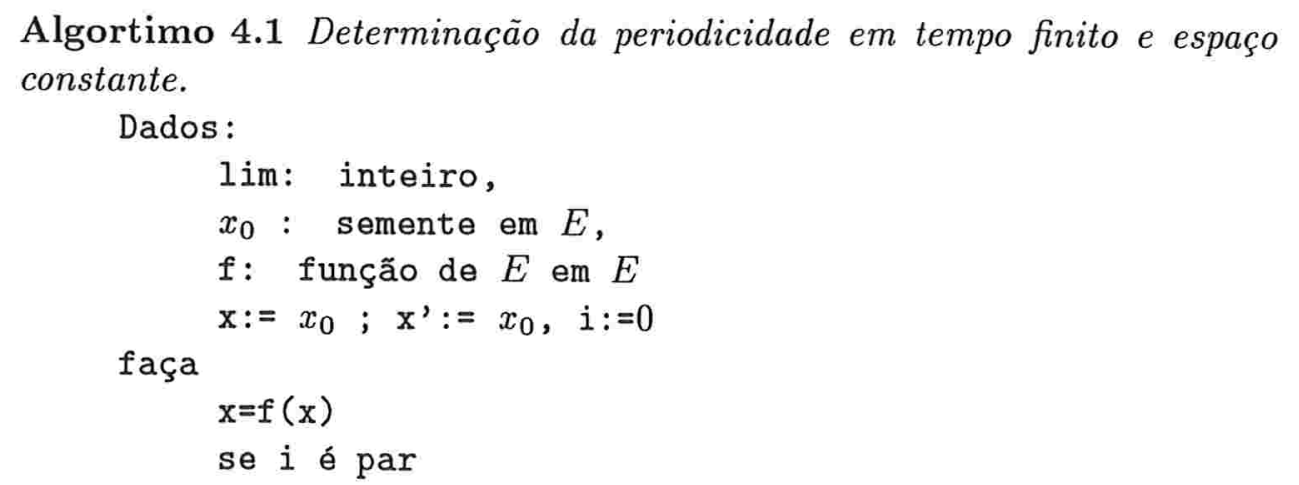




$$
\begin{array}{r}
x^{\prime}=f\left(x^{\prime}\right) \\
\text { até } x=i+1 \\
x^{\prime} \text { ou } i>l i m
\end{array}
$$

Se terminamos com i>lim não se pode afirmar nada (pois a órbita pode ser aperiódica) caso contrário temos a certeza de que a orbita que inicia em $x_{0}$ é periódica. Este algoritmo usa espaço de memória constante e tem tempo linear no número de iterações (ou lim ou o tamanho do período encontrado) executando assimptoticamente no pior caso (todas órbitas aperiódicas) $\frac{3}{2}$ lim cômputos de $f^{7}$.

E quanto tempo ele demora para detectar uma órbita periódica? Tomemos uma órbita com período $p$ então após atingirmos a parte periódica temos uma seqüência: $x_{0}, x_{1}, \ldots, x_{p-1}, x_{p}=x_{0}, x_{1}=x_{p+1}, \ldots$ Enquanto a avaliação da órbita está sendo feita temos uma seqüência da mesma órbita sendo avaliada em paralelo. Supondo que esta segunda seqüência também atingiu a parte periódica (avaliaremos isso a seguir) temos (com $\Delta$ representando a defasagem entre as seqüências):

\begin{tabular}{ccccccccccc} 
Seq. & $\Delta$ & 0 & 1 & $\ldots$ & $p-1$ & $p$ & $p+1$ & $\ldots$ & $2 p-2$ & $2 p-1$ \\
\hline $\mathbf{x}$ & - & $x_{0}$ & $x_{1}$ & $\ldots$ & $x_{p-1}$ & $x_{0}$ & $x_{1}$ & $\ldots$ & $x_{p-2}$ & $x_{p-1}$ \\
$\mathrm{x}^{\prime}$ & 0 & $x_{0}$ & $x_{0}$ & $\ldots$ & $x_{\left\lfloor\frac{p-1}{2}\right\rfloor}$ & $x_{\left\lfloor\frac{p}{2}\right\rfloor}$ & $x_{\left\lfloor\frac{p+1}{2}\right\rfloor}$ & $\ldots$ & $x_{p-1}$ & $x_{p-1}$ \\
$\mathrm{x}^{\prime}$ & 1 & $x_{p-1}$ & $x_{0}$ & $\ldots$ & $x_{\left\lfloor\frac{p-2}{2}\right\rfloor}$ & $x_{\left\lfloor\frac{p-1}{2}\right\rfloor}$ & $x_{\left\lfloor\frac{p}{2}\right\rfloor}$ & $\ldots$ & $x_{p-2}$ & $x_{p-1}$ \\
$\mathbf{x}^{\prime}$ & 2 & $x_{p-1}$ & $x_{p-1}$ & $\ldots$ & $x_{\left\lfloor\frac{p-3}{2}\right\rfloor}$ & $x_{\left\lfloor\frac{p-2}{2}\right\rfloor}$ & $x_{\left\lfloor\frac{p-1}{2}\right\rfloor}$ & $\ldots$ & $x_{p-2}$ & $x_{p-2}$
\end{tabular}

Como podemos caracterizar os valores $\mathrm{x}$ e $\mathrm{x}^{\prime}$ comparado no fim do laço

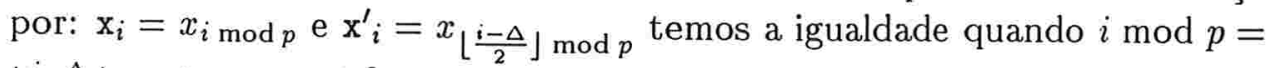
$\left\lfloor\frac{i-\Delta}{2}\right\rfloor \bmod p$, ou $\operatorname{seja}^{8}, i=2 p-1-\Delta$ é o ponto da primeira coincidência entre as séries.

Agora retornando à parte pré-periódica temos: a série $\mathrm{x}$ é avaliada $2 r$ vezes (onde $r$ é o comprimento da parte periódica) enquanto a $x^{\prime}$ é avaliada até o primeiro período. Daí pode-se usar os cálculos acima e no pior caso demoramos: $2 r+2 p-2$ (se a defasagem for zero o encontro se dará mais cedo). Logo com o dobro da soma do comprimento das partes pré-periódicas e do período temos o limitante deste algoritmo.

Se aliviarmos um pouco a necessidade de detectar logo a periodicidade (como no caso anterior) podemos evitar recomputar a f. Este é o caso de

\footnotetext{
${ }^{7}$ Se optássemos por armazenar os cômputos anteriores teríamos um gasto de memória de $\lceil n / 2\rceil$ variáveis, ou seja, $\mathrm{O}(n)$.

${ }^{8}$ Resolvendo para o menor $i>0$, já que o algoritmo começa da mesma semente
} 
outro algoritmo desenvolvido por Mark Peterson e o Stone Soup Group e implementado no programa Fractint ${ }^{9}$. É baseado nas funções:

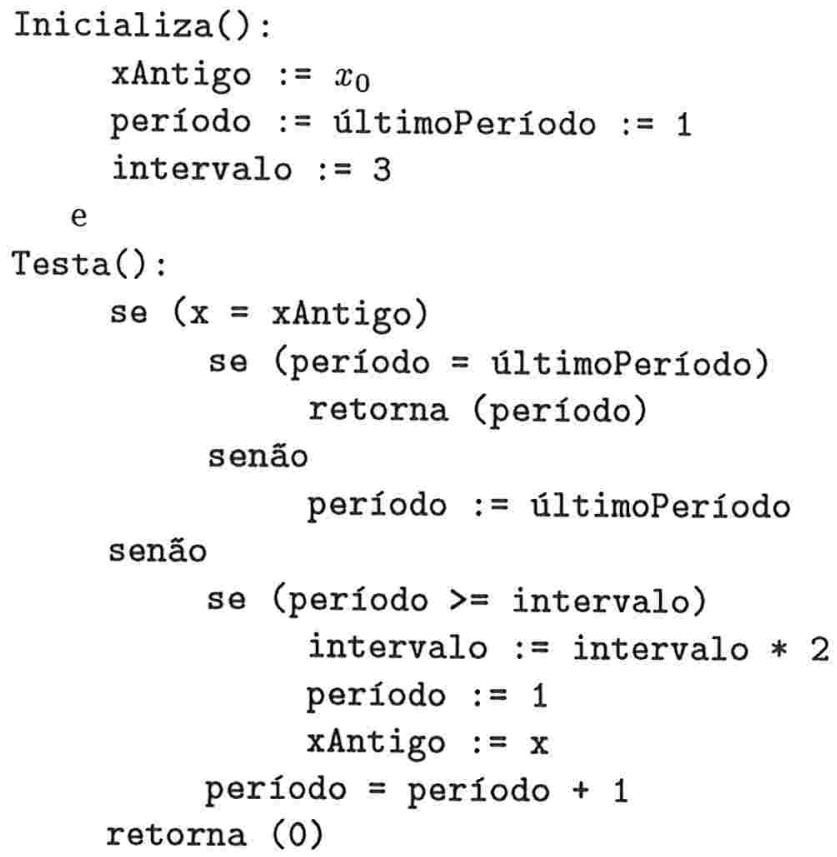

Antes da iteração da órbita chama-se Inicializa() e após cada cálculo executa-se Testa(). Se esta devolver um valor maior que zero um período foi detectado.

Este algoritmo demora mais a detectar períodos do que o anterior, mas evita computar $f$. O intervalo marca quantas iterações esperamos antes de tomar um novo elemento para comparação e ele cresce exponencialmente para detectar períodos de qualquer tamanho sem onerar o processamento. Uma possível otimização é eliminar a espera pela confirmação do período (dentro do primeiro se).

\subsection{Visualização e cálculo de mapas}

Em sistemas mais sofisticados algumas órbitas são suficientes para extrairmos informações a respeito de todo sistema, mas isto depende da estrutura de cada caso. No caso geral, onde não conhecemos o comportamento de uma

\footnotetext{
${ }^{9}$ Uma descrição mais detalhada pode ser vista no [PW91, pg. 276] ou mesmo no códigofonte do programa (disponivel em vários pontos da Internet e BBS, veja apêndices).
} 
função iterada a priori, mapas são a melhor maneira de se avaliar o comportamento geral do sistema. Mesmo quando o comportamento de uma função iterada é parcialmente conhecido novas características e comportamentos são trazidos à tona com o uso e a visualização de mapas.

É também nos mapas que novas facetas da auto-semelhança são trazidas á tona. Trechos supostamente independentes de um mapa de uma função mostram grandes semelhanças sugerindo propriedades ainda não exploradas e novas idéias por trás dos fractais representados.

A idéia não é nova: visualizar o comportamento de uma função para conhecê-la melhor, mas alguns fatores acrescentam novas técnicas e surpresas interessantes neste caso. Optamos por fazer um apanhado geral das técnicas nesta seção por ser um campo com conhecimento muito pulverizado, sendo difícil encontrar em um único trabalho um guia das técnicas utilizadas na visualização de mapas.

\subsubsection{Questão numérica}

A precisão no cálculo de mapas segue basicamente a das órbitas.

\subsubsection{Visualização}

$\mathrm{Na}$ visualização de fractais (ou de mapas) utilizam-se uma série de conceitos, muitas vezes implícitos, para obter imagens do comportamento das funções estudadas.

Um elemento muito empregado hoje é a função cor: $f: \mathbb{N} \rightarrow[0 ; 1]^{3}$, que relaciona um índice (nos $N$ ) a uma tripla de reais entre 0 e um inclusive. Esta tripla representa uma cor em algum modelo de cores $\left(\mathrm{RGB}^{10}\right.$ é típico, mas pode-se usar o HSB, HSL e até mesmo o Lab, para uma discussão detalhada da cor em computadores vide [TRA91]).

Com a função cor, obtém-se uma (ou mais dependendo da escolha do modelo de cor) 'dimensão' adicional na visualização de mapas. Esta é comumente associada a uma propriedade das órbitas avaliadas ou no caso da visualização de órbitas pode ser usada para indicar a densidade de pontos em regiões do espaço ou para dar a noção de profundidade em telas bidimensionais.

Para tornar eficiente a visualização tem-se lançado mão da LUT ${ }^{11}$ também conhecida como palette. A LUT funciona associando índices a triplas

\footnotetext{
${ }^{10}$ indica as porcentagens da três cores primárias: Vermelho (Red), Verde (Green) e Azul (Blue).

${ }^{11}$ Look Up Table, ou tabela de consulta.
} 
RGB, por exemplo em placas de vídeo típicas, temos uma LUT de 256 entradas (baseada em índices de 8 bits):

\begin{tabular}{|c||c|c|c|}
\hline Ind & Red & Green & Blue \\
\hline \hline 0 & 0.3 & 0.6 & 1.0 \\
\hline 1 & 0.1 & 0.2 & 0.0 \\
\hline 2 & 0.8 & 0.0 & 0.3 \\
\hline$\cdots$ & $\cdots$ & $\cdots$ & $\cdots$ \\
\hline 255 & 0.0 & 0.0 & 0.0 \\
\hline
\end{tabular}

Existe também uma quantização ${ }^{12}$ das triplas RGB em um certo número de bits (tipicamente 3 ou 8), que varia conforme os modos de vídeo e placas utilizados.

Como a LUT é finita (e normalmente pequena para os valores de índices produzidos na avaliação de mapas) costuma-se tornar a função cor periódica com o módulo do tamanho da LUT: $f(i)=L U T_{\left(i \bmod 2^{n}\right)}$ onde $L U T_{p}$ é o $p$-ésimo elemento da LUT e $2^{n}$ é o tamanho da LUT (com índices de $n$ bits). Isto causa um efeito ruim quando estuda-se mapas com a propriedade de tempo de escape com um limite de iterações alto. Uma alternativa é usar uma "compressão" logarítmica da LUT: $f(i)=L U T_{\left\lfloor\log _{m}(i) * 2^{n}\right\rfloor}$ onde $m$ é o número máximo de iterações.

Por exemplo, uma imagem hipotética (armazenada como um mapa de índices) é visualizada assim:

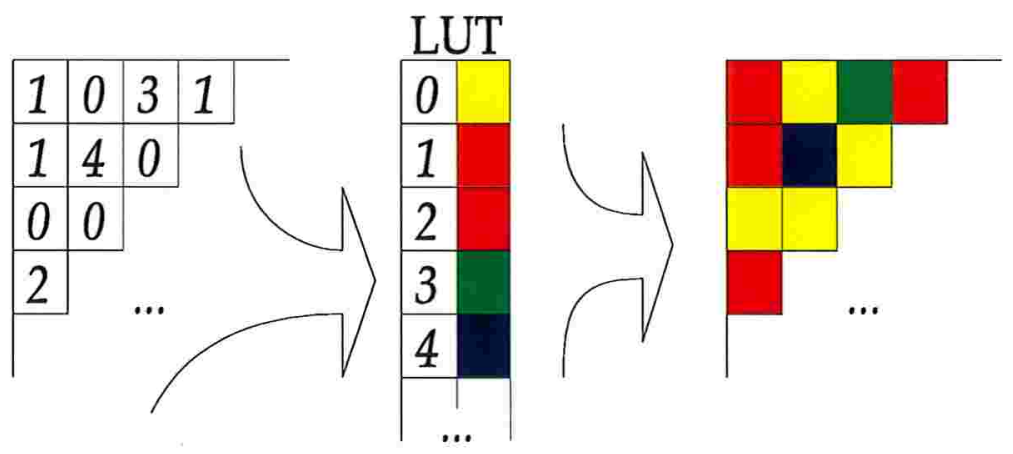

A LUT em ação na visualização de um mapa de índices.

Outra alternativa é aplicar uma função cor arbitrária e sintetizar a imagem diretamente, porém desta forma é mais difícil interagir com a escolha de cores aplicada, já que somos obrigados a recalcular, pelo menos, as novas

\footnotetext{
${ }^{12}$ Quantificação em valores discretos.
} 
cores da imagem a cada alteração na função cor.

\subsubsection{Eficiência espaço-temporal}

Diferente das órbitas, nos mapas é raro armazenarmos as órbitas associadas a cada ponto do mapa. A razão é simples: espaço de memória e adicionalmente não são feitas muitas manipulações que necessitem dos valores dos pontos nas órbitas calculadas, porém com o aumento da capacidade das memórias dos computadores isto pode ser revertido.

$\mathrm{O}$ armazenamento de um mapa normalmente ocupa um espaço diretamente proporcional ao número de pontos presentes no mesmo.

O cálculo dos mapas depende exclusivamente da avaliação da órbita de cada ponto presente, algumas técnicas de varredura (mais sobre isso abaixo) permitem eliminar alguns pontos (embora isso cause perdas na imagem gerada, estas são pequenas em relação ao tempo ganho) e são usadas durante a experimentação inicial. Outras reordenam os pontos para dar uma idéia geral da imagem final antes da avaliação de todos os pontos (métodos progressivos ou por refinamento).

\subsubsection{Cálculo de propriedades}

$\mathrm{Na}$ avaliação de mapas a escolha de propriedades é o primeiro passo para a implementação dos algoritmos de visualização.

\section{Tempo de escape}

Também conhecida como teste de convergência, esta é a avaliação mais comum e uma das mais simples de se implementar, mas pode revelar características interessantes dos mapas estudados.

O algoritmo básico é:

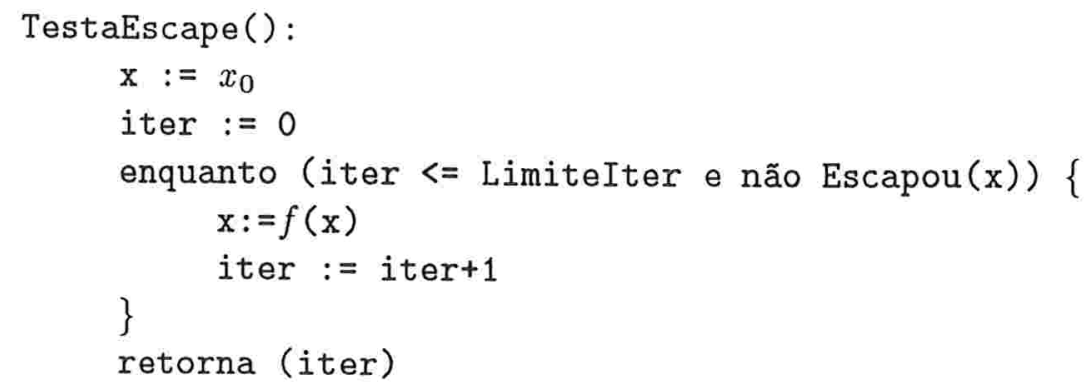


Onde Escapou() é uma função específica de cada $f$ que diz quando a variável $\mathrm{x}$ escapou, ou seja, está divergindo (indo ao infinito), ou ainda pertence a bacia de atração do infinito.

A função Escapou ( $x$ ) típica é: $|x|>\operatorname{Lim}$, por exemplo no conjunto de Mandelbrot de $f(x)=x^{2}+c$ a função é $|x|>2$, pois com o módulo de $x$ acima de 2 a órbita divirgirá não importa o $c$.

Considerando-se um espaço com o elemento "infinito" adicionado (como a esfera de Reimann $\hat{\mathbb{C}}$ ) pode-se tratar a função Escapou $(x)$ como um teste de convergência ao infinito.

Ao término da rotina TestaEscape() é retornado em qual iteração foi encerrado o laço central e esta é usada para indicar o quão rápido os pontos 'escapam' (ou convergem ao infinito). Este índice é em geral associado a um índice de uma LUT para geração da imagem do mapa.

Assim temos a rotina de visualização:

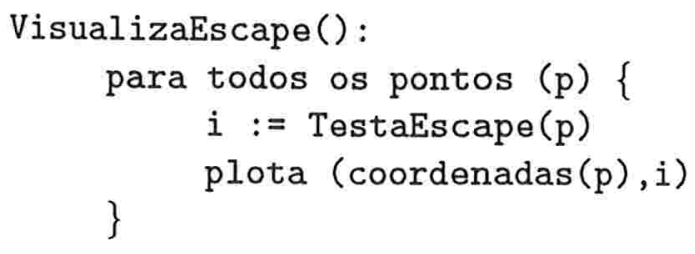

Os pontos que não divergem podem pertencer à uma bacia de atração finita ou divergirem muito lentamente para o número de iterações usado como limite (LimiteIter no TestaEscape)

Embora use a função $f$ direta as imagens de tempo de escape tem características interessantes relacionadas à(s) função(ões) inversa(s) de $f$. Nota-se em uma imagem gerada que as bacias de atração finitas ficam no centro de regiões encaixadas ${ }^{13}$ em uma progressão que acaba chegando a uma grande região de pontos que escapam do limite em uma iteração:

\footnotetext{
${ }^{13}$ Quando a função $f$ tem comportamento contrativo em alguma parte do espaço.
} 


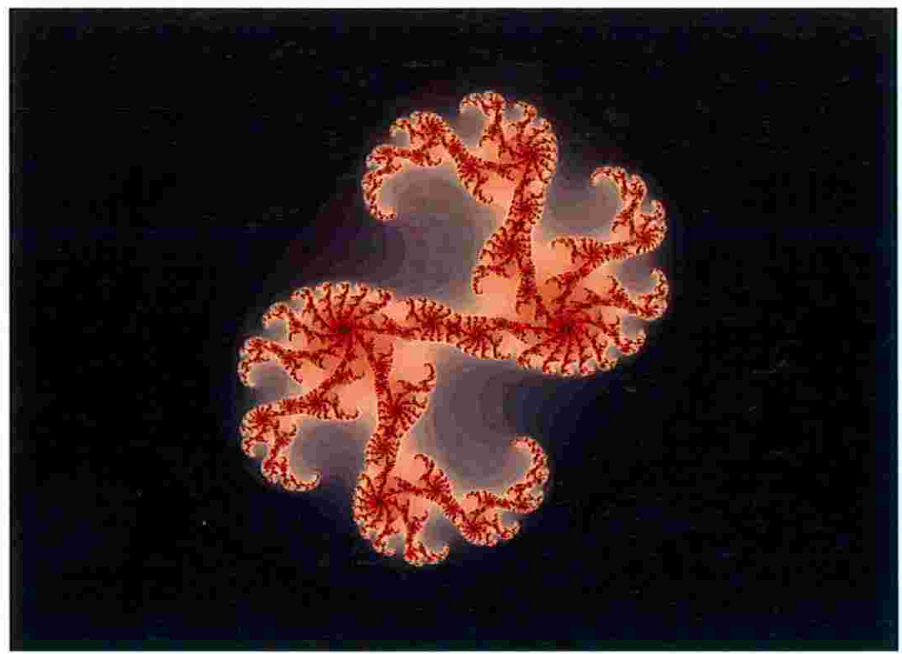

Imagem de tempo de escape de $f(x)=\lambda x(1-x) \operatorname{com} \lambda=0,85+0,6 i$

Estas regiões encaixadas são pré-imagens umas das outras, ou seja a partir de uma região formamos a seguinte (interior a ela) pela aplicação de $f$ a todos os pontos dela. Vejamos o seguinte exemplo: Geramos a imagem acima várias vezes aumentando o LimiteIter pouco a pouco e pode-se ver a formação das regiões:
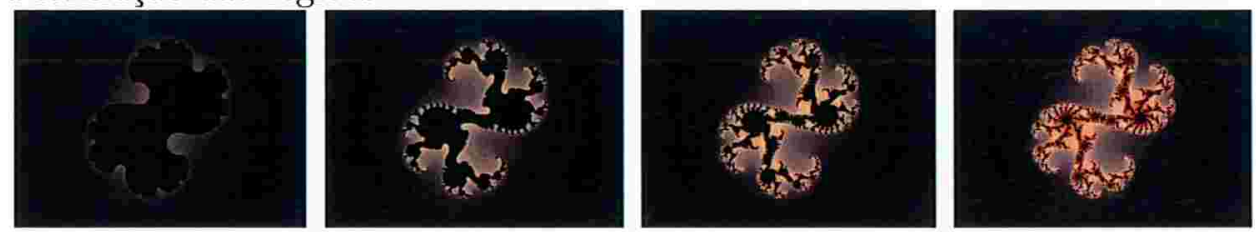

Estas imagens acima são $k$-mapas que aproximam o mapa estudado e permitem vermos a função $f$ atuando em um conjunto de pontos. Seja $F(A)=\{f(x) / \forall x \in A\}$ (ou seja a função $f$ aplicada a conjuntos de pontos do espaço) e seja $L=\{x / x \in E$ e Escapou( $x$ ) é verdadeira $\}$ o conjunto de pontos dentro do limite de convergência de bacias de atração finitas (no exemplo de Mandebrot acima citado é o círculo de centro 0 e raio 2 em $\mathbb{C}$ ou $\hat{\mathbb{C}}$ ). Então temos cada região como um conjunto que é uma pré-imagem do conjunto $L$. Ou seja, para a primeira região $R_{1}$ tomamos $F\left(R_{1}\right)$ e obtemos $L, F\left(R_{2}\right)=R_{1}$ e assim por diante. A forma de $L$ determina a aparência das $R_{i}$ e vemos isso no exemplo a seguir:

Exemplo 4.1 Triângulo de Sierpinski com diferentes testes de divergência

Na figura a imagem do conjunto de Sierpinsky (com um triângulo retângulo de lado 1) em imagens de tempo de escape com testes de escape dados por um círculo, um quadrado e um triângulo. 


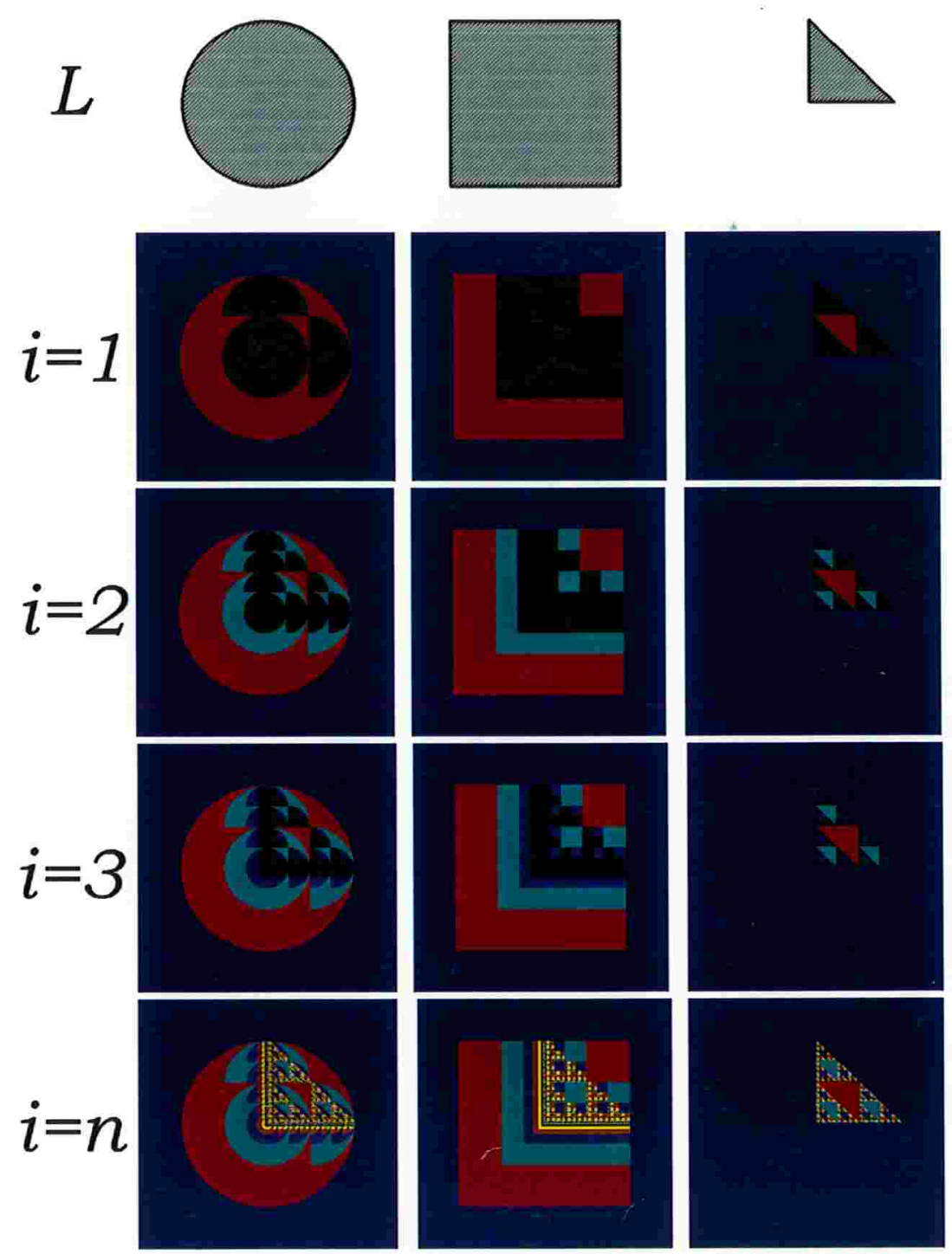

Imagens de tempo de escape do triângulo de Sierpinsky 
Pode-se notar que com o conjunto do triângulo como teste de escape fica-se com uma imagem que esconde a natureza de $L$ : um limitante das iterações.

Podemos interpretar ainda como a iteração da inversa de $F$ (e não de $f$ que pode ter várias inversas): $F^{-1}(L)=R_{1}, F^{-1}\left(R_{1}\right)=R_{2}$ etc. ou em geral: $\left(F^{-1}\right)^{i}(L)=R_{i}$ para $i>=1$.

\section{Periodicidade}

Outra propriedade interessante é a periodicidade, mas que complica bastante os algoritmos utilizados. Caso seja desejada somente a avaliação se as órbitas são ou não periódicas o algoritmo apresentado na seção anterior é suficiente. Caso deseje-se saber o tamanho do período somos obrigados a armazenar cada órbita e a medida em que esta é gerada testar se os pontos já foram visitados ${ }^{14}$.

A partir disto temos o algoritmo:

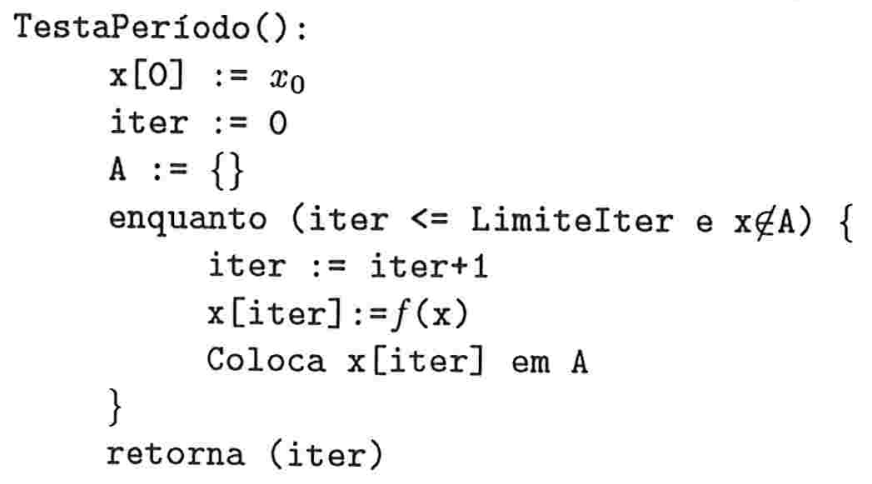

$O$ problema é o teste de inclusão em um conjunto: $x \notin A$ e do comando Coloca $x$ [iter] em A que têm, em boas implementações, complexidade $\mathrm{O}(\log n)$ se usarmos um hash bem feito ${ }^{15}$ estas duas operações levam algo próximo de tempo constante, mas não temos a mesma eficiência dos mapas de tempo de escape.

\footnotetext{
${ }^{14}$ Note que para isso usar o operador de igualdade embutido nas linguagens de programação não é suficiente. São dois problemas: a precisão do computador é finita e podemos erroneamente concluir que uma órbita é periódica quando não é; nas representações de ponto flutuante em computadores é arriscado usar a igualdade, pois podemos demorar a ou mesmo não identificar pontos iguais. Para contornar estes dois problemas normalmente usa-se uma margem de tolerância na qual dois pontos são considerados iguais: $|x-y|<\epsilon$.

${ }^{15}$ Aqui a representação dos números em ponto flutuante pode ser de grande valia.
} 
O espaço ocupado também aumenta, pois devemos armazenar toda a órbita, e ainda as estruturas de dados que implementam o teste de pertinência $\mathrm{x} \notin \mathrm{A}$. No caso de um hash genérico gasta-se além dos $n$ pontos da órbita: $2 n$ elementos na tabela de hash. E a visualização se processa da mesma forma que no tempo de escape.

Existe uma variante que é bastante usada em funções contrativas de $\mathbb{R}$ em $\mathbb{R}$ que é armazenar os últimos $p$ pontos da órbita e mostrá- los em um gráfico como se fossem o período. Isso permite um ganho de eficiência temporal significativo, embora ainda obrigue ao armazenamento de $p$ pontos da órbita.

Esta variante é utilizada em modelo de estudo de populações em ecologia, como no exemplo 2.3 na página 35.

\section{Expoentes e indicadores}

Outra possibilidade é avaliarmos expoentes ou indicadores (no sentido genérico de propriedades das órbitas) para cada ponto no mapa.

Um dos expoentes mais avaliados é o de Lyapunov (discutido anteriormente). A avaliação de expoentes não introduz nenhum detalhe novo na implementação de programas para visualização.

\section{Decomposições}

Uma técnica introduzida no [PR86, pág. 41] é a de decomposição binária do plano complexo, na qual utiliza-se o conceito dos conjuntos de nível (são as pré-imagens, ou conjuntos encaixados da discussão acima) e de decomposição na base 2 do ponto final avaliado.

$\mathrm{O}$ algoritmo é o seguinte:

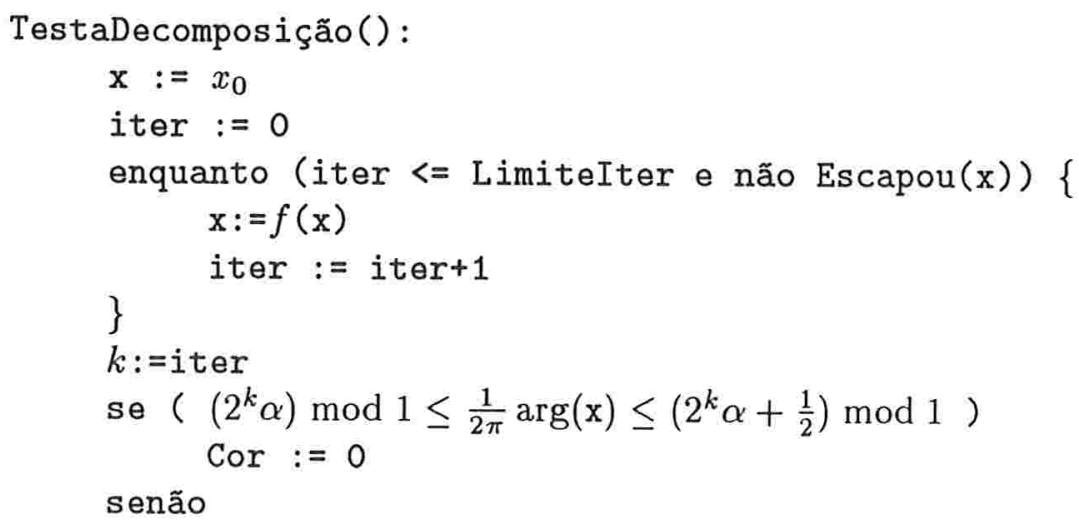




\section{Cor $:=1$ \\ retorna (Cor)}

Onde $\alpha$ é um ângulo de referência (contra o qual se quer medir a decomposição) normalmente 0 . O termo $\frac{1}{2 \pi} \arg (\mathrm{x})$ é o ângulo do ponto $x$ normalizado em $[0 ; 1]$. Se este estiver entre 0 e $1 / 2$ então colorimo-o de branco (ou a cor número 0) caso contrário de preto (ou a cor número 1).

\section{Exemplo 4.2 Decomposição binária}

Vamos verificar a imagem do conjunto de Mandelbrot de $f(x)=x^{2}+c$ com a decomposição binária:

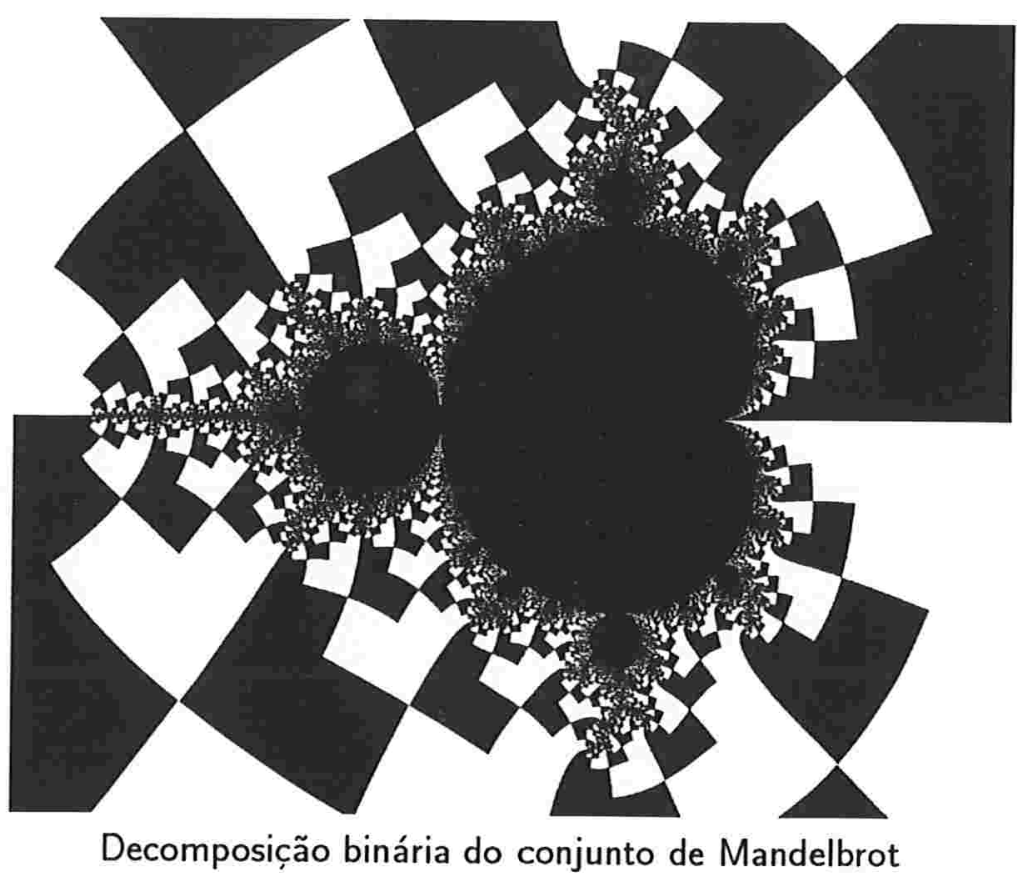

Nota-se as fronteiras das curvas de nível a cada vez que as faixas brancas e pretas ( 0 e 1 ) fundem-se.

As imagens construídas com a decomposição binária são especialmente úteis para estudo de transformações polinomiais no plano complexo indicando, por exemplo, os ângulos externos internos dos mapas.

Uma variante interessante é de se tomar uma decomposição $n$ - ária com $n$ grande ou tomarmos a função cor variando com $\arg (x)$ (o ângulo de $x$ ) isto nos dá um diagrama do 'angulo de escape': 


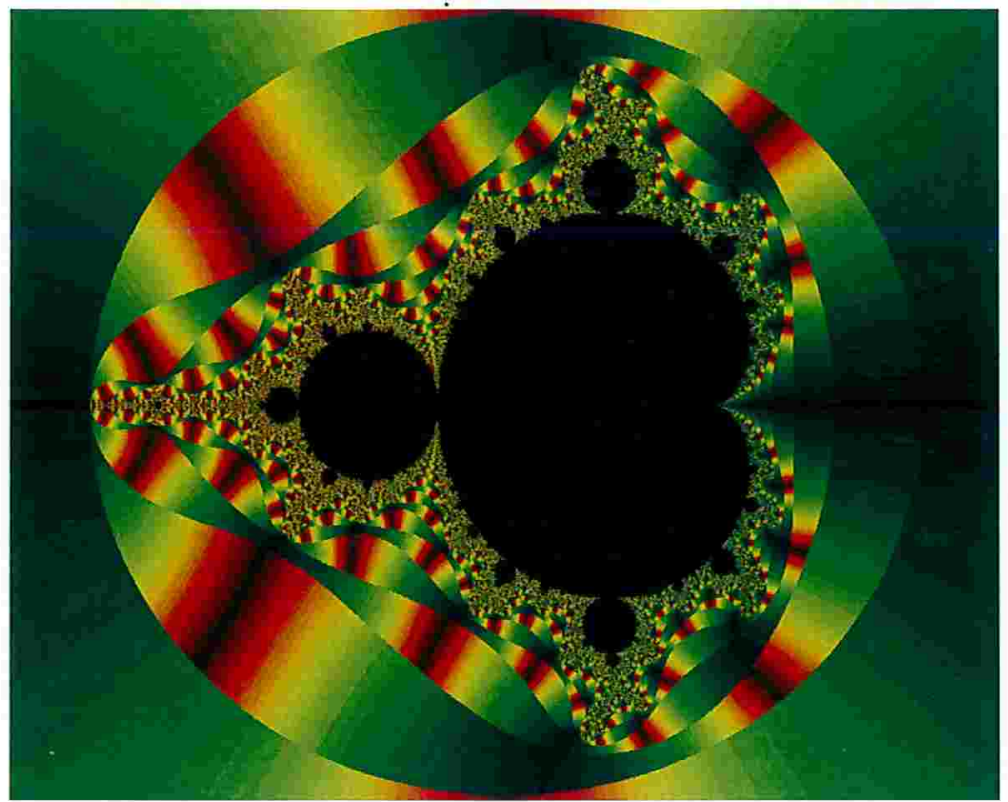

Ângulo de escape do conjunto de Mandelbrot

Neste diagrama marca-se em qual ângulo o ponto escapa (para isso normalmente usa-se um limite de divergência bem maior que o convencional).

\section{Potencial Contínuo}

Supondo que um conjunto no espaço está carregado com uma carga elétrica podemos avaliar o campo elétrico a sua volta. É interessante poder desenhar as linhas de força equipotenciais, já que a medida que o potencial vai se aproximando do potencial do conjunto as linhas equipotenciais o limitam mais de perto.

Com essa idéia [PS88, pág. 187] constrói-se a função de potencial contínuo que marca o "potencial elétrico" em volta de um conjunto como o de Mandelbrot para $f(x)=x^{2}+c$ no plano complexo.

$\mathrm{O}$ potencial é aproximado pela fórmula:

$$
\operatorname{Pot}(x)=\frac{\log \left(f^{k}(x)\right)}{2^{k}}
$$

onde $k$ é a iteração na qual terminou-se a execução do laço de cálculo da órbita. O algoritmo fica então:

TestaPotencial():

$\mathrm{x}:=x_{0}$ 


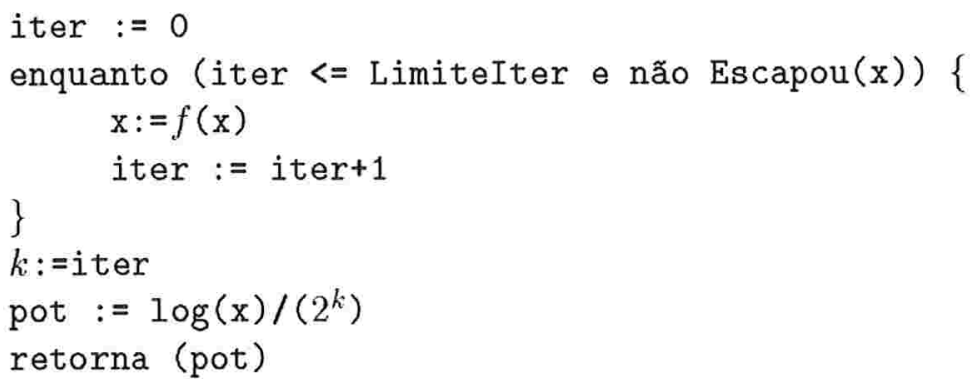

Neste caso o teste Escapou $(\mathrm{x})$ utilizado no tempo de escape costuma ser inadequado. Os valores utilizados para decidir se a órbita diverge ou não são bem maiores ${ }^{16}$.

Por exemplo, vejamos o conjunto de Mandelbrot de $f(x)=x^{2}+c$ desenhado com o potencial contínuo interpretado como "altura" em uma superfície tridimensional:

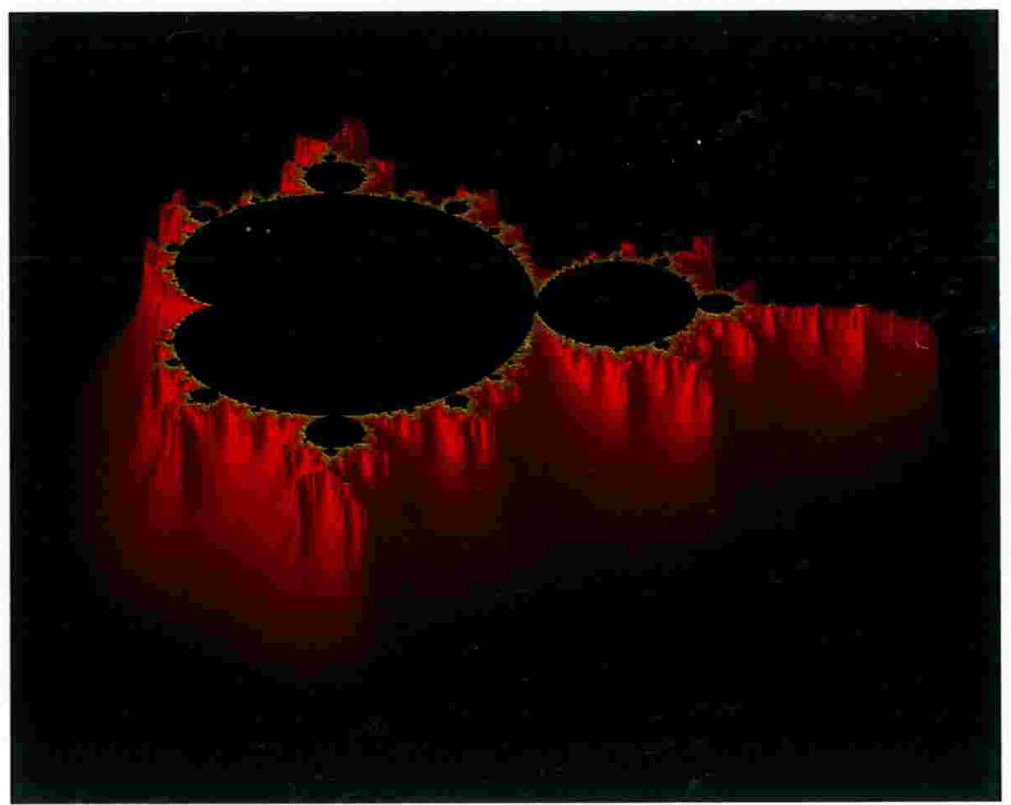

Visão tridimensional do conjunto de Mandebrot com potencial contínuo.

Nesta imagem utilizamos uma iluminação artificial para realçar o efeito de relevo do conjunto.

\footnotetext{
${ }^{16}$ Como referência temos no conjunto de Mandelbrot de $f(x)=x^{2}+c$ um bom teste quando $|x|>2$, já na avaliação do potencial contínuo utilizam-se testes como $|x|>600$.
} 


\subsubsection{Cálculo e Visualização de IFS}

No cálculo de IFS lineares (dados por matrizes de transformação) usa-se uma técnica conhecida como RIA ${ }^{17}$ e é muito similar a Iteração Inversa com Varredura Aleatória, mas aqui o fazemos de maneira a aumentar a eficiência na geração do atrator.

Dado um IFS com $n$ operadores de Hutchinson $w_{i}$ (são a multiplicação por uma matriz $A_{i}$ e a soma de um vetor de deslocamento $t_{i}$ ) pode- se percorrer o atrator (já que o sistema é contrativo) pela aplicação das $w_{i}$ em um ponto arbitrário, o problema é a multiplicação de pontos. A técnica RIA consiste em escolher uma das transformações $w_{i}$ baseado em um peso específico $p_{i}$ (que é traduzido como a probabilidade de escolhermos aquele operador)

Por exemplo, sejam os $w$ em $\mathbb{R}^{2}$ da forma:

$$
w_{i}\left(\begin{array}{l}
x \\
y
\end{array}\right)=\left(\begin{array}{ll}
a & b \\
c & d
\end{array}\right)\left(\begin{array}{l}
x \\
y
\end{array}\right)+\left(\begin{array}{l}
e \\
f
\end{array}\right)
$$

E criamos um IFS pela tabela de $w$ :

\begin{tabular}{cccccccc}
\hline $\mathrm{w}$ & $\mathrm{a}$ & $\mathrm{b}$ & $\mathrm{c}$ & $\mathrm{d}$ & $\mathrm{e}$ & $\mathrm{f}$ & $\mathrm{p}$ \\
\hline 1 & 0 & 0 & 0 & 0,16 & 0 & 0 & 0,01 \\
2 & 0,85 & 0,04 & $-0,04$ & 0,85 & 0 & 1,6 & 0,85 \\
3 & 0,2 & $-0,26$ & 0,23 & 0,22 & 0 & 1,6 & 0,07 \\
4 & $-0,15$ & 0,28 & 0,26 & 0,24 & 0 & 0,44 & 0,07 \\
\hline
\end{tabular}

Simplesmente iterando $w_{i}$ com um $i$ escolhido de acordo com as probabilidades $p_{i}$ tem-se a geração do atrator do IFS. A presença dos $p_{i}$ é para aumentar a eficiência da distribuição dos pontos no atrator. Vejamos duas imagens com o mesmo número de pontos calculados do mesmo IFS acima, uma com todos $p_{i}=0,25$ e a outra com os $p_{i}$ acima:

\footnotetext{
${ }^{17}$ Random Iteration Algorithm ou Algoritmo de iteração aleatória
} 


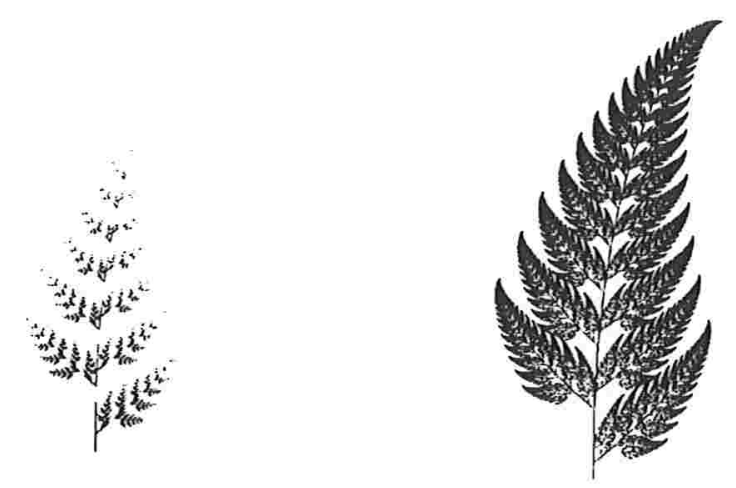

Uso de probabilidades na geração de um IFS

A forma mais imediata de aferir os $p_{i}$ adequados é se usar o valor absoluto do determinante da matriz de transformação normalizado, ou seja:

$$
p_{i} \approx \frac{\left|\operatorname{det} A_{i}\right|}{\sum_{i=1}^{n}\left|\operatorname{det} A_{i}\right|}
$$

Esta solução é razoável contanto que o determinante da matriz em questão não seja nulo, neste caso, usa-se um valor pequeno dependente da resolução de saída.

\subsubsection{Estratégias de varredura}

Os mapas podem ser gerados de diversas formas, mas todas envolvem a varredura ordenada dos pontos que são estudados. No caso mais comum (pela existência de dispositivos de saída baratos: os monitores) a visualização é bidimensional e a maior parte das técnicas é voltada para este caso. Quando deseja-se extrapolar isso para maiores dimensões (para estudar uma imagem volumétrica por exemplo) somente poucos métodos são adequados. Em particular o advento de computadores acessíveis e programas de geração de imagens fractais (cujo maior expoente é sem dúvida o Fractint do Stone Soup Group) aumentou a necessidade de utilização de técnicas incrementais ou interativas. A maior parte das técnicas existentes na computação gráfica não é adequada pois não prevê a avaliação exaustiva de todos os pontos na imagem. A única exceção é na área de visualização (rendering) por raytracing (e mais recentemente radiosidade), mas nestes casos acaba-se ou indo a um processo de "rascunho" de resolução baixa ou modelo de arame (wireframe) ou um processo de qualidade final em processamento por lote (batch). 


\section{Linear por linha-e-coluna}

A técnica mais imediata de varredura é a 'natural': varre-se os pontos de uma linha da esquerda para a direita e passa-se a seguinte:

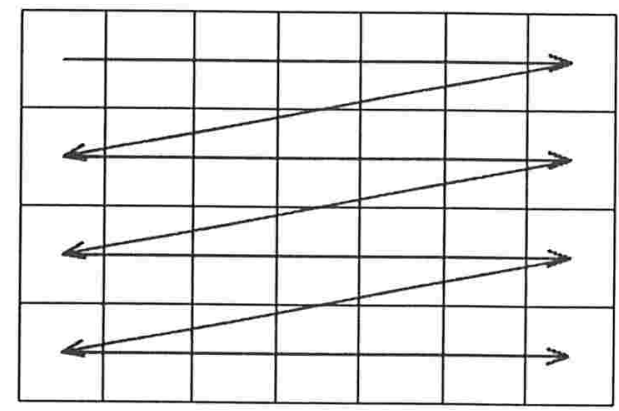

A varredura dos pixels da imagem

O overhead para avaliação desta varredura é mínimo (um incremento e um teste de comparação de inteiros que cabem em palavras da máquina em média por pixel avaliado).

Infelizmente o método é inadequado para processo interativos já que somente a porção superior da imagem proporcional ao número de iterações feitas é apresentada. Com mais dimensões (em imagens volumétricas já é suficiente) a situação fica pior. Esta técnica é recomendada para codificação rápida e processos não interativos.

\section{Por quadratura}

Um método antigo de varredura, a quadratura é uma boa técnica, embora sofra de alguns problemas similares à varredura linear. Trata-se de dividir um retângulo (ou hipercubo) ao meio (por uma dimensão) e novamente (por outra) e assim sucessivamente. A técnica original era destinada a procura de elementos em planos (ou hipercubos) mas foi adaptada para gerar imagens com perdas.

A técnica de geração consiste em traçar o contorno do plano calculando todos os pontos neste, se o contorno for inteiro da mesma propriedade (cor) ele é preenchido com esta e termina-se o cálculo, caso contrário: dividi-mo-lo em duas metades calculando os pontos das duas colunas centrais, se todos os pontos em algum dos dois retângulos forem iguais preenchemo-o caso contrário prossegue-se com a divisão: 

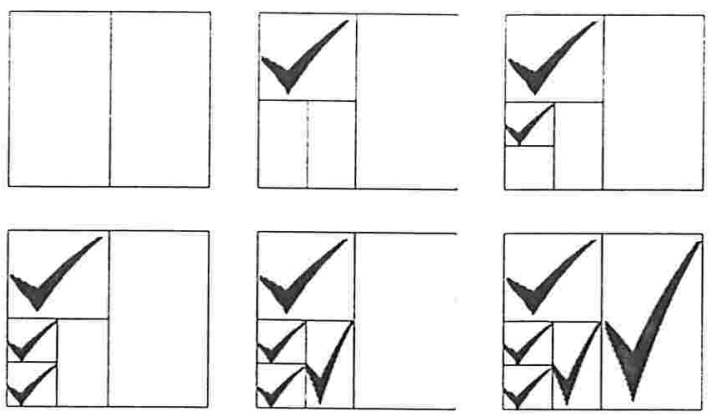

Cálculo de uma imagem por quadratura

Um problema óbvio é que se existem detalhes no interior de retângulos estes são ignorados, além deste método ter um overhead de processamento e armazenamento razoáveis.

\section{Por blocos}

No desenvolvimento do Fractint foi criado um método batizado de 'solidguessing'. A idéia é montar uma grade sobre o plano e ir refinando-a, se os quatro pontos que formam um dos retângulos componentes da grade tiverem a mesma cor ou propriedade preenche-se o bloco e não refinamos mais, caso contrário passa-se ao refinamento. Esta técnica pode ser implementada muito mais facilmente que a anterior, mas também perde alguns detalhes. Como as grades não são escolhidas com um espaçamento grande o resultado é aceitável e como calcula-se $(1 / 4)^{n}$ pontos do total para uma grade de ordem $n$ (isto é uma grade com espaço entre os pontos de $n$ pixels). A cada nova passagem calcula-se 3 vezes mais pontos que a anterior se não houver nenhum refinamento, como isto não acontece os resultado obtidos são bons.

Com a geração de uma imagem e três passos (digamos) avaliando-se somente $(1 / 4)^{3}=1 / 64=1,5625 \%$ dos pontos pode-se ter uma visão grosseira da imagem, com dois passos completados avaliamos no máximo $25 \%$ da imagem e o efeito obtido é bastante bom: 


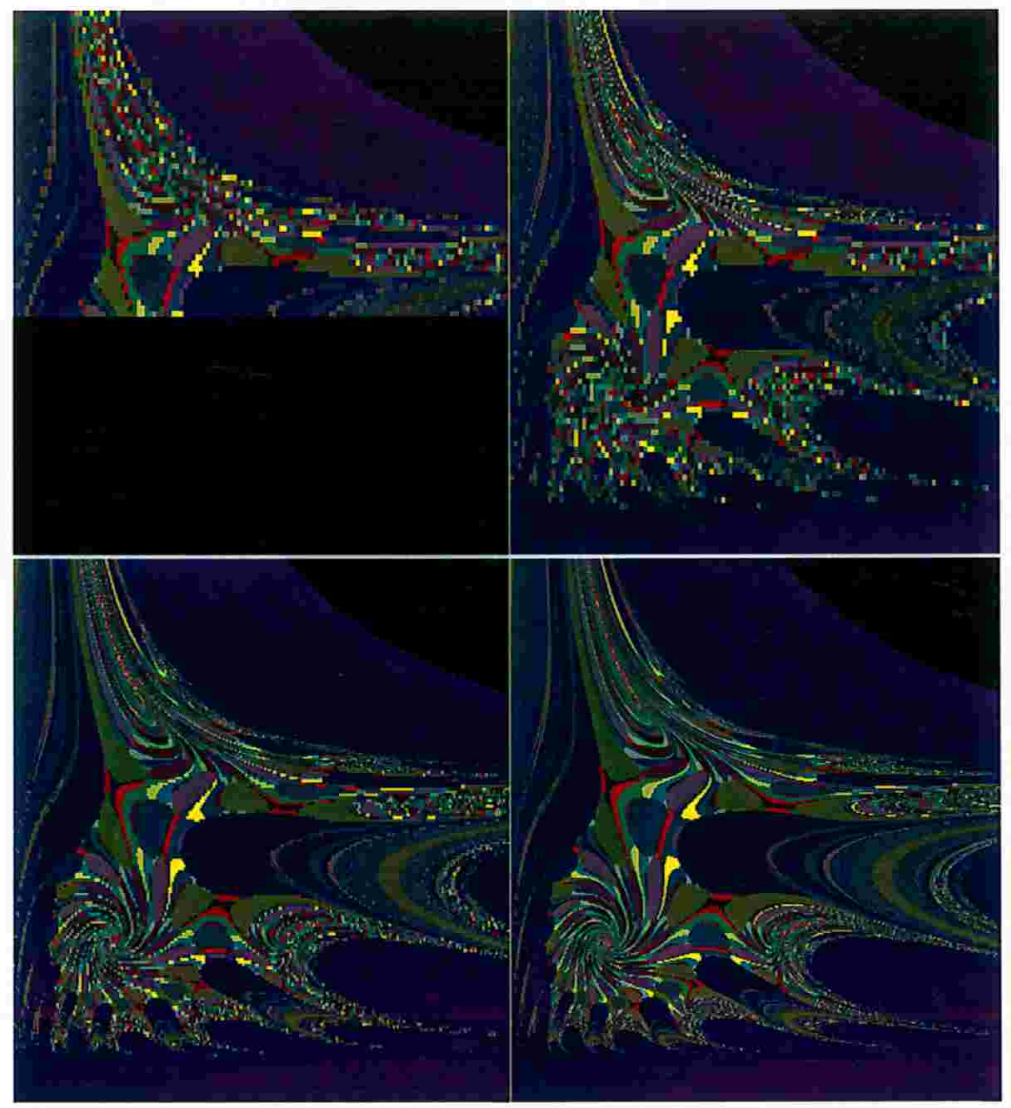

Acima temos uma imagem de um modelo predador-presa de LotkaVolterra onde o método de solig-guessing refina a imagem em quatro passos. No primeiro passo vemos a imagem na primeira passagem com os pontos de referência (que são usados para saber se uma região será refinada ou não) sendo desenhados. em todas imagens o método está com uma das passagens incompleta.

\section{Por traçado de borda}

Outra técnica oriunda provavelmente dos algoritmos de traçado de borda para identificação de contornos em imagens é a varredura por traçado de borda.

O algoritmo consiste em acompanhar a fronteira dos conjuntos de nível (ou as fronteiras dos conjuntos de pontos com a mesma propriedade) e preencher se interior. Tem-se o mesmo problema da varredura por quadratura, mas a implementação é mais simples e o método é mais controlável. 
A idéia é triangular o plano e avaliar cada triângulo na borda de um dado conjunto:

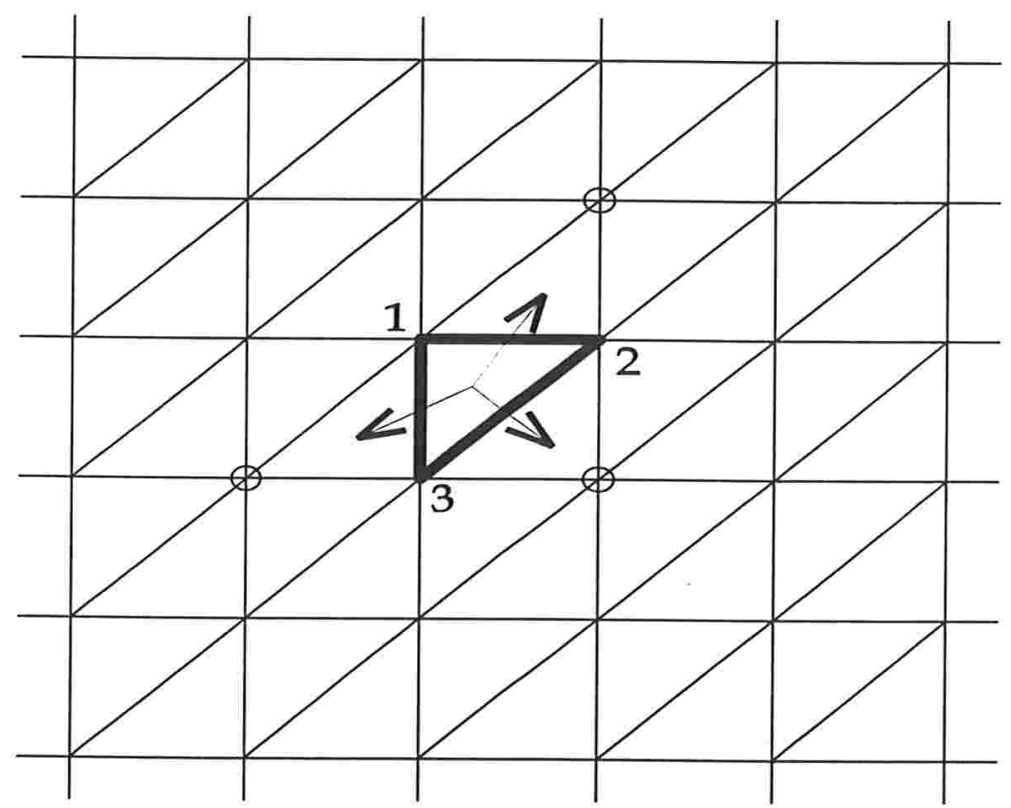

Possibilidades de movimento de um triângulo para os adjacentes

Alguns fatos fazem o método funcionar: marcando os vértices (1,2 e 3$)$ de qualquer triângulo com 0 se ele estiver fora do conjunto e 1 se estiver dentro, ele terá: todos os vértices iguais ou dois vértices iguais. Os triângulos com exatamente dois vértices iguais são chamados de completamente marcados, estes têm a seguinte propriedade: sempre têm como vizinhos pelo menos dois outros triângulos completamente marcados (TCM para abreviar).

Logo o algoritmo consiste em duas fases: procurar por um TCM; encontrado o $\mathrm{TCM}_{0}$ escolher um lado arbitrário e seguir para o TCM adjacente $\left(\mathrm{TCM}_{1}\right)$, como um dos vizinhos do $\mathrm{TCM}_{1}$ é o $\mathrm{TCM}_{0}$, seguimos para o outro vizinho o $\mathrm{TCM}_{2}$, e assim por diante. Caso seja encontrada a borda da janela da imagem, volta-se a procurar pot outro TCM, caso encontre-se o $\mathrm{TCM}_{0}$ em algum ponto da iteração é sinal que pode-se preencher uma área com todos os pontos (quer fora quer dentro do conjunto).

Abaixo vemos uma imagem gerada com o traçado de borda sem preencher as regiões interiores e preenchendo. Note-se que foi necessário escolher um enquadramento adequado, caso contrário o traçado de borda ignoraria o conjunto de Julia no interior. 

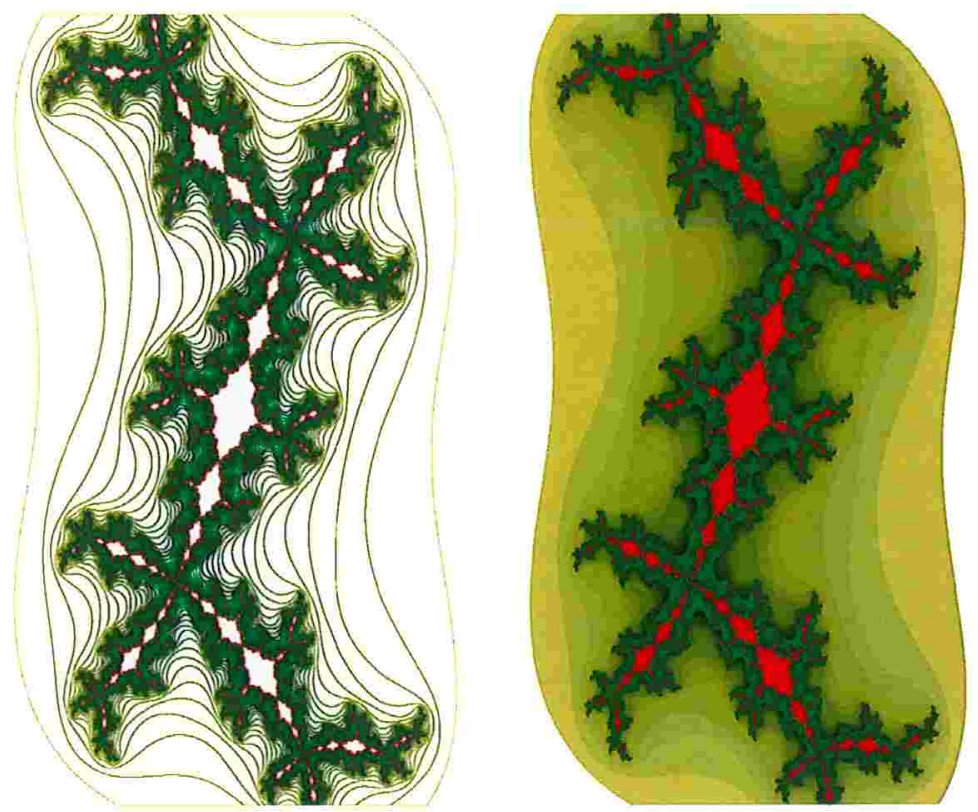

Conjunto de Julia de $x^{2}+c$ pelo traçado de borda (sem e com preenchimento)

\section{Pela função distância}

Em alguns casos na avaliação de convergência - e não tempo de escape (como no conjunto de Mandelbrot para $f(x)=x^{2}+c$ em [PS88, pag. 288]) pode-se estabelecer uma função distância para o o conjunto de pontos não divergentes $A$. Esta função não precisa ser exata, mas basta apresentar uma desigualdade (ou fornecer um disco que está necessariamente fora do conjunto $A$ ):

$$
D: E \rightarrow \mathbb{R}^{+} \text {e o disco } \delta(x, D(x)) \cap A=\emptyset
$$

A partir disto vai-se marcando uma região do plano (embora o método possa ser usado em espaços com mais ou menos dimensões) com discos que eliminam da computação diversos pontos (todos no interior do disco têm a mesma propriedade: divergem).

O método é bastante flexível e pode ser usado para avaliação de outras propriedades embora dê uma resposta simples (sim ou não) em contrasta com outros métodos que oferecem uma gama de resultados para as propriedades. Mas apesar de não calcular todos os pontos oferece uma imagem correta das propriedades estudadas. O problema é que é necessário criar uma função distância para cada $f$ estudada o que limita seriamente a aplicação do método. 


\section{Por difusão}

Uma técnica desenvolvida pelo autor ${ }^{18}$ que é inspirada nos métodos de dithering (simulação de tons intermediários) é a de difusão. O método consiste em usar uma função de enumeração $E n: \mathbb{N} \rightarrow\{0 . . n-1\} \times\{0 . . m-1\}$ de todos os pontos da região a ser avaliada que tenha as seguintes características:

- visite todos os pontos

- visite cada ponto uma vez

- cada ponto visitado deve esta o mais afastado possível dos demais (já avaliados)

Os itens (i) e (ii) são necessários para constituirmos uma função de enumeração dos pontos eficiente e (iii) é uma característica para gerarmos uma imagem com detalhes progressivamente maiores.

A figura 4.1 mostra a geração de uma imagem progressivamente pela técnica de difusão, da esquerda para a direita, de cima para baixo: 1, 4, 16,$32 ; 64,128,256,1024 ; 4096,16384,64536$ iterações e a imagem final (respectivamente $0,0004 \%, 0,002 \%, 0,006 \%, 0,012 \% ; 0,025 \%, 0,05 \%, 0,1 \%$, $0,39 \% ; 1,56 \%, 6,25 \%, 25 \%$ e $100 \%$ dos pontos calculados). Note que com $6,25 \%$ pontos calculados já é possível uma boa visão da imagem final e com $25 \%$ temos um detalhamento bastante bom.

A implementação do algoritmo envolve muitas manipulações com bits a cada iteração, mas pode-se evitá-las com tabelas de apoio o que deixa o algoritmo muito eficiente e provê a função desejada. Inclusive permitindo um preenchimento de quadrados progressivamente menores que irão cobrir toda a imagem sem erros.

Esta técnica é interessante pois permite uma visualização rápida e interação com a imagem parcialmente gerada (como no método por blocos) mas se for levada a cabo a geração da imagem todos os pontos terão sido avaliados (mesmo com o preenchimento de quadrados) corretamente.

É possível ainda utilizar-se esta técnica para um hipercubo de dimensão arbitrária sem problemas (embora para dimensões elevadas o uso de tabelas de aceleração possa se tornar impraticável).

\footnotetext{
${ }^{18}$ Aprovada para publicação na Computer $\&$ Graphics - Pergamon Press
} 


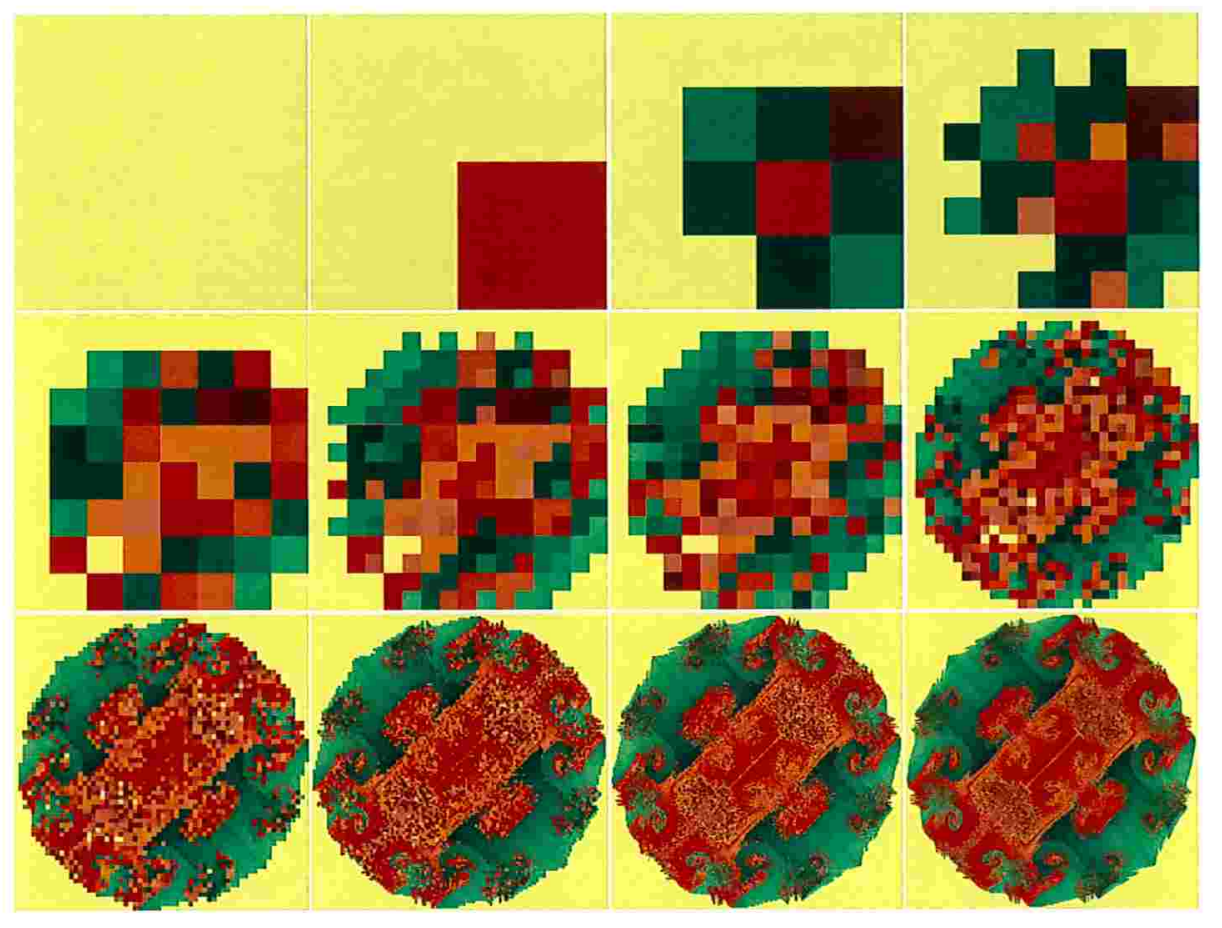

Figura 4.1: Algoritmo de varredura por difusão com preenchimento 


\subsection{Cálculo de dimensões e outros indicadores}

Algumas propriedades e indicadores são muito importantes e concentram muita informação sobre o sistema em si e permitem a montagem de bons modelos paramétricos de sistemas naturais estudados. Nesta seção apresentamos alguns dos algoritmos mais importantes para avaliação dos principais indicadores.

\subsubsection{Dimensões: Algoritmos e eficiência}

A avaliação de dimensões mais interessantes do ponto de vista matemático é no mínimo complicada. Basicamente por ter de lidar com definições abstratas como 'para todas as coberturas de abertos' etc. Algumas dimensões se prestam mais a cálculos numéricos, em particular: a de contagem de caixas e a de correlação.

\section{Algoritmo de Contagem de Caixas}

O cálculo da dimensão de contagem de caixas não é um procedimento complicado. Mas tem limitações sérias em espaços de maior dimensão (p.ex. $D_{E}>3$ ) pelo número de "caixas" envolvidas na contagem.

Basicamente usam-se duas técnicas: uma para dados sintetizados (a partir de uma $f$ conhecida) outra a partir de dados experimentais (amostrados).

Dados sintetizados Toma-se uma região do espaço na qual o conjunto alvo é contido, e passamos a dividi-la em grades de tamanho decrescente e contar as caixas que são ocupadas por elementos do conjunto estudado.

Uma tabela de número de caixas e tamanho da grade é feita com estes dados e monta-se uma regressão linear com os logaritmos das duas quantidades (ou melhor com o número de caixas e o inverso do tamanho da grade para ajustarmos o sinal da dimensão obtida).

A reta obtida pela regressão tem inclinação $\alpha$, que é exatamente a dimensão estimada $D_{C C} \rightarrow \alpha$.

Dados experimentais Os dados experimentais são quantizados para armazenamento e tratamento em computadores. Seja $\epsilon$ a menor unidade quantizável na representação escolhida dos dados (ou a precisão dos dados) para termos um mínimo de pertinência devemos tomar caixas de tamanho $2 \epsilon$ em diante. O processo ai se repete como no caso anterior, mas com uma es- 
colha conveniente (por exemplo $2^{n} \epsilon$ ) pode ser possível evitar a varredura dos dados em cada tamanho de caixas.

Em ambos os casos a questão é o tempo de varredura da grade, sempre $\mathrm{O}(m)$ (onde $m$ é o número de pontos na grade) e para espaços de dimensão $d$ temos um tempo de execução de $\mathrm{O}\left(n^{d}\right)$ onde $n$ é o número de pontos de cada dimensão do espaço. O espaço ocupado pelas estruturas de dados é proporcional ao número de contadores de caixas $(N(\epsilon))$.

\section{Algoritmo de Grassemberger-Procaccia para cálculo da Dimensão de Correlação}

$\mathrm{O}$ algoritmo de Grassemberger-Procaccia permite o cálculo de uma aproximação da dimensão de correlação notando que: $\log _{2} \sum_{i} p_{i}^{2}$ (a probabilidade de que dois pontos do conjunto estejam na mesma caixa) é aproximada pela probabilidade de que dois pontos do conjunto estejam separados por uma distância menor que $\epsilon$.

$$
\sum_{i} p_{i}^{2} \approx \lim _{N \rightarrow \infty} \frac{1}{N^{2}}\left\{\text { num. pares } i, j \operatorname{com} d\left(x_{i}, x_{y}\right)<\epsilon\right\} \equiv C(\epsilon)
$$

$\mathrm{E} C(\epsilon)$ é a integral de correlação:

$$
C(\epsilon)=\lim _{N \rightarrow \infty} \frac{1}{N^{2}} \sum_{i, j i \neq j} \theta\left(\epsilon-d\left(x_{i}, x_{j}\right)\right)
$$

onde $\theta$ é a função degrau de Heaviside, que é igual a um se seu parâmetro é positivo ou nulo e é igual a zero se seu parâmetro é negativo:

$$
\theta(x)= \begin{cases}1 & \text { se } x \geq 0 \\ 0 & \text { se } x<0\end{cases}
$$

Logo a dimensão de correlação é aproximada por:

$$
D_{2} \approx \lim _{\epsilon \rightarrow 0} \frac{\log C(\epsilon)}{\epsilon}
$$

A implementação direta deste algoritmo tem complexidade $\mathrm{O}\left(n^{2}\right)$ onde $n$ é o número de pontos avaliados. Existem outros métodos para reduzir o tempo de execução e tornar o algoritmo viável em espaços de maior dimensão. Outro ponto importante é que estamos supondo que se conhece a dimensão do espaço no qual os dados se inserem. Mas nem sempre este é o caso, e precisamos caracterizar o espaço mais adequado no qual o sinal deve ser estudado. Para maiores detalhes desta questão e de outros algoritmos [FFP94]. 


\section{Espectro de dimensões generalizadas}

Existe uma variante do algoritmo de Grassemberger-Procaccia que permite estimar o espectro de dimensões generalizadas. Este se baseia na generalização da integral de correlação:

$$
C_{q}(\epsilon)=\lim _{N \rightarrow \infty}\left[\frac{1}{N} \sum_{i=1}^{N}\left\{\frac{1}{N} \sum_{j=1, j \neq i}^{N} \theta\left(\epsilon-d\left(x_{i}, x_{j}\right)\right)\right\}^{q-1}\right]^{1 /(q-1)}
$$

Neste caso utiliza-se a integral generalizada $C_{q}$ de ordem $q$ para aproximar a dimensão de Renji $D_{q}$. Infelizmente a generalização dificulta ainda mais a implementação eficiente desta técnica, maiores detalhes em [FFP94].

\section{Relação com Expoente de Lyapunov}

Kaplan e York conjecturaram que os expoentes de Lyapunov podem se relacionar com a dimensão de contagem de caixas (o mais especificamente a dimensão generalizada de ordem 0 ) $D_{C C}$ (ou $D_{0}$ ) (definição na pag. 64 na seção 3.2 .2 ).

Tomemos a seguinte definição de $D_{K Y}$ a dimensão de Kaplan-York (também conhecida como dimensão de Lyapunov):

$$
D_{K Y}=j+\frac{\sum_{i=1}^{j} \lambda_{i}}{\left|\lambda_{j+1}\right|}
$$

onde $j$ é o maior inteiro tal que $\sum_{i=1}^{j} \lambda_{i}>0 . D_{K Y}$ pode ser visto como o ponto em que a curva $f(j)$ corta o eixo $x$. A curva é dada por $K(j)=\sum_{i=1}^{j} \lambda_{i}$ para $j \in\{1 . . n\}$ e entre os número inteiro interpolamos linearmente os valores intermediários:

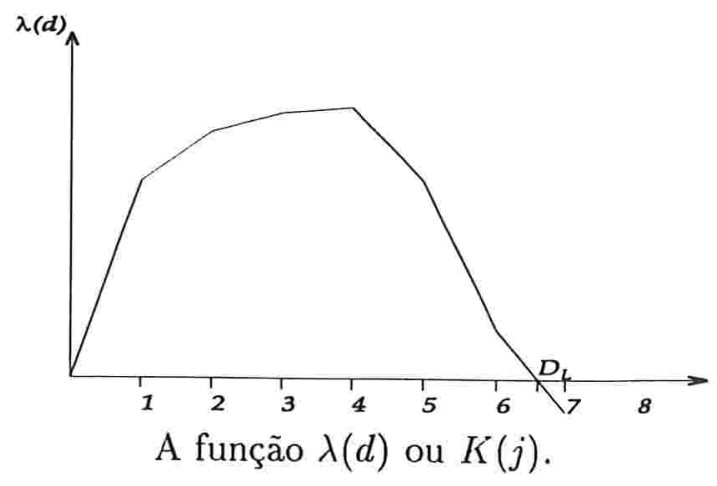


A conjectura diz que $D_{K Y}=D_{C C}$ e verificou-se uma boa correspondência com testes numéricos. Esta conjectura não é sempre válida, falhando em casos em que existe um processo de "dobra" (uma sobreposição de partes diferentes do espaço pela função iterada $f$ ) para maiores detalhes [FFP94, pag. 271].

\subsubsection{Outros Indicadores}

\section{Lyapunov}

Estimar o expoente (ou espectro de expoentes) de Lyapunov é bastante delicado. Em sistemas modelados por alguma função, pode-se tentar aproximações analíticas ou numéricas, mas é com sinais experimentais que reside a maior dificuldade de se estimar o expoente de Lyapunov.

Tanto em estimativas numéricas quanto em sinais experimentais a forma de estimar o expoente de Lyapunov é a mesma: avaliar a velocidade de afastamento de pontos vizinhos. No caso de sinais experimentais existe a complicação adicional que não temos várias medições simultâneas para comparar, então lança-se mão de uma técnica de comparação de sinais distantes no tempo mas de posição próxima.

As técnicas mais conhecidas são as de Wolf, Eckermann-Ruelle e BrownBryant.

Wolf É voltada para a avaliação dos expoentes positivos de Lyapunov. A técnica consiste em escolher um ponto em uma trajetória e outro ponto próximo dele e avaliar a distância entre eles, isto nos dá o maior expoente de Lyapunov $\lambda_{1}$. A medida que a distância cresce acima de um certo limite, escolhemos um novo ponto próximo ao avaliado e armazena-se as distâncias iniciais $L_{i}$ e finais $L_{i}^{\prime}$ de cada trecho $i$ e aproxima-se o expoente por:

$$
\lambda_{1}=\frac{1}{t_{M}-t_{0}} \sum_{i=0}^{M-1} \lg \frac{L_{i}^{\prime}}{L_{i}}
$$

A dificuldade é escolher os "novos" próximos, mas o algoritmo é bastante robusto para sinais ruidosos ou sem muitos pontos. O cálculo do segundo expoente é feito tomando-se um ponto e dois próximos a ele, acompanha-se então o crescimento da área do triângulo formado pelos três e escolhe-se novos pontos da mesma forma que no caso anterior. Com isso obtém-se uma estimativa de $\lambda_{1}+\lambda_{2}$ e assim por diante. $\mathrm{O}$ 
problema da escolha dos novos pontos próximos se intensifica quando calculamos as somas dos expoentes com vários pontos.

Eckermann-Ruelle Neste caso o objetivo é calcular todos expoentes de Lyapunov. A técnica consiste em aproximar um sistema multidimensional iterado $f(x)$ por $f(x)=D_{x} x+c$ onde $x, c$ são vetores multidimensionais e $D_{x}$ é a matriz Jacobiana de $f$ em $x$. A aproximação de $D_{x}$ é feita por mínimos quadrados e os expoentes são avaliados a partir da triangularização das matrizes.

Brown-Bryant É um método semelhante ao anterior mas usa-se um ajuste por polinômios de grau maior (do que o ajuste por mínimos quadrados) para tentar aumentar a precisão das matrizes Jacobianas.

Maiores detalhes e uma discussão da passagem de sinais experimentais para o espaço de fases (normalmente pela técnica de Takens) podem ser vistos em [FFP94]

\subsection{Conclusão}

Nesta dissertação o objetivo foi apresentar o campo dos fractais, seus aspectos teóricos e alguns desdobramentos e aspectos práticos.

No primeiro capítulo forma apresentados os conceitos sobre órbitas sempre tendo unificar a linguagem e terminologia utilizados enquanto eram citados os termos e linguagem utilizados em outros campos. Além dos aspectos lingüísticos alguns conceitos como o de $k$-atrator que facilita a definição teórica de atratores de órbitas foram criados no desenrolar deste trabalho. E com outros conceitos prepara-se o estudo das propriedades das órbitas. Alguns exemplos e paralelos apresentados dão a dimensão dos resultados deste estudo: os expoentes de Lyapunov, como medida de imprevisibilidade, o teorema de Sarkovsky como estudo da periodicidade a priori, entre outros.

Com a base apresentada o autor introduz outro conceito criado neste trabalho: Mapas. No segundo capítulo o conceito de mapa é apresentado, diferente do significado habitual em outras áreas da matemática, como uma forma de estudo das propriedades 'de órbitas que se originam em todos os pontos do espaço. São então apresentados os tipos de diagramas e mapas que são mais utilizados no estudo e na visualização de fractais e de propriedades de órbitas.

Os mapas começam a delinear os conceitos que serão utilizados no capítulo seguinte em uma nova definição de fractal. Alguns mapas são relacionados 
com trabalhos pioneiros como os de Julia e Fatou bem como os trabalhos de Mandelbrot que criaram o termo fractal.

No terceiro capítulo é feito um desvio que mostra uma outra maneira de se aproximar do conceito de fractais: a topológica. Para melhor situar a discussão sobre o conceito e a definição de fractal que é o objetivo do capítulo apresenta-se antes uma tipologia de fractais com as principais "famílias": algébricos, afins, não-lineares, IFS e probabilísticos. Com isto passa-se as definições e discussão da teoria das medidas e sua relação com diferentes definições de dimensão, com uma ligação entra a teoria da informação de Shannon e as dimensões generalizadas de Renji, bem como com os expoentes de Lyapunov. Com estes elementos em mãos pode-se discutir as definições de fractais propostas na história do campo.

Mandelbrot propõe que fractais sejam conjuntos caracterizados por desigualdade entre a dimensão topológica $\left(D_{T}\right)$ e a de Hausdorff- Besicovich $\left(D_{H B}\right)$. Mas apesar de interessante e útil esta definição tem dois problemas: é muito difícil calcular os dois lados da desigualdade, em particular $D_{H B}$. E por outro lado porque falha em classificar objetos claramente percebidos como fractais (como conjuntos de Cantor 'gordos' e a fronteira do conjunto de Mandelbrot!)

A definição de Barnsley é muito geral e engloba todos subconjuntos de espaços métricos compactos completos. $\mathrm{E}$ o faz sem acrescentar nenhum elemento a mais, com a exceção da métrica de Hausdorff induzida no espaço de partes do espaço original. Com isto perde características importantes, sendo uma definição mais adequada para os trabalhos desenvolvidos pelo próprio Barnsley do que para o uso geral.

Três características norteiam o uso e estudos dos fractais: iteração, autosemelhança e dimensionalidade. As duas últimas forma bastante utilizadas nas definições atualmente existentes, optamos por apresentar, então uma nova definição relacionada a iteração.

Além do conceito de iteração a nova definição utiliza também o conceito de lugar geométrico para definir 'fractal' como o conjunto dos pontos de mesma propriedade em uma função iterada no espaço. Esta definição é bastante geral englobando potencialmente tantos conjuntos como a de Barnsley, mas explicita os mecanismos iterativos e de avaliação das propriedades de órbitas da função iterada em questão. Com isso permite a visão da gênese iterativa dos conjuntos fractais na própria definição dos mesmos. Discute-se a seguir desdobramentos e possíveis evoluções das definições e do campo.

No último capítulo são apresentadas técnicas computacionais de cálculo e visualização mostrando como são aplicados os conceitos apresentados nos capítulos anteriores em problemas práticos. Este capítulo serve mais como 
um guia de áreas e indicador das principais técnicas e conceitos utilizados na solução de problemas utilizando-se fractais. Alguns foram desenvolvidos durante o decorrer da pesquisa deste trabalho pelo autor como o algoritmo de varredura por difusão (na pag. 111).

Esperamos com este trabalho apresentar uma base comum de intercâmbio e entendimento entre profissionais de diversas áreas para trocarem informações e auxiliarem-se mutuamente no desenvolvimento do campo. A nova definição aqui apresentada serve como síntese desta forma de comunicação e dos conceitos que delineiam as idéias sobre os fractais.

Mesmo não sendo utilizada a definição, talvez pelo surgimento de outra ou outras melhores, os demais capítulos desta dissertação ainda se mantém úteis para profissionais de diversas áreas que aplicam a teoria de fractais ou a estudam. 


\section{Bibliografia}

[ACG88] A. AMANN, L. CEDERBAUM, e W. GANS, editores. Fractals Quasicrystals, Chaos, Knots and Algebraic Quantum Mechanics (proceedings). Kluwer Academic, Martinus Nijhoff, 1988.

[ANS93] Louisa F. ANSON. Fractal image compression. Byte, V18(N11):195-202, Jan 1993.

[AVN89] D. AVNIR, editor. Fractal Approach to Heterogeneous Chemistry: Surfaces, Colloids and Polymers. John Wiley \& Sons, Chichester, 1989.

[BAR88] Michael Fielding BARNSLEY. Fractals Everywhere. Academic Press, Londres, 1988.

[BAR89] Michael Fielding BARNSLEY. Desktop fractal design handbook, 1989.

[BD86] Michael Fielding BARNSLEY e Stephen G. DEMKO. Chaotic Dynamics and Fractals. Academic Press, New York, 1986.

[BD90] Karl-Heinz BECKER e Michael DÖRFLER. Dynamical Systems and Fractals. Cambridge University Press, Cambridge, 1990.

[BH91] A. BUNDE e S. HAVLIN. Fractals and Disordered Systems. Springer-Verlag, Berlin, 1991.

[BH92] Michael Fielding BARNSLEY e Lyman P. HURD. Fractal Image Compression. AK Peters, Wellesley, 1992.

[BM93] Pietro Alessandro BRINTO e Daniele MARINI. A fractal method for digital elevation model construction and its application to a mountain region. Computer Graphics, V12(N50):297-309, Dec 1993. 
[BRI92] John BRIGGS. Fractals - The Paterns of Chaos. Thames and Hudson, Londres, 1992.

[CAV84] Joseph J. F. CAVANAGH. McGraw-Hill Computer Science Series. Digital Computer Arithmetic. McGraw-Hill, New York, 1984.

[CE91] A. J. CRILLY e R. A. EARNSHAW. Fractals and Chaos. Springer-Verlag, New York, 1991.

[CHE90] G. CHERBIT, editor. Fractals - Non-integral Dimensions and Applications. John Wiley \& Sons, West Sussex, 1990.

[DEK82] F. M. DEKKING. Recurrent sets. Advances in Mathematics, .(N44):78-104, Jan 1982.

[DEV89] Robert L. DEVANEY. Introduction to Chaotic Dynamical Systems. Adison-Wesley Publ. Company, Redwọod City, 1989.

[DEV90] Robert L. DEVANEY. Chaos, Fractals and Dynamics: Computer Experiments in Mathematics. Adison-Wesley Publ. Company, Menlo Park, 1990.

[DEV92] Robert L. DEVANEY. A First Course in Chaotic Dynamical Systems: Theory and Experiment. Adison-Wesley Publ. Company, New York, 1992.

[DK88] Robert L. DEVANEY e Linda KEEN, editores. Chaos and Fractals - The Mathemathics Behind the Computer Graphics, Proceedings of Symposia in Applied Mathematics. American Mathemathica Society, Providence, Rhode Island, 1988.

[DK93] R. L. DOBRUSHIN e S. KUSUOKA. Statistical Mechanics and Fractals. Springer-Verlag, Berlin, 1993.

[EDG90] Gerald A. EDGAR. Measure, Topology and Fractal Geometry. Springer-Verlag, New York, 1990.

[EDG91] Gerald A. EDGAR. A fractal puzzle. Mathematical Inteligencer, V13(N3):44-50, Jan 1991.

[EDG93] Gerald A. EDGAR, editor. Classics on Fractals. Adison-Wesley Publ. Company, New York, 1993. 
[FA90] Jens FEDER e A. AHARONY, editores. Fractals in Phisics: Essays in Honour of Benoit B. MandelBrot. North-Holland, N/D, 1990.

[FAL85] K. J. FALCONER. Geometry of Fractal Sets. Cambridge University Press, Cambridge, 1985.

[FAL90] K. J. FALCONER. Fractal Geometry: Mathematical Foundations and Applications. John Wiley \& Sons, Chichester, 1990.

[FED69] Herbert FEDERER. Geometric Measure Theory. SpringerVerlag, New York, 1969.

[FED88a] Jens FEDER. Fractals. Plenum, New York, 1988.

[FED88b] Jens FEDER. Physics of Solids and Liquids. Fractals. Plenum, New York, 1988.

[FFP94] Nelson FIEDLER-FERRARA e Carmem P. Cintra do PRADO. Caos Uma Introdução. Edgar Blücher, São Paulo, 1994.

[FTB89] M. FLEISHMANN, D. J. TILDESLEY, e R. C. BALL. Fractal in the Natural Sciences. University Press, Princeton, 1989.

[GAA64] Steven A. GAAL. Point Set Topology. Academic Press, New York, 1964.

[GAR70] Martin GARDNER. Mathematical games. Scientific American, 70(Oct):120-123, Oct 1970.

[GGR92] A. V. GAPONOV-GREKHOV e M. I. RABINOVICH. Nonlienarities in Action: Oscillations, Chaos, Order Fractals. SpringerVerlag, Berlin, 1992.

[GLE90] James GLEICK. Caos - A Criação de uma Nova Ciência. Editora Campus, Rio de Janeiro, 1990.

[HAD49] Jaques HADAMARD. The Psycology of Invention on the Mathematical Field. Dover Publications, New York, 1949.

[HAL74] Paul HALMOS. Measure Theory. Springer-Verlag, N/D, 1974.

[HAM80] Richard Wesley HAMMING. Coding and Information Theory. Prentice Hall, New Jersey, 1980. 
[HF ] Jay R. HILL e Yuval FISHER. Bounding the area of the mandelbrot set. Numerish Mathematik, no prelo, -(-):-/-,--.

[HIN75] J. O. HINZE. McGraw-Hill Series in Mechanical Engeneering. Turbulence. 2.ed. McGraw-Hill, New York, 1975.

[HOG92] Stuart G. HOGGAR. Mathemathics for Computer Graphics. Cambridge University Press, Cambridge, 1992.

[HOL80] Douglas R. HOLFSTADTER. Göedel, Escher, Bach: An Eternal Golden Braid. Penguim Books, New York, 1980.

[HUN70] H. E. HUNTLEY. The Divine Proportion: A Study in Mathematical Beauty. Dover Publications, New York, 1970.

[HUT81] John E. HUTCHINSON. Fractals and self-similarity. Indiana University Mathemathics Journal, V30(N5):713-747, Jan 1981.

[HW41] W. HUREVICZ e H. WALLMAN. Dimention Theory. Princeton University Press, Princeton, 1941.

[IFR89] Georges IFRAH. Os Números - História de uma Grande Invenção. Editora Globo, Rio de Janeiro, 1989.

[JB87] R. JULIEN e R. BOTET. Aggregation and Fractal Aggregates. World Sicentific, Singapura, 1987.

[KA64] Leonid Vitalyevich KANTOROVICH e G. P. AKILOV. Functional Analysis in Normed Spaces. MacMillian Co., New York, 1964 .

[KAR94] Elisabeth Wegner KARAS. Iteração de Transformações Racionais Aplicada ao Método de Newton no Plano Complexo. Nenhuma, São Paulo, 1994.

[KNU81] Donald E. KNUTH. The Art of Computer Programming, Vol. 2: Seminumerical Algorithms. Addison Wesley, Reading, Massachusets, 1981.

[LIN90] Tom LINDSTRON. Brownian Motion on Nested Fractals (Memoirs of the AMS; 420). AMS, Providence, 1990.

[LUD90] Arnold LUDGWIG, editor. Workshop on Lyapunov Exponents, Oberwolfach - 1990 (proceedings). Springer-Verlag, Berlin, 1990. 
[LUG87] L. A. LUGIATO, editor. Chaos, Noise and Fractals (Malvern Phisics Series - 3). Adam Hilger, Bristol, 1987.

[LY75] T.-Y. LI e James YORKE. Period three implies chaos. American Mathematical Monthly, \#1975(82), - 1975.

[MAN77] Benoît B. MANDELBROT. Fractals: Form, Chance, and Dimension. W. H. Freeman and Company, San Francisco, 1977.

[MAN83] Benoît B. MANDELBROT. The Fractal Geometry of Nature Updated and Augmented. W. H. Freeman and Company, New York, 1983.

[MAN91] Benoît B. MANDELBROT. Objetos Fractais, Forma, Acaso e Dimensão (seguido de panorama da linguagem). Gradiva, Lisboa, 1991.

[MAR] A. MARKUCHEVITCH. Seqüências Recorrentes. Editora Mir, Moscou, ?

[MÉH91] Alain le MÉHAUTÉ. Fractal Geometries - Theory and Applications. CRC Press, Boca Raton, 1991.

[MIL88] J. Van MILL. Infinite-Dimentional Topology: Prerequisites and Introduction. North-Holland, Amsterdan, 1988.

[MMA57] Benoît B. MANDELBROT, A. MORFE, e Leo APOSTEL. Logique, Langage et Theorie de l'Iinformation. Pres. Universitaries de France, Paris, 1957.

[MOR87] Frank MORGAN. Geometric Measure Theory - A Beguinner's Guide. Academic Press, San Diego, 1987.

[MP58] Benoît B. MANDELBROT e Jean PIAGET. Lecture de l'Experience. Pres. Universitaries de France, Paris, 1958.

[NAG] Sun-Iti NAGATA. Modern Dimention Theory. P. Noordhoff NV., Groningen, ?

[OLI92] Dick OLIVER. Fractal Vision. Sams Publishing, Carmel, 1992.

[PEN91] Roger PENROSE. A Mente Nova do Rei. Editora Campus, Rio de Janeiro, 1991. 
[PHM93] Przemyslaw PRUSINKIEWIKCZ, Mark S. HAMMEL, e Eric MJOLSNESS. Comp. Graph. Proc., An. Conf. Ser. 93 - Animation of Plant Development. Adison-Wesley Publ. Company, N/D, 1993.

[PIC90] Clifford A. PICKOVER. Computers, Pattern, Chaos and Beauty: Graphics from a Unseen World. St. Martin's Press, New York, 1990.

[PIC91] Clifford A. PICKOVER. Computers and The Imagination. St. Martin's Press, New York, 1991.

[PIC92a] Clifford A. PICKOVER. Mazes for the Mind: Computers and The Unexpected. St. Martin's Press, New York, 1992.

[PIC92b] Clifford A. PICKOVER, editor. Visions of the future: Art, Technology, and Computing in the Next Century. St. Martin's Press, N/D, 1992.

[PIE89] Luciano PIETRONERO, editor. Fractal's Physical Origin and Properties. Plenum, New York, 1989.

[PJS92] Heinz-Otto PEITGEN, Harmut JÜRGENS, e Deitmar SAUPE. Chaos and Fractals: The Frontiers of a New Science. SpringerVerlag, New York, 1992.

[PJSZ90] Heinz-Otto PEITGEN, Harmut JÜRGENS, Deitmar SAUPE, e C. ZAHLTEN. Fractals - an animated discussion, 1990.

[PN84] Heinz-Otto PEITGEN e Roger D. NUSSBAUM. Memoirs of the $A M S$; 310 Special and Spurious Solutions of $X(T)={ }^{\prime}$ alfa' $F(X(T$ 1)). American Math. Soc. (AMS), N/D, 1984.

[PR86] Heinz-Otto PEITGEN e Peter H. RICHTER, editores. The Beauty of Fractals: Images of Complex Dynamical Systems. Springer-Verlag, Berlin, 1986.

[PS88] Heinz-Otto PEITGEN e Deitmar SAUPE, editores. The Science of Fractal Images. Springer-Verlag, Berlin, 1988.

[PSJ+92] Heinz-Otto PEITGEN, Deitmar SAUPE, Harmut JÜRGENS, Evan MALETSKY, Terry PERCIANTE, e Lee YUNKER. Fractals for the Classroom - Strategic Activities - Vol 1. SpringerVerlag, Berlin, 1992. 
[PW79] Heinz-Otto PEITGEN e H. O. WALTHER. Functional Diferential Equations and Approximation of Fixed Points. SpringerVerlag, Berlin, 1979.

[PW91] Mark PETERSON e Timothy WEGNER. Fractal Creations. Waite Group Press, Mill Valley, 1991.

[SCH86] Manfred Robert SCHROEDER. Number Theory in Science and Communicarion. Springer-Verlag, Berlin, 1986.

[SCH89] Christopher SCHOLZ. Fractals in Geophisics. Birkhauser Verlag, Basel, 1989.

[SCH91] Manfred Robert SCHROEDER. Fractals, Chaos, Power Laws. W. H. Freeman and Company, New York, 1991.

[SF85] William R. SHITH e P. FISHER, editores. Chaos, Fractals and Dynamics. Marcel Dekker, New York, 1985.

[SG92] Branko SOUCEK e The IRIS Group, editores. Dynamic, Genetic, and Chaotic Programming - The Sixth Generation. John Wiley \& Sons, New York, 1992.

[SGC83] D. SULLIVAN, L. GARNET, e J. H. CURRY. On the iteration of rational functions: Computer's experiments with newton's method. Communications in Mathematic Physics, V91(\#2):265227, Oct 1983.

[SHI91] M. SHISHIKURA. The hausdorff dimention of the boundary of the mandelbrot set and julia sets. SUNY Stony Brook, \#1991(7), - 1991.

[SO86] H. E. STANLEY e Nicole OSTROWSKY, editores. On Growth and Form: Fractal and Non-Fractal Patterns in Phisics. Dordrech, Martinus Nijhoff, 1986.

[SPR93] Julien C. SPROTT. Strange Attractors: Creating Patterns in Chaos. M\&T Books, New York, 1993.

[TRA91] Davis TRAVIS. Effective Color Displays, Theory and Practice. Academic Press, Cambridge, 1991.

[VIC89] Tomas VICSEK. Fractal Growth Fenomena. World Sicentific, Singapura, 1989. 
[VIN93] Greg VINES. Signal Modeling with Iterated Function Systems. PhD thesis, Georgia institue of Technology, 1993.

[WAL93] M. Mitchell WALDROP. Complexity. Simon and Shuste, New York, 1993.

[WES90] Bruce WEST. Fractal Phisiology and Chaos in Medicine. World Sicentific, Singapura, 1990.

[WIC91] Keith R. WICKS. Fractals and Hyperspaces. Springer-Verlag, Berlin, 1991. 